Review

\title{
Copper Containing Molecular Systems in Electrocatalytic Water Oxidation-Trends and Perspectives
}

\author{
Dávid Lukács ${ }^{1}$, Łukasz Szyrwiel ${ }^{2}$ and József S. Pap ${ }^{1, *(D)}$ \\ 1 Surface Chemistry and Catalysis Department, Institute for Energy Security and Environmental Safety, \\ Centre for Energy Research, Hungarian Academy of Sciences, Konkoly-Thege street 29-33, \\ H-1121 Budapest, Hungary; lukacs.david@energia.mta.hu \\ 2 European XFEL, Albert-Einstein-Ring 19, 22761 Hamburg, Germany; lukasz.szyrwiel@xfel.eu \\ * Correspondence: pap.jozsef@energia.mta.hu; Tel.: +36-1-392-2222 (ext. 3284)
}

Received: 20 December 2018; Accepted: 9 January 2019; Published: 14 January 2019

\begin{abstract}
Molecular design represents an exciting platform to refine mechanistic details of electrocatalytic water oxidation and explore new perspectives. In the growing number of publications some general trends seem to be outlined concerning the operation mechanisms, with the help of experimental and theoretical approaches that have been broadly applied in the case of bioinorganic systems. In this review we focus on bio-inspired Cu-containing complexes that are classified according to the proposed mechanistic pathways and the related experimental evidence, strongly linked to the applied ligand architecture. In addition, we devote special attention to features of molecular compounds, which have been exploited in the efficient fabrication of catalytically active thin films.
\end{abstract}

Keywords: copper; water oxidation; electrocatalysis; molecular catalyst; precursor; copper oxide; oxygen evolving reaction

\section{Introduction}

The current usage of energy and raw materials by humankind leads to a dead-end. Our chances to avoid the devastating consequences seem to drop quickly. The concept of artificial photosynthesis (AP) $[1,2]$ might contribute to build a sustainable energy future on the analogy of the natural molecular process that is initiated by sunlight as the ultimate renewable energy source in photosystem II (PS II) [3] and relies on abundant, environmentally friendly elements. Fundamental research on such systems may be justified in many ways. Note in the very beginning however, the authors think that none of these should be to supply the energy and raw materials usage like it is done today; instead, the aim should be to acquire the ability of realizing our place and role as part of the biosphere, which is perhaps the most important learning process we must face.

Solar energy irradiation reaching Earth considerably exceeds our total demands, which has been estimated 15 terawatts $\left(15 \times 10^{12} \mathrm{Js}^{-1}\right)$, whereas the Sun can provide over at least 50 terawatts of energy [4]. On the basis of the AP concept the conversion and storage of solar energy in chemical form can be done efficiently by connecting or integrating light-harvesting and catalytic sub-units into one system in different ways. In one of the existing systems water electrolysis cells are coupled with solar cells and the latter units are connected in series to provide sufficient potential for the electrodes to carry out water splitting. Another type, the photoelectrochemical water splitting cell, is based on photoelectrodes made of semiconducting materials coated with catalysts. In this case one photoelectrode (anode or cathode) is immersed in an electrolyte and contacted with a counter electrode, which is usually highly efficient for the desired half-cell reaction of water splitting. These 
two systems have generally better overall efficiency than the fully integrated photocatalytic water splitting systems. Nevertheless, each setup is subject to broad research and the benefits from viable strategies with respect to new developments are immense.

In plants $\mathrm{O}_{2}$ is released, whereas energy is captured in NAD(P)-H. In the AP process, water is split into $\mathrm{H}_{2}$ and $\mathrm{O}_{2}$ and optionally, the former may be further utilized in catalytic $\mathrm{CO}_{2}$ reduction to produce industrially relevant compounds on a renewable basis. Water splitting (Equation (1)) is an energetically uphill process with $\Delta G^{\circ}=237.2 \mathrm{kJmol}^{-1}$, or $2.46 \mathrm{eV}$ therefore the reverse reaction, combustion of $\mathrm{H}_{2}$ with $\mathrm{O}_{2}$ in fuel cells produces energy, the density of which is comparable to that of fossils, but the only exhaust product this time is water.

$$
2 \mathrm{H}_{2} \mathrm{O}(l) \rightarrow 2 \mathrm{H}_{2}(\mathrm{~g}, 1 \mathrm{bar})+\mathrm{O}_{2}(\mathrm{~g}, 1 \text { bar })
$$

Water splitting and $\mathrm{H}_{2}$ combustion thus might create a cycle to provide clean and sustainable energy. In this cycle, the hydrogen and oxygen evolving reactions (HER and OER, respectively, corresponding to the redox half-cell reactions of water electrolysis) affect the efficiency of the overall energy conversion and their broader application at larger scales requires components that are abundant.

\subsection{On the Use of Copper in AP Systems}

The research on water splitting and $\mathrm{CO}_{2}$ reduction witness accumulating experimental and theoretical evidence indicating, that AP is easily becoming an emblematic application area of copper. The abundance of copper in Earth's crust is roughly $50 \mathrm{ppm}$. Although the volume of its use has been greatly expanded in the past decades and the reserves are prognosticated to run out earlier than 60 years, by conscious recycling copper may remain a meaningful resource for catalysts benefiting from its unmatched redox reactivity. This applies to water oxidation electrocatalysts (WOCs) as well, since substitutes for the very efficient but rare Ir and Ru electrocatalysts are highly desired. These elements are among the least abundant ones that means a serious drawback considering the expected scale-up needs, and beside other first row transition metals, copper seems to be a true alternative.

Note that findings on the mechanism of water oxidation obtained in the homogeneous, heterogeneous, and biocatalytic research fields have been discussed elsewhere along with some potentially unifying concepts [5]. Therein the thermodynamics and mechanism of the electrochemical water splitting have been discussed in details. Other insightful reviews discussed WOCs made of abundant elements [6-10], mononuclear, first row transition metal molecular catalysts [11,12], homogeneous copper molecular catalysts [13], or touched dicopper catalysts [14]. The aim of the present review is rather to give a systematic insight into the structure/mechanism interplay specifically in $\mathrm{Cu}$-based molecular catalysts, and the suggested pathways leading to practically important catalytic film deposits from molecular precursors (relying on commonly available literature as of September 2018).

Below is provided a brief overview on the general methodological approach to molecular electrocatalytic systems for water oxidation focusing on the most relevant aspects regarding copper complexes.

\subsection{Methodological Approach to Cu-Based Molecular WOCs}

The nature of a catalytic reaction evidently determines the experimental conditions and methods to be applied. The OER shows much slower kinetics compared to the HER, therefore the water oxidation side is regarded as the limiting process of the overall efficiency of water-splitting systems. This is because the oxygen evolving half-cell reaction is a complicated process involving the transfer of a total of four electrons and four protons in the course of producing one dioxygen from two water molecules (Equation (2)).

$$
2 \mathrm{H}_{2} \mathrm{O}(l) \rightarrow \mathrm{O}_{2}(g, 1 b a r)+4 e^{-}(a q)+4 H^{+}(a q)
$$


This is challenging from the thermodynamic point of view, since its standard potential is $1.23 \mathrm{~V}$ versus the reversible hydrogen electrode (RHE), as well as for kinetic reasons, because it involves a series of molecular rearrangements. According to the general reaction scheme the proton-coupled electron transfer (PCET) of $\mathrm{H}_{2} \mathrm{O}$ bound to the metal center yielding an $\mathrm{M}-\mathrm{OH}$ species is regarded the first step in the OER (Equation (3)). The characteristics of the different PCET processes are broadly discussed elsewhere [15].

$$
\mathrm{M}^{n+}-\mathrm{OH}_{2} \rightarrow \mathrm{M}^{(n+1)+}-\mathrm{OH}+e^{-}+H^{+}
$$

In principle, two such intermediates with close geometric positions might interact to produce hydrogen peroxide, which can be further oxidized to $\mathrm{O}_{2}$, however, in molecular systems a further $1 \mathrm{e}^{-}$ oxidation of $\mathrm{M}-\mathrm{OH}$ takes place more likely to provide an $\mathrm{M}=\mathrm{O}$ intermediate (Equation (4)).

$$
\mathrm{M}^{(n+1)+}-\mathrm{OH} \rightarrow \mathrm{M}^{(n+2)+}=\mathrm{O}+e^{-}+H^{+}
$$

From this point in the mechanism two representative pathways for the generation of $\mathrm{O}_{2}$ may occur. The first is the nucleophilic attack of the $\mathrm{M}=\mathrm{O}$ by a water molecule (Equation (5), WNA mechanism). The superoxide/peroxide intermediates can rapidly undergo electrochemical oxidation to release $\mathrm{O}_{2}$.

$$
\mathrm{M}^{(n+2)+}=\mathrm{O}+\mathrm{H}_{2} \mathrm{O} \rightarrow \mathrm{M}^{n+}-\mathrm{OOH}+\mathrm{H}^{+}
$$

Another pathway is the interaction of two proximate $\mathrm{M}=\mathrm{O}$ intermediates (I2M mechanism), which more commonly occurs in heterogeneous electrocatalysts or binuclear molecular catalysts having $\mathrm{M}=\mathrm{O}$ species with proper spacing (Equation (6)).

$$
\mathrm{M}^{(n+2)+}=\mathrm{O}+\mathrm{M}^{(n+2)+}=\mathrm{O} \rightarrow \mathrm{M}^{n+}-\mathrm{OO}-\mathrm{M}^{n+}
$$

From the experimental point of view the sub-unit responsible for carrying out the OER as part of an AP system is an electrocatalyst and tested accordingly, independently from other units (i.e., semiconductors, photosensitizers and the other half-cell components).

Copper-based molecular WOCs are no exception. In order to focus as much as possible on their intrinsic catalytic abilities, as their role is to promote the kinetics at the electrode surface, the catalyst candidates can be conveniently investigated in a 3-electrode setup. In this setup a highly polarizable working electrode is applied with a very broad solvent window, i.e., low activity in water splitting separated by a membrane or glass frit from the counter electrode, which is most often Pt. This way the observed activity can be fully attributed to the tested compound. The electrode materials are most often glassy carbon (GC), indium tin oxide (ITO), fluorine doped tin oxide (FTO), boron doped diamond (BDD), rarely gold, or carbon. In this setup a plethora of electrochemical methods are available to obtain kinetic and thermodynamic data on a system [16,17]. Most often linear polarization techniques such as linear sweep voltammetry (LSV) or cyclic voltammetry (CV), pulse techniques such as square wave (SWV) or differential pulse voltammetry (DPV) and chronoampero- (CA, also named as controlled potential electrolysis, $\mathrm{CPE}$ ) or chronopotentiometry (CP), moreover, electrochemical impedance spectroscopy (EIS) are applied as it will be seen from the examples. Note that carbon-based electrodes are less suitable for electrolysis tests, because the electrode material itself is prone to undergo oxidation under the typical conditions for water oxidation.

Another important component in a cell is the buffer, which is present in much higher concentration than the molecular catalyst and it is responsible for taking care of the protons released in the course of catalytic OER (Equation (2)) thus maintaining a preferably unchanged $\mathrm{pH}$ in the close proximity of the electrode. Especially in the case of copper this is a very important aspect, because complexes can undergo structural changes with shifted $\mathrm{pH}$, may dissociate and release $\mathrm{Cu}^{2+}$ below neutral $\mathrm{pH}$, or simply lose their activity. Typical buffers include phosphate, borate and carbonate, but above $\mathrm{pH}$ $12, \mathrm{NaOH}$, or $\mathrm{KOH}$ and $\mathrm{NaOAc}$ (to adjust the ionic strength) constitute the electrolyte. Note that the 
buffer is also critical, if different copper oxide catalyst films are deposited from precursor molecules, as shown later. Compatibility of the selected methodological approaches with the particular molecular system including its solubility, molecular speciation, and propensity for degradation is also crucial and we fully relied on the original observations and conclusions made by the authors cited here.

\subsection{Cross-Linkages Between Homogeneous and Heterogeneous Catalysis-Molecular Systems} Trespassing Borders

In homogeneous systems the molecular catalysts exert their effect dissolved in the electrolyte, while other complexes form deposits (films) on surfaces of (semi)conducting electrodes, which will be the major criterion to distinguish the examples listed in this review. Understanding the operation mechanism and structure-reactivity relationships may request new methodological developments, because homogeneous and heterogeneous processes may take place simultaneously exhibiting complicated equilibrium character, i.e., the molecular compounds may serve as precursors for in situ generated surface catalyst films, and vice versa, surface-bound heterogeneous catalysts may partly get into solution and contribute to the overall activity this way.

In Figure 1 some cross-links potentially occurring between homogeneous and heterogeneous electrocatalytic cycles are sketched to illustrate the complexity of electrocatalytic WOC. The starting point is [CAT $]_{\text {red }}$ as this entity symbolizes the resting state of the complex. This form is generally identical to the synthesized $\mathrm{Cu}^{\mathrm{II}}$ complex, but in many cases can be also self-assembled from the ligand and the metal salt in situ.

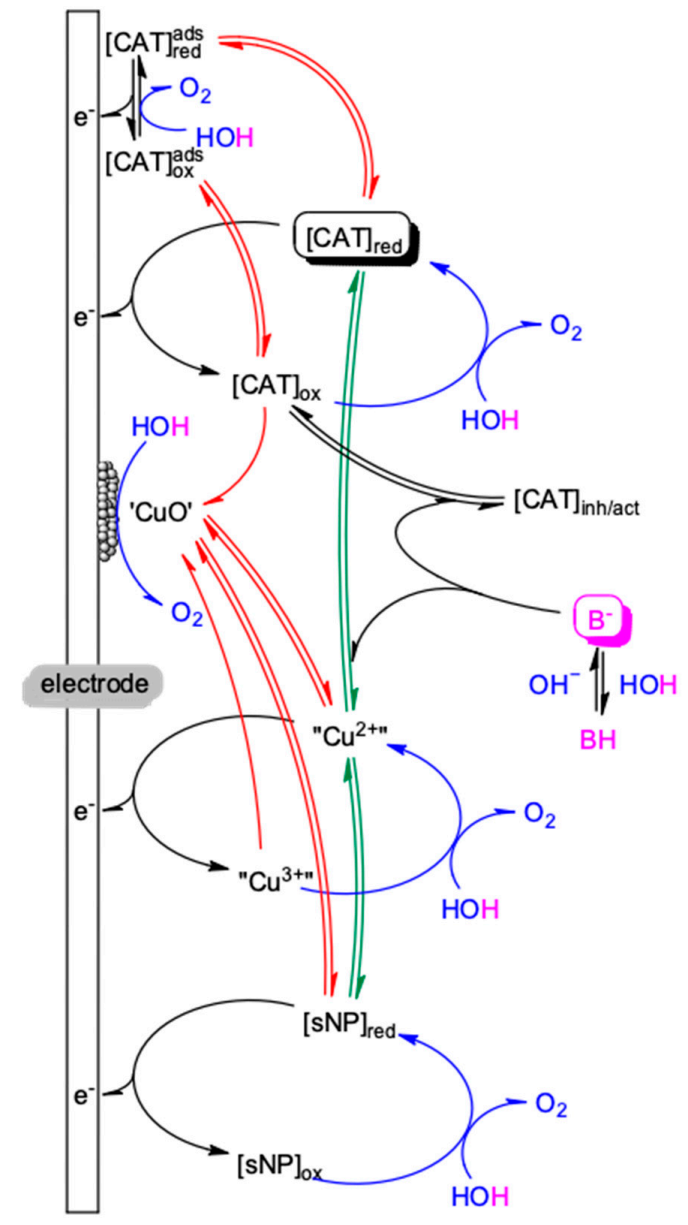

Figure 1. Some representative operando processes that can lead to water oxidation electrocatalysts (WOCs) derived from a primary molecular system. 
Multiple electron transfers to the electrode yield [CAT $]_{\text {ox }}$ that represents here the active form initiating the key $\mathrm{O}-\mathrm{O}$ bond forming chemical reaction (distinguished by blue color). The $[\mathrm{CAT}]_{\text {red/ox }}$ can be adsorbed to the electrode surface thus deviations from the classical homogeneous catalytic behavior are observed (processes linking heterogeneous cycles to homogeneous ones are highlighted in red). Note that a rinse test may be inconclusive about the in situ accumulated molecular [CAT] $]^{\text {ads }}$ species, because its diffusion from the used electrode rinsed and placed in a new buffer may be too rapid in the absence of [CAT] $]_{\text {red/ox }}$ to detect any residual WOC activity. The situation is very different, when ' $\mathrm{CuO}$ ' films are formed under WOC conditions, which is usually traced in the electrochemical behavior of the system.

The buffer anions ( $\mathrm{B}^{-}$in cyan color in Figure 1 ) as a third pillar of the catalytic system may assist to side-equilibria in addition to its crucial role as base. Either or both of the [CAT] $]_{\text {red/ox }}$ forms may be prone to dissociation and release its metal ion content. Upon complexation by the buffer anion this part of the copper ions will contribute to the overall activity since such complexes have been revealed to act as homogeneous catalysts (discussed in Section 2.1.1). Also, ternary ligand-metal-anion complex forms may either limit catalysis depending on the concentration of the components ([CAT $]_{\text {inh }}$ ) or promote it, if the ligand structure favor this scenario ([CAT $]_{\text {act }}$ ). Finally, in situ formed soluble nanoparticle (sNP) may also contribute as colloidal WOCs residing near the electrode surface. Monitoring such WOC transformations is challenging and it will increasingly rely on emerging in situ/operando analytical approaches [9], although these are not yet broadly available. Nevertheless, these new approaches will provide valuable input for WOC construction through revealing the dynamics of catalytic systems.

Another conceptual overview includes a guide on how to identify the true catalyst in a system by more common methods [18]. Hereby the reactivity (i.e., kinetic) and structural analysis methods will be touched only briefly, without the necessity of completeness, only as much as relevant for the discussion of the corresponding Cu-based system herein.

\section{Types of Molecular Catalysts and Associated Mechanisms}

Ancillary ligands that has been so far applied in this field show high structural variety from bi- to pentadentate ones, including heterocycles, amines, amides and other, mixed-donor types. To our knowledge no monodentate supporting ligand in equimolar amounts to copper has ever been reported in water oxidation that, considering the labile nature of copper-ligand interactions lacking the stabilizing chelate effect is no surprise (note that fluoride and oxyanions form complexes with copper, but only in very high excess as discussed later).

There are differences between the ways how supporting ligands allow access to open sites around copper to furnish the necessary ligand-copper(II)-water ternary formations and these differences will fundamentally determine the possible mechanistic pathways of the catalytic cycle.

\subsection{Single-Site Catalysis}

\subsubsection{Inorganic Ligands}

Chronologically the first report on a Cu-based molecular WOC was that of Meyer et al. from 2012 [19], but systems reported since then with all inorganic anions are discussed here first (Figure 2). In a concentrated fluoride solution $(1 \mathrm{M})$ Chen et al. demonstrated that electrocatalytic water oxidation occurs homogeneously from near-neutral to basic $\mathrm{pH}$ [20]. Fluoride that enhances the solubility of $\mathrm{Cu}^{\mathrm{II}}$ and moderates its redox potential is considered as an oxidatively resistant, bystander supporting ligand due to the high value of fluoride oxidation potential, $E^{\circ}\left(\mathrm{F}_{2} / \mathrm{F}^{-}\right)=2.87 \mathrm{~V}$. The onset potential for WOC was reported at $\sim 445 \mathrm{mV}$ at $\mathrm{pH}=7.2$ and the catalytic current increased linearly with copper concentration under $0.6 \mathrm{mM}$, where saturation occurred (Table 1). On this basis a single-site mechanism was proposed involving $\mathrm{Cu}^{\mathrm{III}}$-O • active species in the water nucleophilic attack with uncertain, mixed $\mathrm{H}_{2} \mathrm{O} / \mathrm{OH}^{-}-\mathrm{F}^{-}$composition (Figure 2, 1). The coordination of $\mathrm{F}^{-}$to $\mathrm{Cu}^{\mathrm{II}}$ was evidenced by the hypsochromic shift in the $\mathrm{d}$-d transitions compared to those occurring in the presence 
of non-coordinating anions. Over $8 \mathrm{~h}$ electrolysis $\mathrm{O}_{2}$ could be produced at $94 \%$ Faraday efficiency. A unique feature of this report was the observed counter-anion effect that enhanced the catalytic current in the order of $\mathrm{Cs}^{+}>>\mathrm{K}^{+} \sim \mathrm{Na}^{+}$. This effect was speculatively associated with ion-pair formation between the complex anion and the solvated cation driven by Coulombic force. To our knowledge such an effect has not yet been tested in other copper-ligand systems.<smiles>O=S1(=O)OC(O)([GeH](O)O)O1</smiles><smiles>O=C(O)O[Ge](O)(O)OC(=O)OC1(O)OC(=O)O1</smiles>

Figure 2. Cu-based molecular WOCs with inorganic ligands.

Chen and Meyer described single site water oxidation catalysis linearly dependent on $\left[\mathrm{CuSO}_{4}\right] /\left[\mathrm{Cu}\left(\mathrm{NO}_{3}\right)_{2}\right] /\left[\mathrm{Cu}\left(\mathrm{ClO}_{4}\right)_{2}\right]<1.2 \mathrm{mM}$ added to $1 \mathrm{M} \mathrm{NaHCO}_{3}$ buffer at $\mathrm{pH} \sim 8.2$, or saturated with $\mathrm{CO}_{2}$ at $\mathrm{pH} \sim 6.7$ [21]. Sustained $\mathrm{O}_{2}$ evolution was reported with $96 \%$ Faraday efficiency on ITO (at $1.55 \mathrm{~V}$ ), and similarly good results were obtained on FTO or GC working electrodes with no evidence on buildup of a film or precipitate. The coordination of bicarbonate and carbonate to copper (Figure 2, 2a, $\mathbf{2} \mathbf{b}$ and $\mathbf{2} \mathbf{c}$ ) was evidenced by UV-Vis measurements detecting a blue-shifted and intensified d-d transition for the carbonate/bicarbonate coordinated cupric center compared to that of the solvated ion. The reaction mechanism applying under these conditions was later analyzed by means of DFT computations by Winikoff and Cramer (Figure 3) [22]. Their proposal underlines the importance of the dissolved $\mathrm{CO}_{2}$ as co-catalyst and $\mathrm{pH}$ moderator, moreover, implies carbonate acting as non-innocent and reactive ligand that forms peroxycarbonate metallo-cycle, which decomposes through retrocylization to liberate $\mathrm{O}_{2}$ and $\mathrm{CO}_{2}$ due to its small calculated singlet-triplet splitting. The small energy differences associated with monodentate versus bidentate coordination enabling less hindered ligand rearrangement to facilitate the pre-O-O bond forming complex, and high spin delocalization through $\mathrm{Cu}-\mathrm{O}$ covalency were also concluded as key features contributing to catalytic efficiency of this system.

In contrary to the above proposal, Mizrahi et al. concluded by combining pulse radiolysis experiments and detailed kinetic analysis with DFT calculations that the only plausible mechanism would be when $\mathrm{C}_{2} \mathrm{O}_{6}{ }^{2-}$ (formally $\mathrm{CO}_{4}{ }^{2-}+\mathrm{CO}_{2}$ ) was produced as the first peroxide product from the decomposition reaction between two $\left[\mathrm{Cu}^{\mathrm{III}}\left(\mathrm{CO}_{3}\right)_{3}\right]^{3-}$ complexes [23]. In the electrocatalytic process the electron transfer to the electrode was proposed to involve the oxidation of $\mathrm{Cu}^{\mathrm{II}}\left(\mathrm{CO}_{3}\right)_{\mathrm{n}}{ }^{2-2 \mathrm{n}}$ to $\mathrm{Cu}^{\mathrm{III}}\left(\mathrm{CO}_{3}\right)_{\mathrm{n}}{ }^{3-2 \mathrm{n}}$ directly without the involvement of $\mathrm{CO}_{3}{ }^{--}$radical anions. According to this explanation $\mathrm{C}_{2} \mathrm{O}_{6}{ }^{2-}$ is hydrolyzed to give $\mathrm{H}_{2} \mathrm{O}_{2}$ that can react with the $\mathrm{Cu}^{\mathrm{III}}$ complexes explaining the eventual production of $\mathrm{O}_{2}$. These results predict second order in copper concentration irrespective of the $\mathrm{pH}$, whereas in the electrochemical study the catalytic current was first order in copper at $\mathrm{pH} 8.2$ or lower. The source of this discrepancy remains a question. Note, on the other hand, that di-copper pathway based on second order kinetics in $\left[\mathrm{Cu}^{\mathrm{II}}\right]$ was indeed found in concentrated $\mathrm{CO}_{3}{ }^{2-}$ or $\mathrm{HPO}_{4}{ }^{2-} / \mathrm{PO}_{4}{ }^{3-}$ buffers, too, at $\mathrm{pH}$ of ca. 10.8, but the possible rate limiting step in the original work by $\mathrm{Chen}$ and Meyer was assigned as a $\mathrm{CuO}-\mathrm{OCu}$ coupling to form $\mu$-peroxide on the analogy to well-defined copper peroxide complexes [24,25]. From the practical point of view the varied 
mechanisms experienced in these systems highlight their sensitivity to the changed conditions $(\mathrm{pH}$, concentration and type of the buffer components) that in turn becomes critical when fine-tuning of the catalytic activity is considered. Undoubtedly, a variety of experimental evidence is needed to decide debates about the behavior of the carbonate system and other, similar ones.

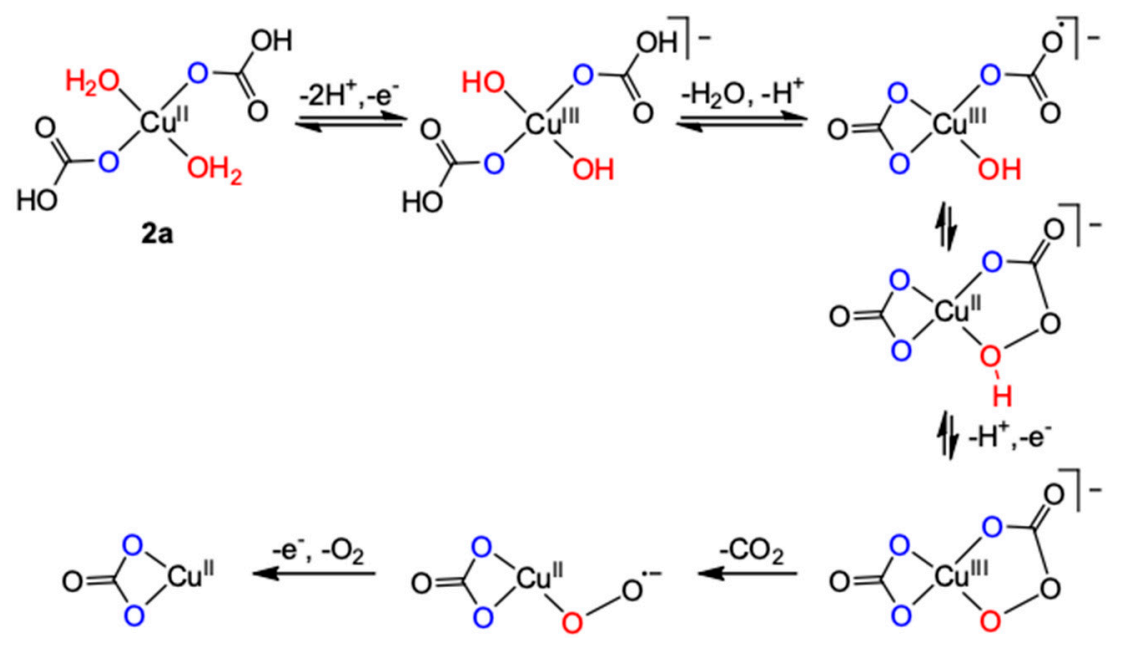

Figure 3. Initial oxidation steps of copper-carbonate suggested by Winikoff and Cramer starting from the conformer $\mathbf{2 a}$ (only selected ones are shown here), and the final steps relevant to the catalytic cycle at $\mathrm{pH}=8.2$ in $1 \mathrm{M}$ carbonate [22].

Table 1. ${ }^{1}$ Kinetic, electrochemical data and reaction conditions of single-site water oxidation catalysts with inorganic ligands and copper.

\begin{tabular}{|c|c|c|c|c|c|c|}
\hline Catalyst & $\mathrm{pH}$ & $\begin{array}{l}{[\text { Ligand }] /\left[\mathrm{Cu}^{\mathrm{II}}\right]} \\
\text { Ratio }\end{array}$ & Electrolyte Anion & $\eta^{2}(\mathrm{mV})$ & $\begin{array}{c}\text { Faraday Eff. } \\
(\%)\end{array}$ & Ref. \\
\hline $\mathrm{Cs}_{(2-\mathrm{x})}\left[\mathrm{Cu}(\mathrm{F})_{\mathrm{x}}\left(\mathrm{OH}_{2}\right)_{(6-\mathrm{x})}\right]^{(2-\mathrm{x})}(\mathbf{1})$ & 7.2 & $>6000$ & $\mathrm{~F}^{-}, 1 \mathrm{M}$ & 445 & 94 & {$[20]$} \\
\hline$\left[\mathrm{Cu}\left(\eta^{1}-\mathrm{OCO}_{2} \mathrm{H}\right)_{2}\left(\mathrm{OH}_{2}\right)_{2}\right](2 \mathbf{a})^{3,4}$ & 8.2 & $>250^{5}$ & $1 \mathrm{M} \mathrm{HCO}_{3}^{-}$ & $\sim 800$ & 96 & [21] \\
\hline 'Cu-carbonate' 6 & 10.8 & $>1000$ & $1 \mathrm{M} \mathrm{HCO}_{3}{ }^{-} / \mathrm{CO}_{3}{ }^{2-}$ & $\sim 700$ & 97 & [21] \\
\hline$\left\{\left[\mathrm{B}(\mathrm{OH})_{4}\right] \mathrm{Cu}\left(\mathrm{OSO}_{3}\right)\left(\mathrm{OH}_{2}\right)\right\}(3)$ & 7.0 & $>7250$ & $0.45 \mathrm{M}$ borate $/ 1 \mathrm{M} \mathrm{SO}_{4}{ }^{2-}$ & 750 & $\sim 100$ & [26] \\
\hline
\end{tabular}

${ }^{1}$ studies were carried out under different conditions therefore direct comparison of the selected data throughout Tables 1-5 is circumstantial, for details the reader should always consult the cited papers; ${ }^{2}$ on indium tin oxide (ITO) electrode, in several cases data with fluorine doped tin oxide (FTO), boron doped diamond (BDD) or glassy carbon (GC) are also reported; ${ }^{3}\left[\mathrm{Cu}\left(\eta^{2}-\mathrm{O}_{2} \mathrm{CO}\right)\left(\mathrm{OH}_{2}\right)\right]$ was also suggested as equilibrium species [22]; ${ }^{4}$ at higher $\mathrm{Cu}^{2+}$ concentration, or when carbonate is replaced by other oxyanions, surface ' $\mathrm{CuO}^{\prime}$ ' film is deposited and contributes to catalysis; ${ }^{5}$ single site mechanism applies if $\left[\mathrm{Cu}^{2+}\right]<4 \mathrm{mM}$, similar results were reported for a $0.1 \mathrm{M} \mathrm{HCO}_{3}^{-}$ solution saturated with $\mathrm{CO}_{2}$ at $\mathrm{pH} 6.7 ;{ }^{6}$ dicopper mechanism was suggested based on second order in [CuII].

More recently, a catalytic system in neutral borate buffer has been applied by Lu et al. on similar grounds to those of the earlier examples [26]. In this borate system sulfate was applied in $1 \mathrm{M}$ concentration to facilitate a soluble copper complex for which a simplified structure was tentatively proposed as 3 (Figure 2) based on a characteristic absorption band at $300 \mathrm{~nm}$ in UV-Vis. This band was only detected in sulfate and borate solution, but it was missing in the absence of either sulfate or borate. Although borate concentration was set to $0.45 \mathrm{M}$, close to its solubility limit, catalysis occurred at lower concentrations, too. Electrocatalytic oxygen evolution at $1.55 \mathrm{~V}$ on ITO resulted in nearly unity Faraday efficiency at $\mathrm{pH}$ 7. The observed first order dependence of the catalytic current in borate and $\mathrm{Cu}^{\mathrm{II}}$ suggested single-molecule catalysis and differential pulse voltammetry (DPV) confirmed a $1 \mathrm{H}^{+} / 1 \mathrm{e}^{-}$PCET by the $\mathrm{pH}$-dependence of the irreversible anodic current peak.

However, in this case the kinetic isotope effect (KIE), that is calculated in the case of electrocatalysis as $K I E=\left(i_{\text {cat }}, \mathrm{H}_{2} \mathrm{O} / i_{\text {cat }}, \mathrm{D}_{2} \mathrm{O}\right)^{2}$ and its value is informative about the involvement of protons in the electron transfer processes, suggested a different scenario. The KIE of 1.01 indicated that protons are not involved in the rate limiting chemical step, excluding the option of borate acting as proton acceptor. Indeed, in accordance with the experimental findings, DFT calculations on the mechanism 
steps supported the coordination of tetrahydroxyborate and its participation in the rate limiting O-O bond formation step as oxygen donor thus decreasing the activation barrier and enhancing the rate of electrocatalysis (Figure 4).

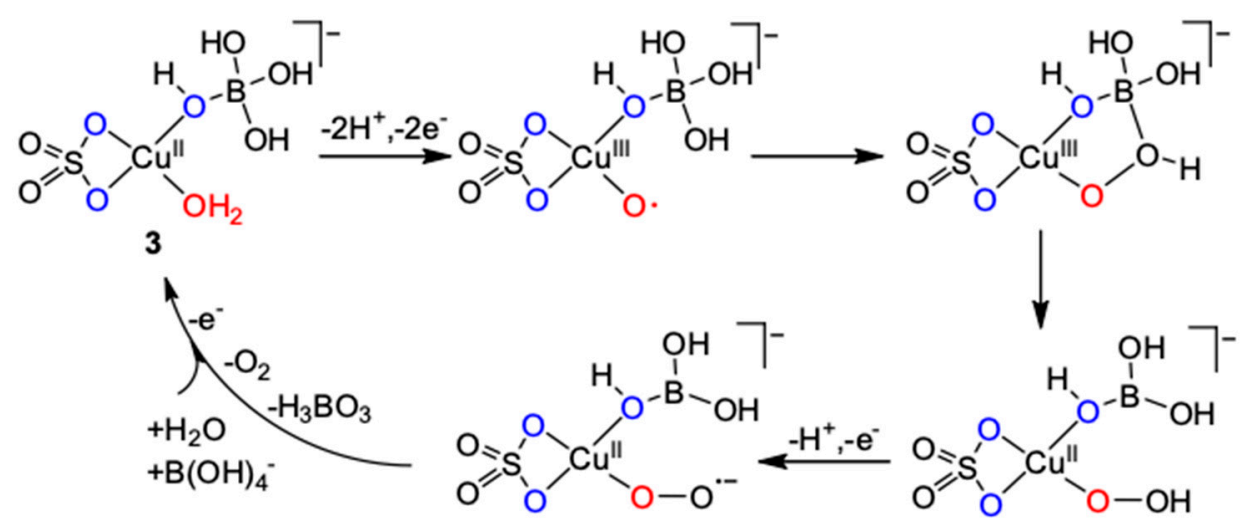

Figure 4. Proposed mechanism for the electrocatalytic oxygen evolving reaction by the ternary complex 3 [26].

\subsubsection{Organic Ligands}

A common feature of the above discussed, purely inorganic molecular systems is the high concentration of the coordinating oxyanion that is always necessary owing to the low solubility of the stoichiometric $\mathrm{Cu}$-oxyanion compounds [27]. On the other hand, if organic chelators are applied as supporting ligands instead of the inorganic anions high excess is not a requirement anymore. It has to be considered though that such compounds are often inherently prone to oxidative degradation under the demanding conditions of WOC that in turn may shorten the attainable lifespan.

\subsubsection{2,2'-Bipyridine and Related Ligands}

Mayer et al. reported the first single site molecular water oxidation catalyst by mixing equimolar amounts of different cupric salts with 2,2'-bipyridine (bpy) and setting $\mathrm{pH}$ above 12 [19]. An apparent rate constant $\left(k_{o b s}\right)$ of $100 \mathrm{~s}^{-1}$ at an overpotential of $\sim 750 \mathrm{mV}$ at $\mathrm{pH}=12.8$ was reported, irrespective of the applied electrolyte $\left(\mathrm{SO}_{4}{ }^{2-}, \mathrm{OAc}^{-}\right.$or $\left.\mathrm{OTf}^{-}\right)$. The alkaline speciation of $\mathrm{Cu}^{\mathrm{II}}$ with bpy also supported by the quantitative presence of a quartet signal in X-band EPR confirmed that the catalyst was the monomeric bis-hydroxide complex (bpy)Cu ${ }^{\mathrm{II}}(\mathrm{OH})_{2}$ (Figure 5, 4). Note that a related tetranuclear system by Li et al. [28] will be discussed in Section 2.4.

In a later computational work Llobet, Maseres et al. revisited the activation pathway of 4 among other, known complexes [29] by extending their unifying single electron transfer-water nucleophilic attack (SET-WNA) scenario originally introduced to explain the mechanism of WOC by a redox non-innocent ligand containing system [30]. According to their mechanism proposal, since bpy cannot be oxidized in the catalytically relevant potential range, the activation of 4 at $\mathrm{pH} 12.5$ starts with the $1 \mathrm{e}^{-}$oxidation of the $\mathrm{Cu}^{\mathrm{II}}$ center at $1.12 \mathrm{~V}$ followed by another PCET step at $1.45 \mathrm{~V}$ to generate $\left[(\text { bpy }) \mathrm{Cu}^{\mathrm{III}}(\mathrm{OH})\left(\mathrm{O}^{\bullet}\right)\right]^{+}$. These potentials are in good agreement with the experimental ones. They found that from this species an intermolecular SET-WNA step is energetically favored over the intramolecular coupling between the hydroxide and the oxyl ligands (Figure 6). The low barrier obtained for the SET-WNA mechanism in conjunction with the high potential needed to reach the active species is consistent with the reported high turnover frequency. More significantly, it confirms the prevalence of this type of mechanism for $\mathrm{Cu}$-based water oxidation catalysts, even when the ligand is not involved in the redox process. 
<smiles></smiles>

4<smiles></smiles><smiles>NC(=O)CN(CCO)C(=O)CN(CCO)C(=O)CNCc1ccccc1</smiles>

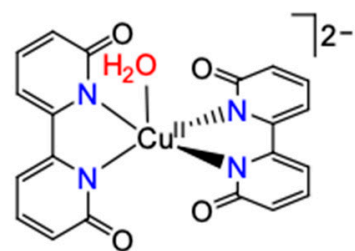

6<smiles>O[Si](O)(O)n1c2ccccc2c2nccn21</smiles>

8

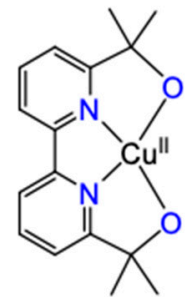

9

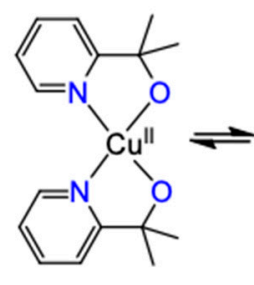

$10 a$

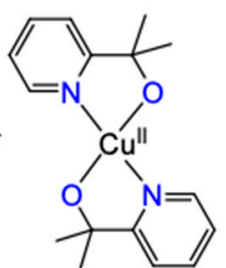

$10 b$

Figure 5. Single site $\mathrm{Cu}$-based molecular WOCs with bpy and related ligands.

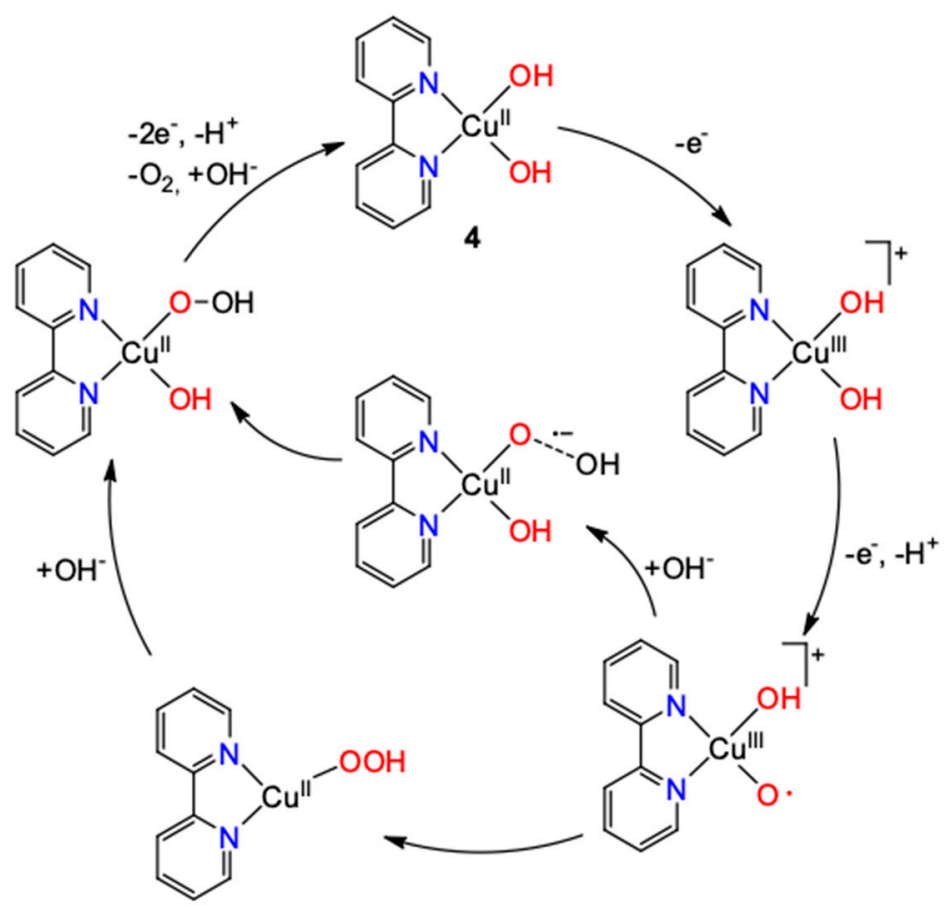

Figure 6. Mechanistic scheme of the OER catalyzed by 4 [29].

The early paper by Meyer highlighted that in situ formed electrocatalysts from inexpensive materials represent a viable option for further developments. Indeed, Lin and coworkers reported the use of the $6,6^{\prime}$-dihydroxy-2,2' -bipyridine (6,6'-dhbpy) that considerably reduced $\eta$ by ca. $200 \mathrm{mV}$ (Table 2) [31]. The pendant groups were to mimic the function of tyrosine $\mathrm{Z}$ of PS II in facilitating 
the oxidation of the $\mathrm{Cu}$ center. The $k_{o b s}$ of $0.4 \mathrm{~s}^{-1}$ for the catalytic water/hydroxide oxidation was determined from the slope of the plotted $i_{c a t} / i_{d}$ versus $v^{-0.5}$, where $i_{d}$ is the diffusion controlled current peak for the $\mathrm{Cu}^{\mathrm{II} / \mathrm{I}}$ transition and $i_{c a t}$ is that of the irreversible catalytic peak. Titration experiment indicated that 5 (Figure 5) was the dominant species and possibly the true catalyst. DFT calculations aided to identify the most probable pathway of catalysis (Figure 7). According to the explanation of the authors, the second oxidation step can take place at the dihydroxide ligand due to its redox activity to yield a $1 \mathrm{e}^{-}$oxidized species with radical anion character $\left(5^{\mathbf{0 x}}\right)$ at a calculated oxidation potential of $1.4 \mathrm{~V}$ versus NHE. Spin delocalization at the redox active ligand and stabilization of $\mathbf{5}^{\mathbf{o x}}$ were held responsible for the lowered onset potential and, at the same time, for the milder electrophilic character disfavoring the O-O formation step and yielding much lower $k_{o b s}$ in WOC compared to 4 . However, SWV studies showed that only 6,6'-dhbpy lowers the overpotential for WOC, while substituents only slightly affected either the $\mathrm{Cu}^{\mathrm{III} / \mathrm{II}}$ or the water oxidation potential leaving a question mark behind the sole effect of spin densities.

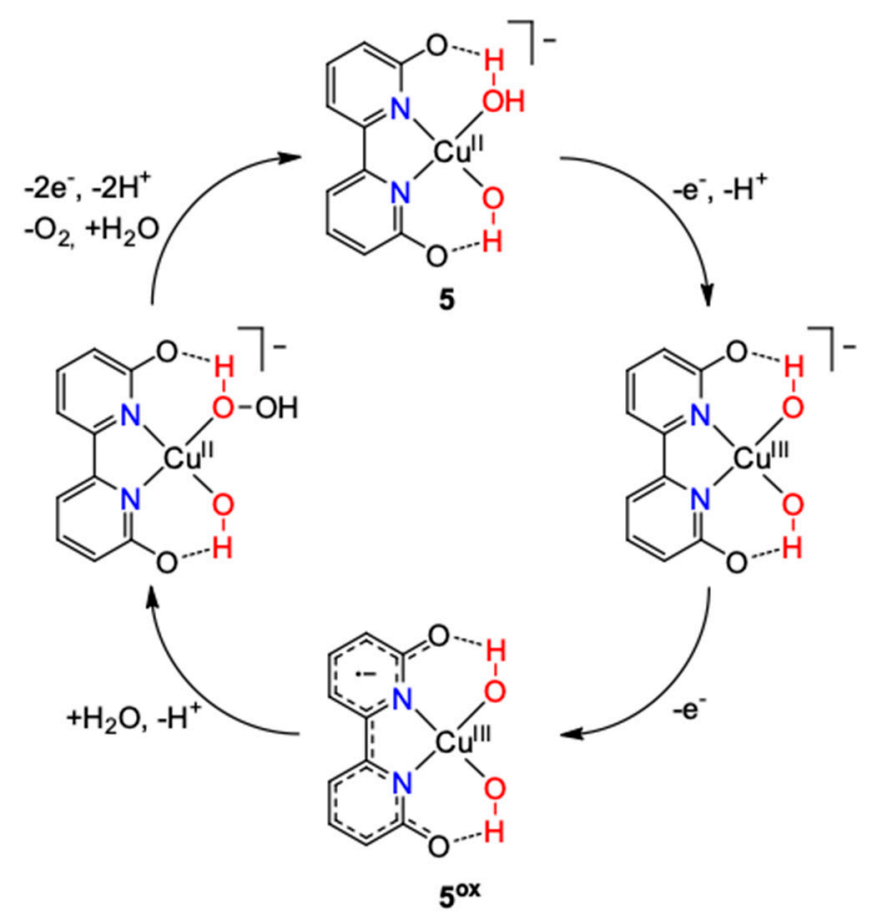

Figure 7. The most probable pathway of catalysis by 5 [31].

During electrolysis, a deposit on the electrode was observed and characterized as a partially oxidized oligomer/polymer of the complex instead of metal oxide. Catalytic cycles in pure electrolyte returned the coordination polymer to its original state and the film re-dissolved into solution again. Lowering the $\mathrm{pH}$ to $\sim 11$ of an aqueous solution of 5 allowed crystallographic studies that confirmed a 1-D coordination polymer with $\mu-\mathrm{OH}$ bridges and hydrogen bonding network. The monomer and oligomer/polymer equilibrium was also associated with the curving-over behavior of catalytic peak currents at high complex concentrations in CVs. This equilibrium was also proposed to be responsible for the film formation, owed to the local $\mathrm{pH}$ decrease during the controlled potential electrolysis. Accumulation of molecular catalysts on electrode surfaces has been proposed to cause deviations from the diffusion controlled behavior upon electrolysis [31,32] and in other cases coordination polymerization was exploited to generate catalytic films [33-35]. These observations may inspire further investigations on the $\mathrm{pH}$-dependent speciation and redox transformations of molecular systems and how these properties influence their affinity for surfaces that can potentially promote their immobilization at the electrode via adsorption instead of covalent linkage. 
Papish and coworkers published about substituted bpy compounds including 6,6'-dhbpy, but applying these ligands in 2:1 stoichiometry to the cupric ion and paying attention to accompanying, non-catalytic processes [36]. From EPR and HYSCORE data at $\mathrm{pH} 12.6$, where water oxidation occurred they inferred that the major species present was the aqua-coordinated $\left[\left(6,6^{\prime}-(\mathrm{O})_{2}-\mathrm{bpy}\right)_{2} \mathrm{Cu}\left(\mathrm{H}_{2} \mathrm{O}\right)\right]^{2-}$ complex (6, Figure 5). Data fitting to CVs allowed an estimate of the charge transfer rate, the average $k_{o b s}$ and the overpotential (Table 2) by assuming that 6 undergoes a heterogeneous charge transfer step and two following homogeneous reactions. The latter included one catalytic water oxidation and a competing non-catalytic degradation at a faster rate of $1.082 \mathrm{~s}^{-1}$, forming an unidentified product. Accordingly, bulk electrolysis of 6 at $\mathrm{pH} 12.6$ in aqueous $0.1 \mathrm{M} \mathrm{NaOAc}$ at $0.9 \mathrm{~V}$ yielded only a small amount of $\mathrm{O}_{2}$. Interestingly, the 1:2 complexes of $\mathrm{CuSO}_{4}$ and $4,4^{\prime}$-disubstituted analogs were inactive at water oxidation. This led the authors to conclude that the neighboring $\mathrm{O}^{-} / \mathrm{OH}$ groups facilitate PCET steps and may stabilize proposed oxo-copper species. Crystal structures of the copper compounds and follow-up thermodynamic acidity studies [37] all indicated that hydrogen bonding interactions can aid transformations of the water substrate, in addition to the redox non-innocence of $6,6^{\prime}-(\mathrm{OH})_{2}$-bpy reported in their prior work on its Ir-complex [38] and also by Lin. The very slow turnover rate falling close to that of 5 was associated with slow $\mathrm{O}-\mathrm{O}$ coupling. The authors finally remarked that small amounts of 2:1 complex could be conceivably formed in the previously reported study on 5 [31] and might be the active catalyst. Likewise, in their own study, changes may occur to the structure of 6 upon oxidation.

Maayan and coworkers reported very recently the first high resolution single crystal X-ray structure of a self-assembled dicopper complex with a peptoid ligand (BPT) that utilized a covalently bound bpy prosthetic group [39]. Based on this ligand they made a copper-peptidomimetic complex as a stable and efficient electrocatalyst for water oxidation (Figure 5,7) [40]. The peptoid trimer combines a 2,2'-bipyridine (bpy) ligand, an -OH group and a benzyl group. Experimental and computational data revealed that $\mathrm{Cu}$ iI is bound to this peptoid via bpy and two hydroxide ligands originating from the solvent water. In contrast to former studies on bpy-based systems (4-6) adding the metallopeptoid as solid to an aqueous solution at $\mathrm{pH} 12.5$ resulted in a brown precipitate. On the other hand the complex is stable in aqueous phosphate buffer up to $\mathrm{pH} 11.5$, conditions more similar to those applied in the case of peptide-containing systems (discussed later) [32,41-43]. Under these conditions oxygen evolution occurred with $k_{o b s}$ of $5.8 \mathrm{~s}^{-1}$ (determined by foot-of-the-wave, i.e., FOWA analysis [44]) and Faraday efficiency of up to $91 \%$. The catalyst was stable over at least 15 hours of electrolysis and could be reused for at least 9 times in 40 min runs (an overall TON of $\sim 56$ within 6 hours), if the lowered $\mathrm{pH}$ was re-adjusted after each run. Based on electrochemical experiments, spectroscopic data and density functional theory (DFT)-D3 calculations the authors identified a key peroxide intermediate and proposed an intramolecular cooperative catalytic pathway, suggesting that the proximal -OH group and the etheric oxygen atom attached to the bpy moiety form strong $\mathrm{H}$-bonds with the coordinated hydroxide ligands, thus has a major role in the high stability of the complex. The reversible $\mathrm{Cu}^{\mathrm{III} / \mathrm{II}}$ oxidation wave occurred at an unusually low $E_{1 / 2}$ of $0.30 \mathrm{~V}$ versus NHE (very close to the observed $\mathrm{Cu}^{\mathrm{II} / \mathrm{I}}$ waves) in contrast to a ligand analog, in which the ethanolic $-\mathrm{OH}$ group was replaced by $-\mathrm{OCH}_{3}$ to give a potential of $0.50 \mathrm{~V}$ for the $\mathrm{Cu} \mathrm{u}^{\mathrm{III} / \mathrm{II}}$ transition. The key step in the proposed mechanism was suggested to be the WNA at the oxyl ligand of $\left[(\mathrm{BPT}) \mathrm{Cu}^{\mathrm{III}}(\mathrm{OH})\left(\mathrm{O}^{\bullet}\right)\right]^{+}$by an external hydroxide anion.

Another option of reducing the overpotential need was demonstrated by Warren and coworkers who introduced a pyrazole moiety in the ligand 2-(2'-pyridyl)-imidazole (pimH, Figure 5, 8) [45]. EPR and UV-Vis spectroscopic evaluation of catalyst speciation showed that pimH undergoes deprotonation at $\mathrm{pH} \sim 12$ in its copper complex. This way the bis(hydroxide) $\mathrm{Cu}^{\mathrm{II}}$ active catalyst was formed (8) and rapid electrochemical WOC ( $35 \mathrm{~s}^{-1}, 0.85 \mathrm{~V}$ onset potential) was observed with only $150 \mu \mathrm{M}$ catalyst, however, catalyst decomposition was considerable. These results demonstrate that catalytic water oxidation potentials can be shifted significantly by applying molecular metal catalysts bearing an ionizable imidazole ligand. 
The fully characterized copper complex, 9, of a tetradentate ligand based on bpy, $2,2^{\prime}-\left[\left(2,2^{\prime}\right.\right.$-bipyridine)-6,6'-diyl]bis(propan-2-ol) (bpydipyal $\left.\mathrm{kH}_{2}\right)$ has been tested in water oxidation very recently [46] in context with the corresponding complex cis-Cu(pyalk) $)_{2}(\mathbf{1 0 a}$, the catalytically active isomer of 10b) [47] utilizing 2-pyridyl-2-propanol (pyalkH), a ligand known to be very robust from molecular WOC systems involving other metals $[48,49]$. Both complexes contain two alkoxide and two pyridyl groups coordinated to copper, but the rigid, tetradentate ligand structure of bpydipyalk ${ }^{2-}$ in 9 impedes flexibility for the pyridines. Under the electrocatalytic conditions applied for the bis-pyalk complex, and in sharp contrast to all other bpy-based systems reviewed above, 9 did not promote OER. On the other hand, $\mathbf{1 0}$ proved to be a robust molecular electrocatalyst at $\mathrm{pH}>10.4$ exhibiting a relatively low overpotential for copper with $k_{o b s}$ of $\sim 0.7 \mathrm{~s}^{-1}$ (Table 2). CPE over $12 \mathrm{~h}$ at $1.1 \mathrm{~V}$ versus NHE yielded $>30$ catalytic turnovers of $\mathrm{O}_{2}$ with only $\sim 20 \%$ catalyst degradation. This degradation was associated with the electrodeposition of metallic copper on the counter electrode, a result of diffusion of some of the complex through the glass frit connecting the working and counter electrodes. After $2 \mathrm{~h}$ of CPE at an ITO electrode, neither particle or film formation was detected over the surface nor was catalytic activity observed when the electrode was rinsed and then placed into a catalyst-free solution. The related copper(II)-bis-picolinate (Figure $8, \mathbf{1 1}$ ) was also tested in WOC, but the observed activity at $\mathrm{pH} 12.5$ could be clearly assigned to in situ forming $\mathrm{Cu}(\mathrm{OH})_{2}$ underlining again the unique robustness of pyalkH.

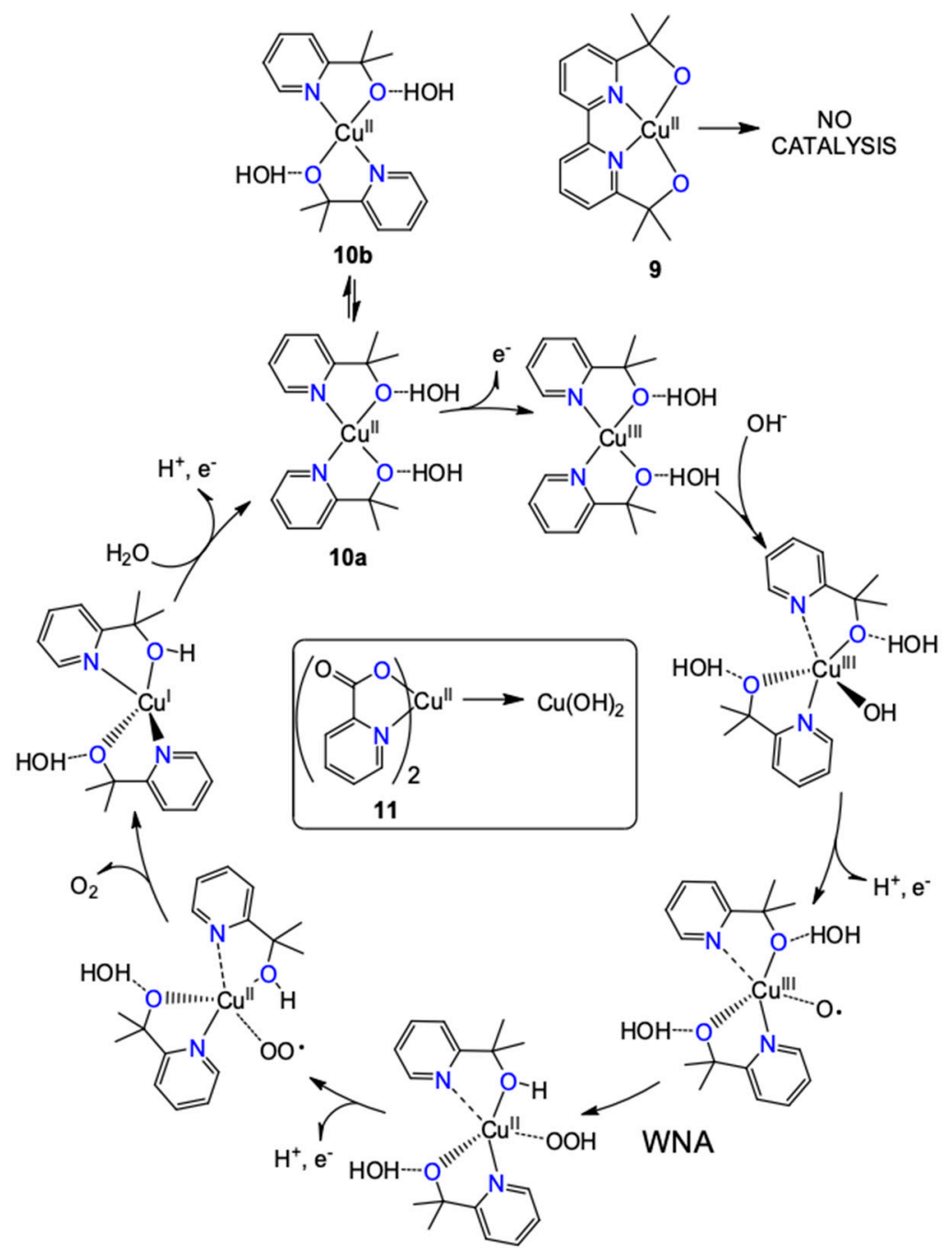

Figure 8. Steps of the water nucleophilic attack mechanism for $\mathbf{1 0}$ by density functional theory (DFT) and the behavior of the closely related $\mathbf{9}$ and $\mathbf{1 1}$ [47]. 
A very detailed WNA mechanism was delineated for 10 by DFT (Figure 8), appropriate for basic solutions, including bulk solvation from the dielectric continuum model as well as direct solvation by two $\mathrm{H}$-bonded water molecules to the pyalk oxygen atoms, moreover, in accordance with the experimental findings (first order dependence confirming single-site mechanism, KIE of 3.4, reactivity difference between 9 and 10, redox inactivity of pyalkH, absence of the partial water oxidation product $\mathrm{H}_{2} \mathrm{O}_{2}$, pH-dependent features of WOC, foot-of-the-wave analysis of the catalytic current to provide mechanistic information on the chemical step following the electron transfer) [46].

\subsubsection{Ligands with Amine Donor Groups}

Amine donor groups were also utilized in several single site catalysts. The tetradentate macrocycle 1,4,8,11-tetramethyl-1,4,8,11-tetraazacyclotetradecane (TMC) was reported to form mononuclear copper(II) complex, $\left[\mathrm{Cu}(\mathrm{TMC})\left(\mathrm{H}_{2} \mathrm{O}\right)\right]^{2+}$ (Figure 9, 12) with an apical aqua ligand [50]. This assembly proved to be a very robust WOC at neutral $\mathrm{pH}$, reaching over 360 turnovers at much higher rate and by $\sim 200 \mathrm{mV}$ lower overpotential than the $\left[\mathrm{Cu}_{2}(\mathrm{BPMAN})(\mu-\mathrm{OH})\right]^{3+}$ complex (BPMAN $=2,7$-[bis(2-pyridylmethyl)aminomethyl]-1,8-naphthyridine) [51] (discussed in Section 2.3) when immobilized on a carbon cloth electrode. Combined with the results of electrochemical and kinetic studies the authors proposed that in the homogeneous reaction, at $\mathrm{pH} 7,\left[\mathrm{Cu}^{\mathrm{III}}(\mathrm{TMC})(\mathrm{OH})\right]^{2+}$ was generated via a PCET process at $1.64 \mathrm{~V}$. The consecutive $1 \mathrm{e}^{-}$oxidation of $\left[\mathrm{Cu}^{\mathrm{III}}(\mathrm{TMC})(\mathrm{OH})\right]^{2+}$ at $1.77 \mathrm{~V}$ was $\mathrm{pH}$-independent, and the authors proposed that the electron is either removed from the ligand, or the $\mathrm{Cu}^{\mathrm{III}}$ center. The narrow separation between these two oxidation steps was associated with an efficient redox potential leveling in the system, which was proposed to facilitate the formation of a key intermediate for water oxidation. The $\mathrm{H}_{2} \mathrm{O} / \mathrm{D}_{2} \mathrm{O}$ KIE value of 2.1 is in accordance with an oxygen atom coupled proton transfer (APT) process in the proposed rate limiting $\mathrm{O}-\mathrm{O}$ bond formation step giving rise to a $\mathrm{Cu}^{\mathrm{II}}(\mathrm{HOOH})$ intermediate. The oxidation of $\mathrm{Cu}^{\mathrm{II}}(\mathrm{HOOH})$ accompanied by the loss of a proton finally leads to oxygen release and the regeneration of $\mathbf{1 2}$.

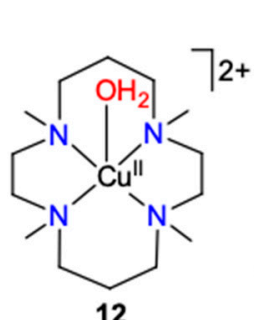

12
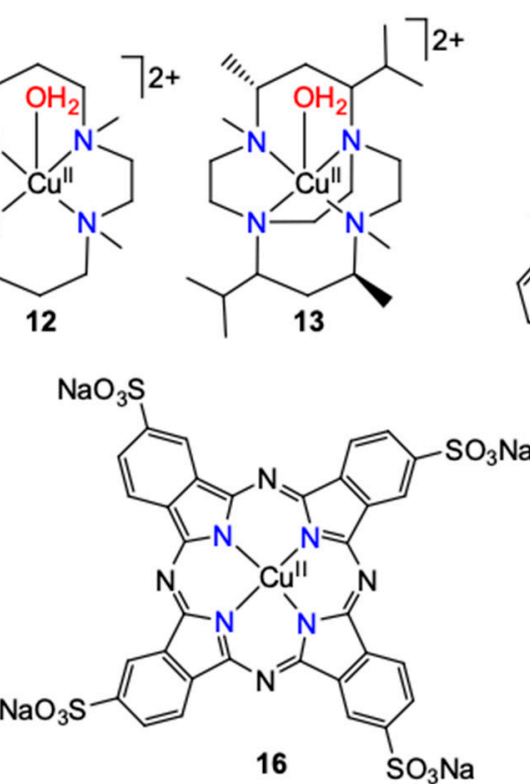

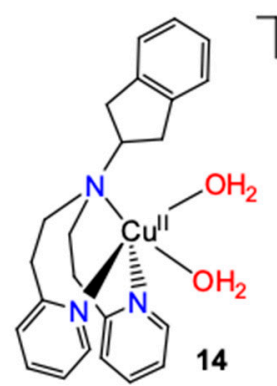

14
$72+$<smiles></smiles>

15

Figure 9. Schematic structure of various single-site catalysts.

A similar Cu-complex bearing a more rigid ligand analog, $\mathrm{L}_{\mathrm{m}}=(5 R, 12 S)-4,5,7,7,11,12,14,14-$ octamethyl-1,4,8,11-tetraazabicyclo[6.6.2] hexadecane (Figure 9, 13) has been recently reported to act as catalyst at high $\mathrm{pH}$ [52]. The metal center is bound by four nitrogen atoms from the ligand and a water molecule, featuring distorted trigonal bipyramidal geometry. The CV of $\mathbf{1 3}$ displayed no current peaks 
below $1.0 \mathrm{~V}$. On the other hand, an irreversible oxidation wave appeared at $1.27 \mathrm{~V}$ versus NHE with nearly four times as high current density as that of the complex-free solution. The current was linearly dependent on the concentration of $\mathbf{1 3}$ indicating single site catalysis. During CPE only 50\% Faraday efficiency was observed on a glassy carbon working electrode that was associated with the degradation of the electrode material, as it has been suggested before [53]. The key step of the proposed mechanism was again WNA

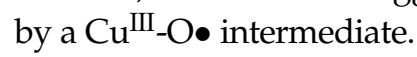

Remarkably, $\mathbf{1 3}$ with the rigid ethylene-bridged macrocycle encapsulating the copper center and leaving only one accessible side for solvent molecules lowers the activity in WOC and necessitates the addition of base. Along with those observed for 9 and 10a these differences underline, too, that the flexibility of ligands may be an important feature to be considered, when putative $\mathrm{Cu}$-based molecular WOCs are designed. As it was explained for 9 and 10a, a lower energy barrier for the reorganization of the ligand geometry supports better the different copper redox states occurring in WOC.

\subsubsection{Mixed Ligand Compositions}

Another interesting option was communicated by Reglier et al., who introduced earlier $\mathrm{C}-\mathrm{H}$ functionality in close proximity to the metal center by an appropriately designed ligand, IndPY $2=$ 2-[bis(2-pyridin-2-ylethyl)amino]indane [54]. Originally, this ligand has been applied to demonstrate stereoselective oxygen atom transfer to the indane unit that produced the 1-indanol derivative upon addition of base and exposure to $\mathrm{O}_{2}$ as a functional model for the dopamine $\beta$-hydroxylase enzyme [55]. The reported single site WOC was associated with the complex 14 (Figure 9) that is formed in situ from the solid precursor $\left[\mathrm{Cu}(\mathrm{IndPY} 2)(\mathrm{OTf})_{2}\right]$. Dioxygen production was the dominant process at neutral $\mathrm{pH}$ as only $\sim 5 \%$ of the complex was hydroxylated. Electrochemical studies at various concentrations of $\mathbf{1 4}$ suggested relatively constant single site, homogeneous catalysis from $\mathrm{pH} 6$ to 8 and the variation of the anodic peak potential, a $1 \mathrm{H}^{+}, 2 \mathrm{e}^{-}$process. The authors proposed that $\mathbf{1 4}$ provided the two-electron oxidized species responsible for WNA, although dimerization and formation of high-valent dinuclear species upon oxidation was not ruled out. At higher $\mathrm{pH}$ (8.0-8.5), this system was able to perform stereoselective oxygen atom transfer from water into the $\mathrm{C}-\mathrm{H}$ bond of the indane moiety upon electrochemical oxidation. The species involved in the hydroxylation of the ligand led to the conclusion that the precursor was likely a dinuclear hydroxo-bridged complex that was inactive in WOC. This work is therefore a unique example of balancing between intramolecular oxygen atom transfer for $\mathrm{C}-\mathrm{H}$ bond activation or WOC through electrolysis in water and demonstrates the use of water as an oxygen source and copper-based catalysts to perform oxygenation reactions.

A mononuclear copper complex utilizing 1,3-bis(((1-methyl-1H-imidazol-2-yl)methyl)amino) propan-2-ol $\left(\mathrm{L}_{\mathrm{OH}}\right)$ in electrochemical WOC has been reported by Siewert [56]. The complex (Figure 9, 15) exhibits $\{4 \mathrm{~N}\}$ donor set consisting of two amine and two imidazole units and a hydroxyl functionality in close proximity to the cupric center. The apparent rate constant of $0.12 \mathrm{~s}^{-1}$ by high overpotential was moderate (Table 2 ). The catalysis proceeded only under basic conditions, where $15-\mathrm{H}^{+}$was the main solution species indicating that a negatively charged ligand is necessary to drive the process. Initial $1 \mathrm{e}^{-}$oxidation of $15-\mathrm{H}^{+}$was a PCET process and further oxidation initiated oxygen evolution. Importantly, the oxidation of $\mathbf{1 5}$ under neutral, i.e., non-catalytic conditions was $\mathrm{pH}$ independent, highlighting the importance of PCET steps during catalysis that proceeds via WNA mechanism. The electrolyte presumably acted as a proton acceptor as the onset potential depended on the employed buffer.

In the last two examples a hydroxyl group was either synthetically introduced near the metal center, but remained uncoordinated (15), or it was in situ generated (14) by electrolysis to provide a bis- $\mu$-hydroxo-bridged dicopper species. Either way, these aliphatic hydroxyl groups played no role in WOC, in sharp contrast to the phenolic $\mathrm{OH}$ in 5 , or the coordinated tertiary alcoholate group in 10a/10b.

Dark electrochemical, or photochemical activation of a water-soluble $\mathrm{Cu}$-phthalocyanine complex (Figure 9, 16) with phthalocyanine tetrasulfonate $\left(\mathrm{PcTS}^{4-}\right.$ ) was also described to lead to water 
oxidation [57]. Although the photochemical activation has been emphasized, the authors proposed a general I2M mechanism, in which the O-O bond formation took place by homo-coupling between two $\left[\mathrm{Cu}\left({ }^{\bullet} \mathrm{PcTS}\right)(\mathrm{O})\right]^{-}$species, with nearly unity calculated radical character on the oxyl ligand. Importantly, chloride binding completely inhibited WOC of $\mathbf{1 6}$ at even low chloride concentrations due to competition between $\mathrm{H}_{2} \mathrm{O}$ and $\mathrm{Cl}^{-}$for the axial site of the copper center.

One of the first stable water oxidation molecular electrocatalysts and the second to utilize deprotonated amide nitrogen donors to stabilize the higher oxidation state intermediates [41] was the monomeric $\left[\mathrm{Cu}\left(\mathrm{Py}_{3} \mathrm{P}\right)(\mathrm{OH})\right]^{-}$(Figure 9, 17, $\mathrm{Py}_{3} \mathrm{P}$ is $N, N$-bis(2-(2-pyridyl)ethyl) pyridine-2,6-dicarboxamidate) [58] in $\mathrm{H}_{2} \mathrm{PO}_{4}{ }^{-} / \mathrm{HPO}_{4}{ }^{2-}$ buffered solutions. Catalysis by 17 was possible near to the neutral $\mathrm{pH}$ that was claimed to allow a derivative to be incorporated into future molecular assemblies for PEC aiming water oxidation. CV and CPE measurements provided experimental evidence for a single-site water oxidation mechanism and the rate constant ratio of catalysis to deactivation $\left(k_{\text {obs }} / k_{\text {deact. }} \sim 6 \times 10^{7} \mathrm{~s}^{-1}\right)$ prognosticated stable, long term performance. The magnitude of the kinetic isotope effect $(K I E=2$, determined by current comparisons at $1.50 \mathrm{~V}$, at $\mathrm{pH} / \mathrm{pD}$ 8.0) was consistent with proton involvement in the rate-limiting step and a possible oxygen atom-proton transfer (APT) pathway for water oxidation. The experimental data, i.e., two close lying, catalytically enhanced current peaks at 1.29 and $1.50 \mathrm{~V}$ versus NHE, were consistent with $2 \mathrm{e}^{-}$ oxidative activation of the complex triggering electrocatalytic water oxidation. Although the electronic formulation of the active intermediate remained unclear, i.e., the $\mathrm{Py}_{3} \mathrm{P}$ ligand, or metal centered nature of the second electrochemical oxidation step at $1.50 \mathrm{~V}$, the twice-oxidized intermediate can either way participate in a subsequent rate-limiting APT O-O bond formation with proton transfer to $\mathrm{HPO}_{4}{ }^{2-}$ giving a $\mathrm{Cu}^{\mathrm{II}}\left(\mathrm{H}_{2} \mathrm{O}_{2}\right)$ intermediate. Importantly, the assistance of $\mathrm{HPO}_{4}{ }^{2-}$ as proton acceptor was clearly demonstrated by kinetic analysis of the dependence of $k_{\text {cat }}$ on $\left[\mathrm{HPO}_{4}{ }^{2-}\right]$ according to the following equation (Equation (7)):

$$
\text { reaction rate }=k_{o b s}[17]=\left(k_{B}\left[\mathrm{HPO}_{4}{ }^{2-}\right]+k_{H 2 O}\right)[17]
$$

which gave $k_{B}=190 \mathrm{M}^{-1} \mathrm{~S}^{-1}$ and $k_{\mathrm{H} 2 \mathrm{O}}=0.32 \mathrm{~s}^{-1}$, in line with an APT pathway and the greater proton accepting ability of $\mathrm{HPO}_{4}{ }^{2-}$ than that of $\mathrm{H}_{2} \mathrm{O}$. In the water oxidation cycle, rapid oxidation of the proposed $\mathrm{Cu}^{\mathrm{II}}\left(\mathrm{H}_{2} \mathrm{O}_{2}\right)$ intermediate can lead to $\mathrm{O}_{2}$ release, $\mathrm{H}_{2} \mathrm{O}$ coordination, and re-entry of $\mathbf{1 7}$ into the catalytic cycle.

The relation between the number of pyridine groups and the water oxidation capacity of $\mathrm{Cu}$-complexes was recently investigated by the comparison of two water soluble catalysts with neutral ligands containing amine and pyridine donor groups [59]. Interestingly, the [(bztpen) $\mathrm{Cu}]\left(\mathrm{BF}_{4}\right)_{2}$ complex, 18 $\left(\mathrm{BF}_{4}\right)_{2}$, (Figure 10, bztpen = $N$-benzyl- $N, N^{\prime}, N^{\prime}$-tris(pyridin-2-ylmethyl)ethylenediamine, with the $\{5 \mathrm{~N}\}$ donor set displayed earlier high catalytic activity in electrochemical HER under acidic conditions [60].
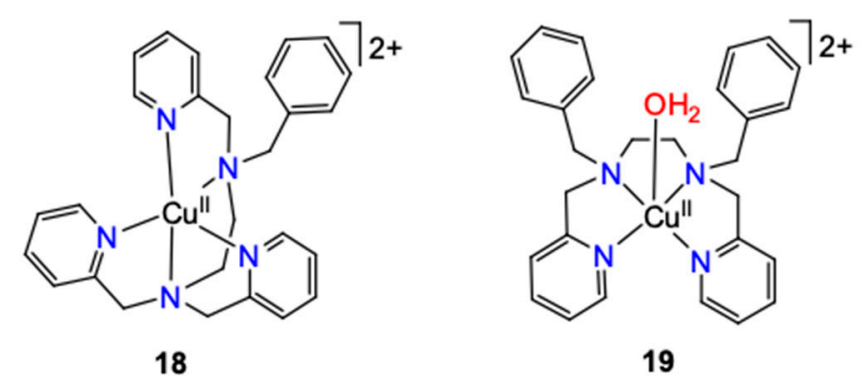

Figure 10. Structural view of catalysts containing amine and pyridine donor groups [59].

In a basic buffer, 18 catalyzed water oxidation with a modest onset potential, despite the fact that no water coordination was evidenced in the SPBY-5 geometric arrangement according to the X-ray diffraction structure. The catalytic activity of this copper catalyst could be improved by 
exchanging a pyridine to a benzyl group, thus attaining [(dbzbpen) $\left.\mathrm{Cu}\left(\mathrm{OH}_{2}\right)\right]\left(\mathrm{BF}_{4}\right)_{2}\left(\mathbf{1 9}\left(\mathrm{BF}_{4}\right)_{2}\right.$, dbzbpen $=N, N^{\prime}$-dibenzyl- $N, N^{\prime}$-bis(pyridin-2-ylmethyl)ethylenediamine). This tetradentate $\{4 \mathrm{~N}\}$ ligand leaving an open site for the coordination of water resulted in better catalytic performance than that of $\mathbf{1 8}$ in phosphate buffer at $\mathrm{pH} 11.5$ (Table 2). The authors gathered experimental evidence, e.g., the first order in $\left[\mathrm{HPO}_{4}{ }^{2-}\right]$, the KIE of about 2 and the catalytic current potentials shifted by roughly $-59 \mathrm{mV} / \mathrm{pH}$ unit pointing to a $1 \mathrm{H}^{+} / 1 \mathrm{e}^{-}$PCET process, to support the traditional single-site WNA mechanism with the phosphate anions acting as assisting base. These facts indicated that although the initial two steps for the formation of $\left[\mathrm{LCu}^{\mathrm{III}}(\mathrm{OH})\right]^{2+}$ were different for 18 and $\mathbf{1 9}$, the following pathways should be similar, i.e., once formed, $\left[\mathrm{LCu}(\mathrm{III}(\mathrm{OH})]^{2+}\right.$ could be oxidized to $\left[\mathrm{LCu}^{\mathrm{IV}}=\mathrm{O}\right]^{2+}$ or $\left[\mathrm{LCu}^{\mathrm{III}}(\mathrm{O} \bullet)\right]^{2+}$ intermediate via a PCET process. Subsequently, water attack on either of these would give the same $\left[\mathrm{LCu}^{\mathrm{II}}(\mathrm{OOH})\right]^{+}$, possibly formed through a rate-limiting atom-proton transfer (APT) process as proposed for other, single-site catalysts like 17. According to these results, at least one site pre-occupied by a water molecule is advantageous, but not strictly required for WOC activity.

\subsubsection{Redox Non-Innocent Ligands}

The first, experimentally well documented example for the involvement of ligand redox activity in electrocatalytic water oxidation was published by Maseras and Llobet [30] on the complexes listed in Figure 11 as 20a-d bearing rigid, planar ligands with extended $\pi$-conjugation (L1-L4 = $N 1, N 1$ '-(4,5-R-1,2-phenylene)bis(N2-methyloxalamide), $\mathrm{R}_{1}, \mathrm{R}_{2}=\mathrm{H}$ for $\mathrm{L} 1 ; \mathrm{R}_{1}, \mathrm{R}_{2}=\mathrm{CH}_{3}$ for $\mathrm{L} 2 ; \mathrm{R}_{1}$ $=\mathrm{OCH}_{3}, \mathrm{R}_{2}=\mathrm{H}$ for $\mathrm{L} 3$ and $\mathrm{R}_{1}, \mathrm{R}_{2}=\mathrm{OCH}_{3}$ for L4). Importantly, single crystal X-ray structures confirmed SP-4 geometry for these anionic complexes lacking any axial aqua ligands that can readily accommodate the one electron oxidized $\mathrm{d}^{8} \mathrm{Cu}^{\mathrm{III}}$ metal centers. Fine-tuning of the ligand by introducing electron-donating $R_{1}$ and $R_{2}$ substituents at the benzene ring allowed gradually reducing the $\eta$ by more than $500 \mathrm{mV}$. The correlation between the ligand HOMO energy and the $\eta$ for water oxidation indicated that the electron-donating substituents increase the overall energy of the HOMO and thus, they favor the electron release from the ligand to give the oxidized molecule. The stabilization of the ligand radical thus leads to the decrease in the $\eta$. In addition, DFT analysis revealed an unprecedented pathway where the $\mathrm{O}-\mathrm{O}$ bond formation occurs in a two-step, one-electron process generating a peroxide intermediate with no formal $\mathrm{M}-\mathrm{O}$ bond (Figure 12). This is in sharp contrast with previous single-site mechanisms, which all propose rapidly oxidized peroxo-copper(II) intermediates occurring after the $\mathrm{O}-\mathrm{O}$ bond formation step. Considering that the electrons were removed from the low lying ligand-based HOMOs, new avenues for molecular water oxidation catalyst design were envisioned.

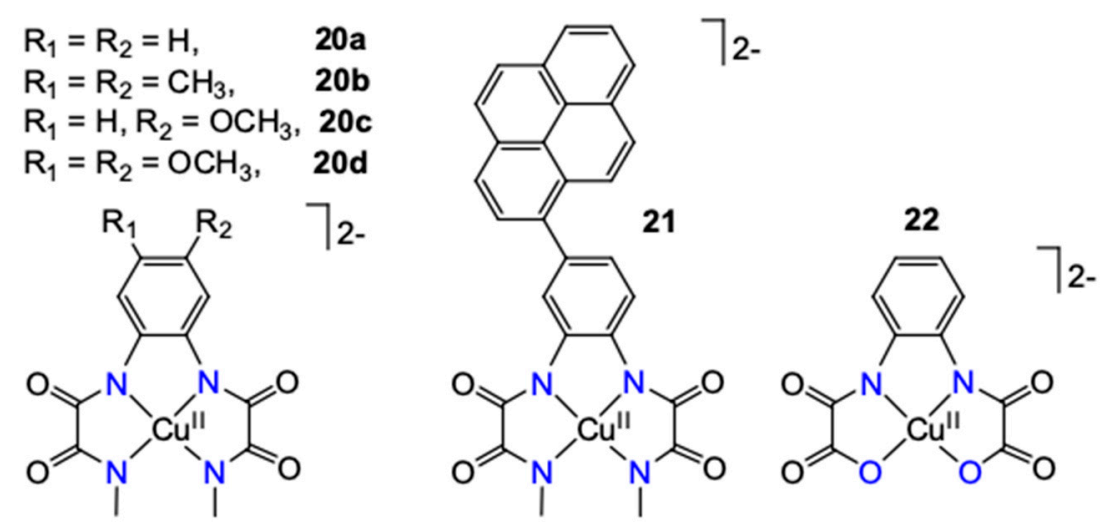

Figure 11. Molecular catalysts with redox non-innocent bis-oxalamide ligands. 

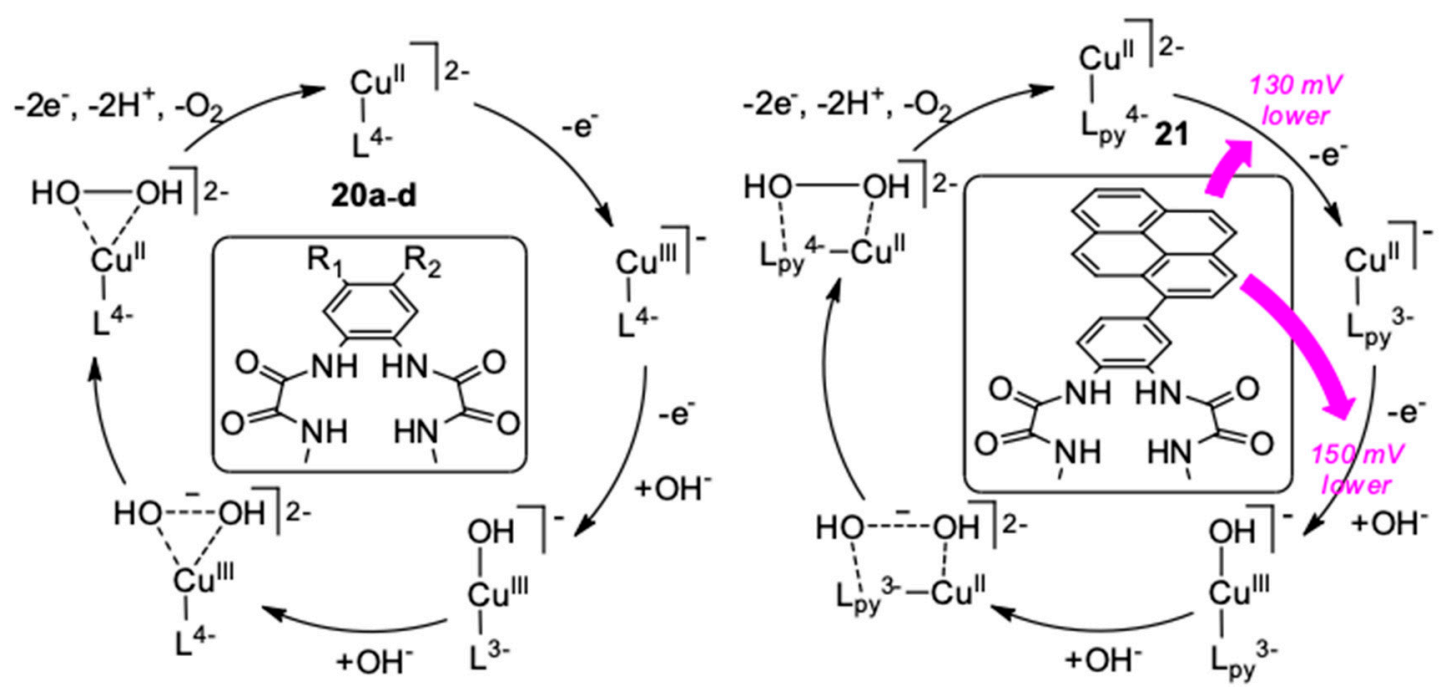

Figure 12. Mechanism proposals for WOCs involving redox non-innocent ligands and the effect of extended $\pi$-delocalization $[30,61]$.

Indeed, a derived complex utilizing the ligand $\mathrm{L}_{\mathrm{py}}=4$-pyrenyl-1,2-phenylenebis(oxamidate), $\left[\left(\mathrm{L}_{p y}\right) \mathrm{Cu}^{\mathrm{II}}\right]^{2-}$ (Figure 11, 21) later provided solid experimental support for this hypothesis [61]. $\mathrm{L}_{\mathrm{py}}$ has been designed to extend more the $\pi$-conjugation through its structure than it was in its parent complex, 20a. The performance of both catalysts has been studied in the homogeneous phase and after deployment by $\pi$-stacking to graphene-based electrodes. In the homogeneous phase the electronic perturbation provided by the pyrene substituent manifested in a $150 \mathrm{mV}$ lower $\eta$ for 21 and a considerable increase in the $k_{o b s}$ to $128 \mathrm{~s}^{-1}$, more than 20 times as high as that of 20a.

The complexes and the $1 \mathrm{e}^{-}$oxidized forms have been characterized thoroughly in solution in attempt to explain the differences. In frozen acetonitrile solution 20a and 21 and the corresponding $1 \mathrm{e}^{-}$oxidized forms were studied by X-ray absorption near edge structure (XANES) and extended $X$-ray absorption fine structure (EXAFS) spectroscopy. The edge energy shift of $1.5 \mathrm{eV}$ clearly indicated metal-centered oxidation to $\mathrm{Cu}^{\mathrm{III}}$ based on the literature [62]. EXAFS analysis indicated that the $\mathrm{Cu}-\mathrm{N}$ distances are characteristically shortened upon $1 \mathrm{e}^{-}$oxidation, in agreement with the calculated relaxed structures from DFT. The UV-Vis spectra on the other hand showed that upon oxidation of 21 in aqueous solution at $\mathrm{pH} 12$, a drastic intensity loss of the LMCT bands at $340 \mathrm{~nm}$ occurred, while the $\mathrm{Cu}^{\mathrm{III}}$ spectrum of the same oxidized species in acetonitrile underwent only a small hypsochromic shift with regard to that of 21. Relying on literature data [63] the authors addressed the oxidation process to the pyrene moiety in aqueous solution that has led to a different mechanistic proposal as shown in Figure 12. Note that for 20a the oxidation remained metal-centered irrespective of the solvent. This striking difference was associated with the significantly lower oxidation potential at the ligand site due to the presence of the pyrene group together with the large stabilization to the putatively charged oxidized species in the aqueous environment. 
Table 2. Selected kinetic, electrochemical data and reaction conditions of single $\mathrm{Cu}$-site water oxidation catalysts (for ligand names see the corresponding discussion).

\begin{tabular}{|c|c|c|c|c|c|c|}
\hline Catalyst & $\mathrm{pH}$ & Electrolyte & $k_{o b s}\left(\mathrm{~s}^{-1}\right)$ & $\eta(\mathrm{V})$ & $\begin{array}{c}\text { Farad. } \\
\text { Eff. }(\%)\end{array}$ & Ref. \\
\hline$\left[(\mathrm{bpy}) \mathrm{Cu}(\mathrm{OH})_{2}\right](4)$ & 12.8 & $0.1 \mathrm{M} \mathrm{NaOH} / \mathrm{NaOAc}$ & 100 & 750 & 90 & [19] \\
\hline$\left[\left(6,6^{\prime}-\right.\right.$ dhbpy $\left.) \mathrm{Cu}\left(\mathrm{OH}_{2}\right)_{2}\right](5)$ & 12.4 & $0.1 \mathrm{M} \mathrm{NaOH} / \mathrm{NaOAc}$ & 0.4 & 640 & 85 & [31] \\
\hline$\left[\left(6,6^{\prime}-(\mathrm{O})_{2}-\mathrm{bpy}\right)_{2} \mathrm{Cu}\left(\mathrm{OH}_{2}\right)\right]^{2-}(6)$ & 12.6 & $0.1 \mathrm{M} \mathrm{NaOH} / \mathrm{NaOAc}$ & 0.356 & 477 & n.a. & [36] \\
\hline$\left[(\mathrm{BPT}) \mathrm{Cu}(\mathrm{OH})_{2}\right](7)$ & 11.5 & $0.1 \mathrm{M}$ phosphate & 5.8 & $\sim 800$ & 91 & [40] \\
\hline$\left[\mathrm{Cu}(\operatorname{pim})\left(\mathrm{OH}_{2}\right)(\mathrm{OH})\right](8)$ & 12 & $0.1 \mathrm{M} \mathrm{NaOH} / \mathrm{NaOAc}$ & 35 & 300 & n.a. & [45] \\
\hline$\left[\mathrm{Cu}(\text { pyalk })_{2}\right](\mathbf{1 0})$ & 12.5 & $0.1 \mathrm{M} \mathrm{KNO}_{3} / \mathrm{KOH}$ & 0.7 & $520-580$ & 75 & {$[46,47]$} \\
\hline$\left[\mathrm{Cu}(\mathrm{TMC})\left(\mathrm{OH}_{2}\right)\right]^{2+}(\mathbf{1 2})$ & 7 & $0.1 \mathrm{M}$ phosphate & 30 & n.a. & $89 / 98^{1}$ & [50] \\
\hline$\left[\mathrm{Cu}\left(\mathrm{L}_{\mathrm{m}}\right)\left(\mathrm{OH}_{2}\right)\right]^{2+}(\mathbf{1 3})$ & 12 & $0.15 \mathrm{M}$ phosphate & n.a. & $\sim 750$ & 50 & {$[52]$} \\
\hline$\left[\mathrm{Cu}(\mathrm{IndPY} 2)\left(\mathrm{OH}_{2}\right)_{2}\right]^{2+}(\mathbf{1 4})$ & 7 & $0.1 \mathrm{NaNO}_{3}$ & 0.02 & $280^{2}$ & 75 & [54] \\
\hline$\left[\mathrm{Cu}\left(\mathrm{L}_{\mathrm{OH}}\right)\left(\mathrm{OH}_{2}\right)\right]^{2+}(15)$ & 12 & $0.1 \mathrm{M}$ phosphate & 0.12 & 830 & 60 & {$[56]$} \\
\hline$[\mathrm{Cu}(\mathrm{PcTS})](16)$ & 9.5 & $0.1 \mathrm{M}$ borate & n.a. & $\sim 570^{3}$ & n.a. & {$[57]$} \\
\hline$\left[\left(\mathrm{Py}_{3} \mathrm{P}\right) \mathrm{Cu}(\mathrm{OH})\right]^{-}(\mathbf{1 7})$ & 8 & 0.1/0.2 M phosphate & $20 / 38$ & $\sim 500^{4}$ & 84 & [58] \\
\hline$[\mathrm{Cu}(\text { bztpen })]^{2+}(\mathbf{1 8})$ & 11.5 & $0.1 \mathrm{M}$ phosphate & 13.1 & 440 & 91 & [59] \\
\hline$\left[\mathrm{Cu}(\text { dbzbpen })\left(\mathrm{OH}_{2}\right)\right]^{2+}(19)$ & 11.5 & $0.1 \mathrm{M}$ phosphate & 18.7 & 570 & 94 & [59] \\
\hline$[(\mathrm{L} 1) \mathrm{Cu}]^{2-}(\mathbf{2 0 a})$ & 11.5 & phosphate, $I=0.1 \mathrm{M}$ & 0.16 & 170 & $\sim 100$ & {$[30]$} \\
\hline$[(\mathrm{L} 2) \mathrm{Cu}]^{2-}(20 \mathrm{~b})$ & 11.5 & phosphate, $I=0.1 \mathrm{M}$ & 0.43 & 270 & n.a. & [30] \\
\hline$[(\mathrm{L} 3) \mathrm{Cu}]^{2-}(20 \mathrm{c})$ & 11.5 & phosphate, $I=0.1 \mathrm{M}$ & 3.58 & 400 & n.a. & {$[30]$} \\
\hline$[(\mathrm{L} 4) \mathrm{Cu}]^{2-}(\mathbf{2 0 d})$ & $11.5 / 12.5$ & phosphate, $I=0.1 \mathrm{M}$ & $3.56 / 12$ & 700 & 47 & {$[30]$} \\
\hline$\left[\left(\mathrm{L}_{p y}\right) \mathrm{Cu}\right]^{2-}(\mathbf{2 1})$ & 11.5 & phosphate, $I=0.1 \mathrm{M}$ & 128 & 550 & $\sim 25^{5}$ & {$[61]$} \\
\hline$[(\text { opba }) \mathrm{Cu}]^{2-}(22)$ & 10.8 & phosphate, $0.25 \mathrm{M}$ & 1.13 & 626 & 95.8 & {$[64]$} \\
\hline$\left[\mathrm{Cu}(\mathrm{GGGG})\left(\mathrm{OH}_{2}\right)\right]^{2-}$ & 11 & phosphate, $0.25 \mathrm{M}$ & 33 & $\sim 650$ & 99 & [41] \\
\hline$\left[\mathrm{Cu}\left(\mathrm{H}_{-2} 3 \mathrm{G}\right)\left(\mathrm{OH}_{2}\right)\right](24)$ & 11 & phosphate, $0.15 \mathrm{M}$ & 24 & $\sim 650^{3}$ & 91 & [42] \\
\hline$\left[\mathrm{Cu}\left(\mathrm{H}_{-2} 2 \mathrm{GH}\right)\left(\mathrm{OH}_{2}\right)\right](25)$ & 11 & phosphate, $0.15 \mathrm{M}$ & 53 & $\sim 620^{3}$ & 95 & [42] \\
\hline$\left[\mathrm{Cu}\left(\mathrm{H}_{-2} \mathrm{GGD}\right)\left(\mathrm{OH}_{2}\right)\right]^{-}(\mathbf{2 6})$ & 11 & phosphate, $0.20 \mathrm{M}$ & 10 & $\sim 670^{3}$ & n.a. & {$[32]$} \\
\hline$\left[\mathrm{Cu}\left(\mathrm{H}_{-2} 2 \mathrm{GD}\right)\left(\mathrm{OH}_{2}\right)\right]^{-}(27)$ & 11 & phosphate, $0.20 \mathrm{M}$ & 16 & $\sim 670^{3}$ & 90 & {$[32]$} \\
\hline$\left[\mathrm{Cu}(\mathrm{TPA})\left(\mathrm{OH}_{2}\right)\right]^{2+}(\mathbf{2 8})$ & 7.0 & phosphate, $0.1 \mathrm{M}$ & 0.10 & 970 & $>90$ & {$[65]$} \\
\hline$\left[\mathrm{Cu}\left(\mathrm{F}_{3} \mathrm{TPA}\right)\left(\mathrm{OH}_{2}\right)\right]^{2+}(\mathbf{2 8 f})$ & 8.5 & borate, $0.1 \mathrm{M}$ & 0.38 & 610 & 93 & {$[66]$} \\
\hline$\left[\mathrm{Cu}\left(\mathrm{L}_{\mathrm{p}}\right)\left(\mathrm{OCO}_{2} \mathrm{H}\right)\right]^{-}(29)$ & 10 & carbonate, $0.1 \mathrm{M}$ & 20.1 & 650 & 95 & [67] \\
\hline
\end{tabular}

Upon anchorage, $\pi$-stacking with the graphene surface provided additional delocalization that improved the catalytic performance of both catalysts, however, 21 turned out to be the more active one due to the added influence of the pyrene to that of the graphene. The $\eta$ of $538 \mathrm{mV}, k_{o b s}$ of $540 \mathrm{~s}^{-1}$ and TON $>5300$ are encouraging data if one considers the generally accepted view about the poor stability of first row TM catalysts.

A complex with similar ligand architecture (Figure 11, 22), but exhibiting $\{2 \mathrm{~N}, 2 \mathrm{O}\}_{\text {eq }}$ ligand set has been reported earlier to catalyze both the HER and the OER [64]. Although the suggested mechanism relied on the traditional WNA, it cannot be excluded that the SET mechanism applies to this system, too.

\subsubsection{Peptide Ligands}

In redox biocatalysts like the oxygen evolving center (OEC) of PSII, polypeptides act the part of shaping the active site environment thus allowing selective substrate transformations, efficiently binding metal ions by various donor groups and tuning their redox properties. No wonder that the coordination of $\mathrm{Cu}$ in metalloproteins and synthetic forms has been thoroughly investigated [68] and recently, metallopeptoids and -peptides gained attention as potential candidates for water oxidation. The first report was about $\left[\mathrm{Cu}(\mathrm{GGGG})\left(\mathrm{OH}_{2}\right)\right]^{2-}$ (Figure 13, 23) with a well-characterized structure at high $\mathrm{pH}[69,70]$, prepared in situ with the triglycylglycine ligand (H-GGGG-OH) [41]. The coordination between $\mathrm{Cu}^{\mathrm{II}}$ and H-GGGG-OH, in the absence of the typical copper anchoring side-chain functionalities like imidazole rings, or carboxylates, completely relies on the in-chain amide groups and shows $\mathrm{pH}$-dependence thanks to these groups successively loosing protons with the increasing $\mathrm{pH}$. For 23 the $\{4 \mathrm{~N}, \mathrm{O}\}$ coordination mode was suggested at $\mathrm{pH}>10$. 


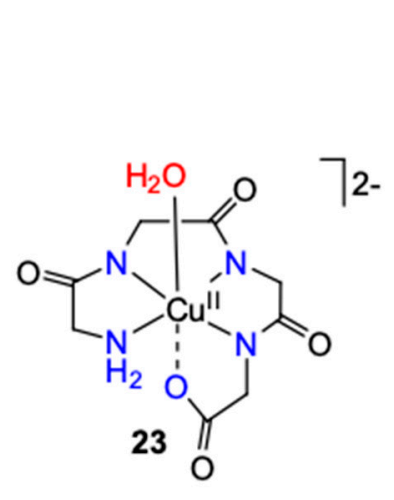<smiles>NCC(N)=O</smiles>

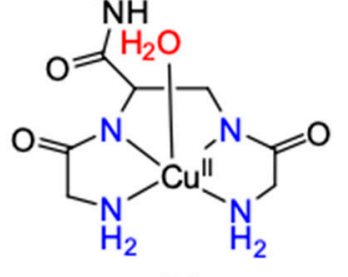

24

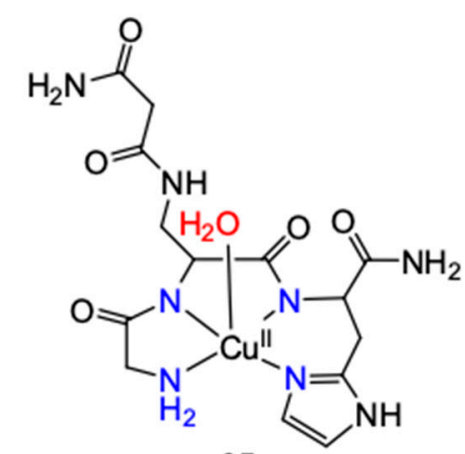

25<smiles>NC(=O)C1CC(=O)ON2C(=O)N3CCN(C2=O)C1(C(=O)O)C3</smiles>

26

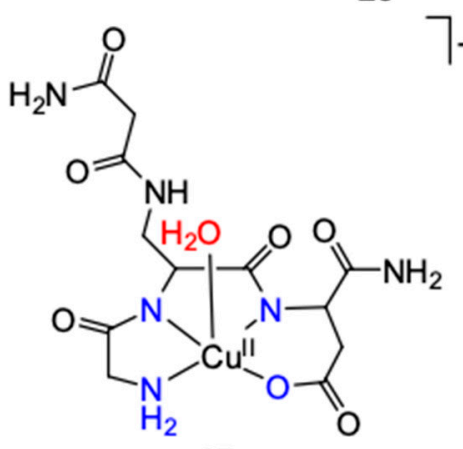

27

Figure 13. Peptide-based $\mathrm{Cu}$ catalysts for water oxidation.

The catalyst pre-synthesized and self-assembled in situ at $\mathrm{pH} 11$ in $0.25 \mathrm{M}$ phosphate buffer showed the same $\mathrm{d}^{9} \mathrm{Cu}^{\mathrm{II}} \mathrm{d}-\mathrm{d}$ band at $530 \mathrm{~nm}$ in UV-Vis and proved to be an efficient and rapid electrocatalyst for water oxidation undergoing multiple turnovers with no detectable loss of its reactivity. In $\mathrm{CV}$ a reversible, diffusion controlled wave for the $\left[\mathrm{Cu}^{\mathrm{III}}(\mathrm{GGGG})(\mathrm{OH})\right]^{2-} /\left[\mathrm{Cu}^{\mathrm{II}}(\mathrm{GGGG})\left(\mathrm{OH}_{2}\right)\right]^{2-}$ couple was observed, followed by an irreversible, current enhanced peak at $1.32 \mathrm{~V}$, consistent with catalytic water oxidation. Importantly, the addition of $1 \mathrm{mM} \mathrm{CuSO}_{4}$ to the buffer at $\mathrm{pH} 11$ resulted in a precipitate and the resulting suspension had no activity toward water activation, therefore it was concluded that catalysis in the presence of $\mathbf{2 3}$ was due to the complex. Evolution of $\mathrm{O}_{2}$ was investigated by CPE at $+1.3 \mathrm{~V}$ on ITO electrode in $0.25 \mathrm{M}$ phosphate buffer at $\mathrm{pH} 11$ and the catalytic current was sustained for at least $\sim 5 \mathrm{~h}$ at a stable current density. After this period, the consumption of $\mathrm{OH}^{-}$by WOC shifted the $\mathrm{pH}$, but the original catalytic current could be recovered upon its re-adjustment to 11. Analysis of the produced $\mathrm{O}_{2}$ confirmed a Faraday efficiency of $99 \%$ through $\sim 13$ catalytic turnovers based on the initial amount of 23 that remained intact according to follow-up UV-Vis spectrophotometry. Rinse tests on a GC electrode or surface analysis of used ITO electrodes showed no evidence for precipitation or film formation that excluded a heterogeneous contribution to WOC through a catalyst decomposition pathway.

The catalytic peak current varied linearly with the concentration of 23 suggesting single-site copper catalysis. The authors provided kinetic evidence from CVs at different scan rates, i.e., the non-diffusion controlled behavior of catalytic currents normalized by the square root of the scan rates, that the rate limiting step was a chemical reaction in nature. On these grounds the proposed mechanism (Figure 14) involved the two-step PCET oxidation of 23 through [Cu $\left.{ }^{\mathrm{III}}(\mathrm{GGGG})(\mathrm{OH})\right]^{2-}$ to $\left[(\mathrm{GGGG}) \mathrm{Cu}^{\mathrm{III}}(\mathrm{O} \bullet)\right]^{2-}$, a largely ligand centered oxyl radical that can undergo WNA. Based on buffer concentration dependence of the catalytic current this step might involve a base $\left(\mathrm{OH}^{-}, \mathrm{HPO}_{4}{ }^{2-}\right.$, $\mathrm{PO}_{4}{ }^{3-}$ ) as a proton acceptor and APT to give a hydroperoxide intermediate directly. Under catalytic conditions an electrochemical current peak at $0.38 \mathrm{~V}$, observed near the $\mathrm{Cu}$ III/II couple of 23 has been tentatively assigned to a peroxide couple, $\mathrm{Cu}^{\mathrm{III}}(\mathrm{OO}) / \mathrm{Cu}^{\mathrm{II}}(\mathrm{OOH})$ or $\mathrm{Cu}^{\mathrm{III}}(\mathrm{OOH}) / \mathrm{Cu}^{\mathrm{II}}(\mathrm{HOOH})$, as the addition of hydrogen peroxide to solutions containing 23 generated the same current peak. This first 
report gave a very detailed mechanistic understanding of a copper-peptide based WOC with some analogies to the single-site Ru-catalysts.

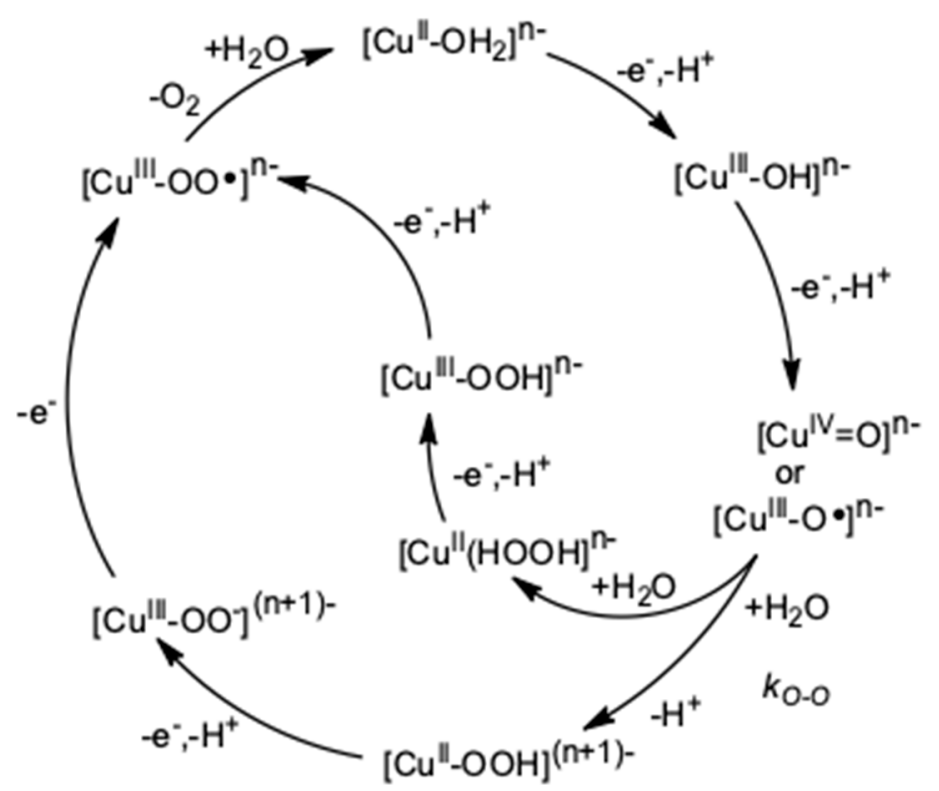

Figure 14. Mechanism proposal typical for the peptide based catalytic systems (ligands omitted for clarity) [41].

The available number of short linear peptides to be applied in single-site catalysts for WOC is somewhat limited by the rigidity of the coordinated backbone chain and the finite combinations of proximate $\alpha-C$ substituents at the amino acid residues that could potentially influence the redox behavior and the catalytic capabilities of the metal complexes [71]. It has been realized, however, that new coordination options for copper could be created by appropriate peptide branching [72]. A set of $C$-terminally amidated homolog ligands were therefore reported by utilizing a branching unit, Dap $=L$-2,3-diaminopropionic acid that has been extended at the two vicinal $N$-termini and the $C$-terminus with various combinations of amino acids. The imidazole ring of histidine (His) and the methylcarboxylate function of aspartic acid (Asp) are typical anchoring groups for $\mathrm{Cu}$ binding in enzymes, artificial proteins and other bio-inspired systems and this fact has inspired a set of ligands including Dap and His, Asp, or Gly amino acids [32,72,73].

In a communication mononuclear Cu complexes with H-Gly-Dap(H-Gly)-Gly- $\mathrm{NH}_{2}$ (Figure 14, $3 \mathrm{G}, 24)$ and $\mathrm{H}-\mathrm{Gly}-\mathrm{Dap}(\mathrm{H}-\mathrm{Gly})-\mathrm{His}_{-} \mathrm{NH}_{2}(2 \mathrm{GH}, 25)$ were compared by their capabilities in water oxidation [42]. X-Band EPR, UV-vis and CD spectroscopic changes with increasing $\mathrm{pH}$ suggested $\left\{\mathrm{NH}_{2}, \mathrm{~N}^{-}, \mathrm{N}^{-}, \mathrm{NH}_{2}\right\}$ equatorial ligand set for 24 , whereas in $25, \mathrm{Cu}$ II was bound by a $\left\{\mathrm{NH}_{2}, \mathrm{~N}^{-}, \mathrm{N}^{-}, \mathrm{N}_{\mathrm{Im}}\right\}$ equatorial set, involving the $C$-terminal His residue as it has been also suggested for the linear H-Gly-Gly-His-OH ligand [74]. Based on analogous examples, a further deprotonation step for both $\mathrm{Cu}^{\mathrm{II}}$ complexes has been associated with proton loss from an axially coordinated water molecule at $\mathrm{pH}>11$. The reversible and $\mathrm{pH}$-dependent $\mathrm{Cu}^{\mathrm{III} / \mathrm{II}}$ redox couple was also observed in both cases at higher potentials than that for $\mathbf{2 3}$, due to its inverse relation to the number of deprotonated amidic $\mathrm{N}$ donors [71]. The high values and the $E^{\circ \prime}(\mathbf{2 4})<E^{\circ \prime}(\mathbf{2 5})$ order were in accordance with the suggested equatorial donor planes. $\mathrm{CV}$ in phosphate buffer at a GC working electrode showed a new electrocatalytic wave with an onset potential over $1.0 \mathrm{~V}$ versus $\mathrm{Ag} / \mathrm{AgCl}$ at $\mathrm{pH} 11$, similar to what was associated with water oxidation catalysis by 23 . The peak potential was found to be $\mathrm{pH}$-dependent and the current became substantially larger under increasingly basic conditions. A catalytically active film or decomposition of the complex could not be detected by successive cycling experiments or rinse tests. Dioxygen evolution was confirmed by detecting its growing electrochemical reduction current over multiple cycles through the high anodic polarization regime under Ar. CPE performed at $1.1 \mathrm{~V}$ 
versus $\mathrm{Ag} / \mathrm{AgCl}$ on ITO in $0.5 \mathrm{mM}$ complex solutions showed that catalysis took place by high Faraday efficiency (Table 2) and some loss in complex concentration. However, like in other cases, when the counter electrode was not separated by a frit from the complex-containing electrolyte, this loss has been later associated with electro-plating of metallic copper on the counter electrode (coloration of the electrode is indicative of this process) rather than oxidative degradation of the complex at the anode. In accordance, XPS on the ITO working electrode after $\mathrm{CPE}$ evidenced no $\mathrm{CuO} / \mathrm{OH}$ deposition and produced negative rinse test. The catalytic current linearly increased with the concentration of both complexes, but dropped at higher scan rates $(v)$ that indicated a chemical rate determining step involving one complex molecule. The $k_{o b s}$ values (Table 2) were calculated from the catalyst dependence plots. These observations implied that the electrocatalyst is of molecular nature and a mechanism analogous to that by Meyer has been suggested (Figure 14).

The effect of Asp at the C-terminus was investigated later by applying H-Gly-Dap(H-Gly)Asp- $\mathrm{NH}_{2}$ (2GD) to ligate $\mathrm{Cu}^{\mathrm{II}}$ [32]. At $\mathrm{pH}<8,2 \mathrm{GD}$ formed a dimeric 2Cu:2L complex that showed no catalytic activity. At increasingly alkaline $\mathrm{pH}$ on the other hand the Asp at the $\mathrm{C}$-terminus resulted in the dominance of the mononuclear 27 with $\left\{\mathrm{NH}_{2}, \mathrm{~N}^{-}, \mathrm{N}^{-}, \mathrm{O}^{-}\right\}_{\text {eq }}$ set identically with the linear fragment GGD and its complex, 26. The changes in speciation with $\mathrm{pH}$ were accompanied by shifts in the $\mathrm{Cu}^{\mathrm{III} / \mathrm{II}}$ redox current peaks that were analyzed by square wave voltammetry (SWV) and allowed the calculation of the $\mathrm{pK}_{a}$ values for the $\mathrm{Cu}^{\mathrm{II}}$ and $\mathrm{Cu}^{\mathrm{III}}$ forms like it was done for $\mathbf{2 4}$ and 25 . This complex also exhibited electrocatalytic activity in water oxidation in phosphate buffer at $\mathrm{pH} 11$.

The order of the $k_{o b s}$ values for the homologue complexes in phosphate buffer at the same $\mathrm{pH}$ showed the following order in relation with the $4^{\text {th }}$ equatorial donor group $\mathrm{N}_{\mathrm{im}}>\mathrm{NH}_{2}>$ $\mathrm{COO}^{-}$branched $>\mathrm{COO}^{-}$linear. Remarkably, when Asp residues were present at every termini to produce $\mathrm{H}$-Asp-Dap(H-Asp)-Asp- $\mathrm{NH}_{2}$, the electrocatalysis of water oxidation by the mononuclear copper complex substantially decreased and, if they were present only at the $N$-termini in H-Asp-Dap(H-Asp)-Gly- $\mathrm{NH}_{2}$, it has ceased.

Phosphate was important as a base to sustain the $\mathrm{pH}$ during WOC, but it also acted as inhibitor according to $\mathrm{CV}$ and SWV observations at varied concentrations of this salt, i.e., above $0.3 \mathrm{M}$ the catalytic current became smaller and new current peaks associated with $\mathrm{Cu}^{\mathrm{III} / \mathrm{II}}$ transitions occurred accompanying those that were present in non-buffered solutions at the same $\mathrm{pH}$. It was supposed that the trivalent $\mathrm{PO}_{4}{ }^{3-}$ could act as a coordinating anion competitor to $\mathrm{OH}^{-}$. Note that these catalysts tolerated chloride in contrast to 16 , which is a feature of potential importance in efficient seawater oxidation.

Note that 24 and 25 have been incorporated into self-assembled, nanostructured coatings by alternating deposition with polyelectrolytes [43]. This work demonstrated a deposition method of molecular WOCs in surface coatings produced by combining the substances with a suitable polyelectrolyte. The water soluble complexes were deposited by building composite layers on ITO. Alternating deposition of the complexes and poly(L-lysine) (PLL) or poly(allylamine hydrochloride) (PAH) were carried out in the presence of phosphate in a $\mathrm{pH}$ range of 7.5-10.5. The fabricated layer-by-layer (LbL) structures had nanoporous topography (atomic force microscopy). Most importantly, WOC and operando changes in the surface concentration could be followed real time by means of EC-OWLS upon alternating positive-zero-positive polarization cycles. Following some initial loss of the surface mass density steady-state electrolysis was sustained by a compact and stable layer. According to XPS, Cu remained in an $\mathrm{N}$-donor ligand environment after CPE. Improved WOC rates versus that of the neat ITO and dependence of this improvement on the incorporated $\mathrm{Cu}$ (II)-complex has been observed, as in the corresponding homogeneous systems. It was found that LbL self-assembly of the 24/PLL/phosphate or 25/PAH/phosphate combinations on ITO was selective with respect to the applied complex-polyelectrolyte combination. Anchoring the complex molecules at the macromolecules apparently requires specific coordinating $\mathrm{N}$ donor ligand options, which makes the self-assembly very selective with respect to complex-polyelectrolyte combinations. 


\subsubsection{Tripodal Polypyridylmethylamine Ligands}

Different $\mathrm{Cu}(\mathrm{II})$-complexes with the tripodal polypyridylmethylamine ligands tris(2-pyridylmethyl)amine (TPA) (Figure 15, 28) [65], bis((6-methyl-2-pyridyl)methyl) (2-pyridylmethyl)amine ( $\left.\mathrm{Me}_{2} \mathrm{TPA}, 28 \mathrm{~m}\right)$ [75], and tris((6-fluoro-2-pyridyl)methyl)amine ( $\mathrm{F}_{3} \mathrm{TPA}$, 28f) [66], have been investigated as WOCs. Structural characterization of the parent compound 28 confirmed earlier TBPY-5 geometry with an aqua ligand occupying the apical position [76]. Albeit the complex with $\mathrm{F}_{3}$ TPA has been isolated from acetonitrile and crystallographically characterized as $\left[\mathrm{Cu}^{\mathrm{II}}\left(\mathrm{F}_{3} \mathrm{TPA}\right)\left(\mathrm{NCCH}_{3}\right)\left(\mathrm{OClO}_{3}\right)\right]\left(\mathrm{ClO}_{4}\right)$, in contrast, from a $75 \mathrm{mM}$ borate solution treated with base $\left[\mathrm{Cu}\left(\mathrm{F}_{3} \mathrm{TPA}\right)(\mathrm{OH})\right]^{+}$could be detected by ESI-MS (done in methanol), therefore the electrocatalytically active form of $\mathbf{2 8 \mathrm { f }}$ is considered hereby on the analogy of $\mathbf{2 8}$, i.e., as monoauqa complex. Note that the $\mathrm{pH}$-dependent speciation has been calculated only for $\mathbf{2 8 m}$ to our knowledge (see the explanation for $\mathbf{3 2}$ in Section 2.3).

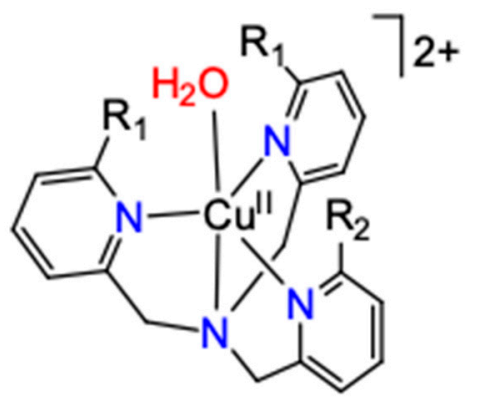

$$
\begin{array}{lc}
\mathrm{R}_{1-2}=\mathrm{H}, & \mathbf{2 8} \\
\mathrm{R}_{1-2}=\mathrm{F}, & \mathbf{2 8 f} \\
\mathrm{R}_{1}=\mathrm{CH}_{3}, \mathrm{R}_{2}=\mathrm{H}, & \mathbf{2 8 m}
\end{array}
$$

Figure 15. General structure of tris(2-pyridylmethyl)amine (TPA)-based catalysts.

Complex $28 \mathrm{f}$ has been investigated in dark electrocatalysis in context with the feasibility of its photochemical activation by $\left[\mathrm{Ru}(\mathrm{bpy})_{3}{ }^{*}\right]^{2+}$. For this reason the authors have chosen borate buffer at $\mathrm{pH}$ 8.5. From CV measurements with the concentration of $28 \mathrm{f}$ ranging up to $1 \mathrm{mM}$, the catalytic peak current varied linearly with [28f] that indicated first-order dependence and single-site mechanism for water oxidation. Beside analyzing the electrode surface after CPE by SEM-EDS, the electrolyte solution was also examined by DLS, and no heterogeneity within the electrolyte mixture due to particle formation or surface deposits due to in situ electrodeposition could be confirmed. The authors pointed out that oxidation of the ligand might be largely diminished by the electron-withdrawing fluoro substituents.

Indeed, under the same conditions 28 showed very moderate catalytic activity. However, others found later that this complex had catalytic activity in phosphate buffer at pH 7 [65]. In their study, 28 served as a single-site benchmarking catalyst to demonstrate the advantage of the dicopper complex 30 (see Section 2.1.2.7). Although the catalytic rate was moderate, the Faraday efficiency and the robustness of $\mathbf{2 8}$ were convincing, moreover, a detailed mechanistic proposal was drawn based on experimental findings, such as KIE of 2, dependence of the catalytic rate on the buffer concentration, on the $\mathrm{pH}$ and the first partial order in [28], finally, DFT calculations.

The mechanism proposal in Figure 16 includes the most favored intermediates as originally published by the authors. The cycle starts from the deprotonated form at $\mathrm{pH}=7$ in accordance with an experimental value of 5.2 for the $\mathrm{p} K_{a}$ of $\mathbf{2 8}$. The redox potential for the first PCET oxidation was calculated to be $1.91 \mathrm{~V}$ by DFT yielding a triplet $\mathrm{Cu}^{\mathrm{II}}-\mathrm{O} \bullet$ intermediate with spin densities on $\mathrm{Cu}$ and $\mathrm{O}$ of 0.62 and 1.17, respectively (the closed shell isomer $\mathrm{Cu}^{\mathrm{III}}-\mathrm{O}^{-}$is higher in energy). The second one-electron oxidation was calculated to have a potential of $1.94 \mathrm{~V}$, leading to the generation of a doublet $\mathrm{Cu}^{\mathrm{III}}-\mathrm{O} \bullet$ intermediate that undergoes the rate-limiting $\mathrm{O}-\mathrm{O}$ bond formation via WNA, likely an ATP reaction to produce a peroxide intermediate. 


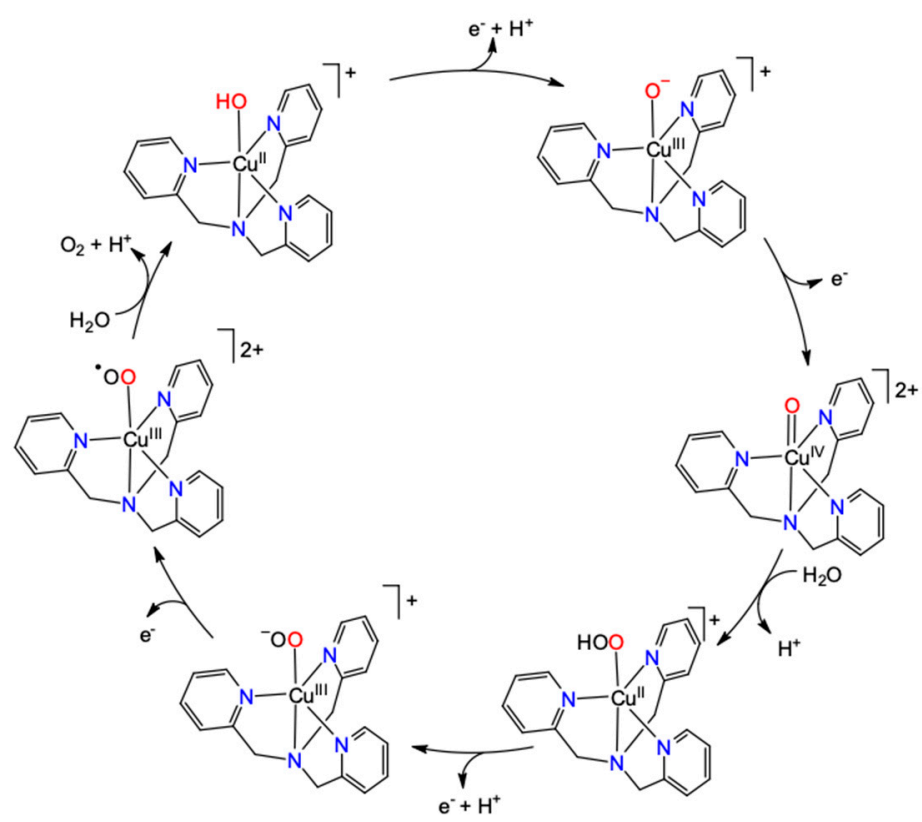

Figure 16. Proposed mechanism for the tris(2-pyridylmethyl)amine (TPA)-based molecular catalyst [65].

Note, however, that this complex has also been reported to act as precursor of nano-CuO water oxidation catalyst film on FTO electrode from $0.1 \mathrm{M}$ borate at $\mathrm{pH}>9$ [77] that points to the crucial role of the concurring molecular catalytic/decomposition processes being very sensitive to the reaction conditions.

\subsubsection{Assisting Inorganic Co-Ligand}

The participation of the buffer anion as co-ligand in proton shuttling was shown through the example of 29 (Figure 17) containing a tridentate pincer ligand, $N, N^{\prime}-2,6$-dimethylphenyl-2,6-pyridinedicarboxamidate $\left(L_{p}\right)$ [67]. Single crystal structures of ternary complexes with $\mathrm{N}, \mathrm{N}$-dimethylformamide, acetate or carbonate illustrated that the ancillary ligand was bound to $\mathrm{Cu}^{\mathrm{II}}$ through three $\mathrm{N}$ atoms defining the equatorial plane, while the fourth coordination site of the equatorial plane was available for a solvent molecule, or anion. Water oxidation occurred at $\mathrm{pH} 10$ in $0.1 \mathrm{M}$ carbonate buffer (data are listed in Table 2), in which 29 is formed according to the spectroscopic, titration, and crystallographic results.

According to the proposed catalytic cycle the two-electron oxidized form of $\mathbf{2 9}$ has been assigned as the catalytically active species. For the preceding oxidation events, the calculated potential values of 1.01 and $1.59 \mathrm{~V}$ vs NHE (Figure 17) agreed with the experimental values. With computational evidence, the coordinated carbonate was claimed to aid water activation as a proton shuttling moiety and the authors provided a very detailed picture of its way of action. After the oxidation at $0.93 \mathrm{~V}$, a water molecule binds to $\mathrm{Cu}^{\mathrm{III}}$, and subsequent intramolecular proton transfer from the aqua to the bicarbonate ligand occurs, accompanied by a structural rearrangement that results in an equatorially bound hydroxide and an axially weakly bound carbonic acid that eventually dissociates from the complex. The resulting ternary complex undergoes PCET to give a dublet copper(III)-oxyl species that is subject to water nucleophilic attack to form the $\mathrm{O}-\mathrm{O}$ bond. This process is assisted by a bicarbonate anion, which can accept a proton from the attacking water molecule. 


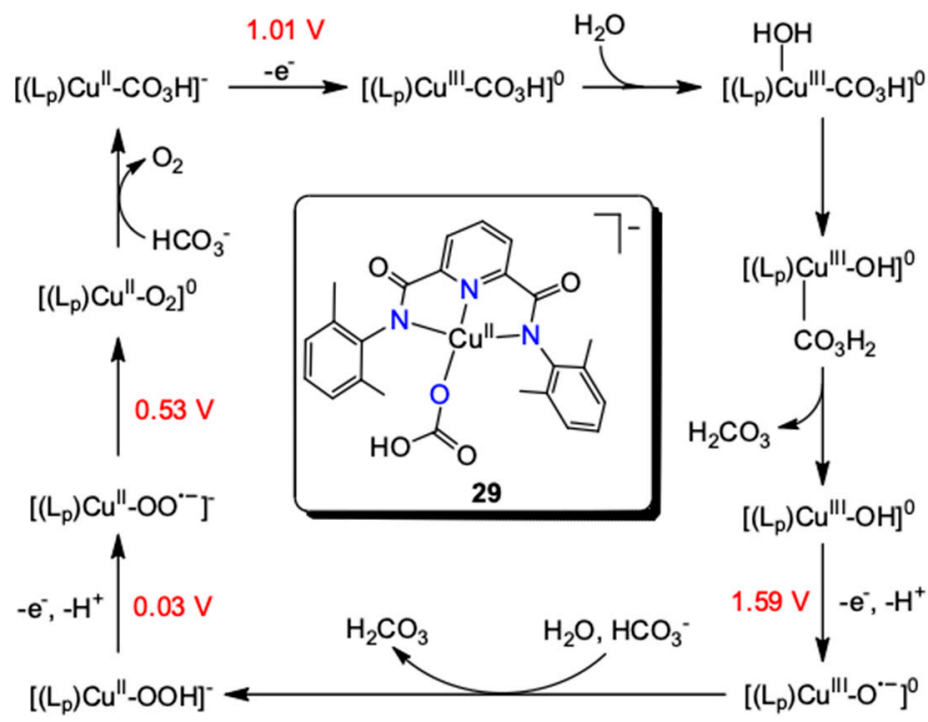

Figure 17. Structure for 29 and the proposed mechanism for water oxidation by this system [67].

\subsubsection{Overview of the Mechanistic Scenarios with Respect to Single-Site Catalysts}

A comprehensive theoretical DFT study lined up recently the plausible mechanistic scenarios for water oxidation and classified the typical consecutive steps in the early stage of catalysis (e.g., reversible activation of the metal center, irreversible activation of the complex, formation of the O-O bond) [29]. The steps taking place after the O-O bond formation are rapid enough not to be rate limiting under the great thermodynamic driving force by the high anodic polarization. The authors took the landmark examples of 4, 5, and 20a and suggested/confirmed single electron transfer (SET) steps to connect the classical pathways through a $2 \mathrm{c}-3 \mathrm{e}^{-} \mathrm{O} \cdots \mathrm{O}$ intermediate (Figure 18). It is clear that group 9 and 10 transition metals are unlikely to undergo a second oxidation step (irreversible activation of the complex) involving the metal center to give $\mathrm{M}^{(\mathrm{n}+2)+}$ and yield $\mathrm{M}=\mathrm{O}$ species. Based on kinetic results and/or theoretical calculations the above listed $\mathrm{Cu}$ single-site catalysts were all concluded to undergo $1 \mathrm{e}^{-}$ligand oxidation at this stage, either concerning the ancillary ligand, or the coordinated hydroxide to give $(\mathrm{L}) \mathrm{Cu}^{\mathrm{III}}-\mathrm{O} \bullet$ or $\left(\mathrm{L}^{+}\right) \mathrm{Cu}^{\mathrm{III}}-\mathrm{OH}$ active species.

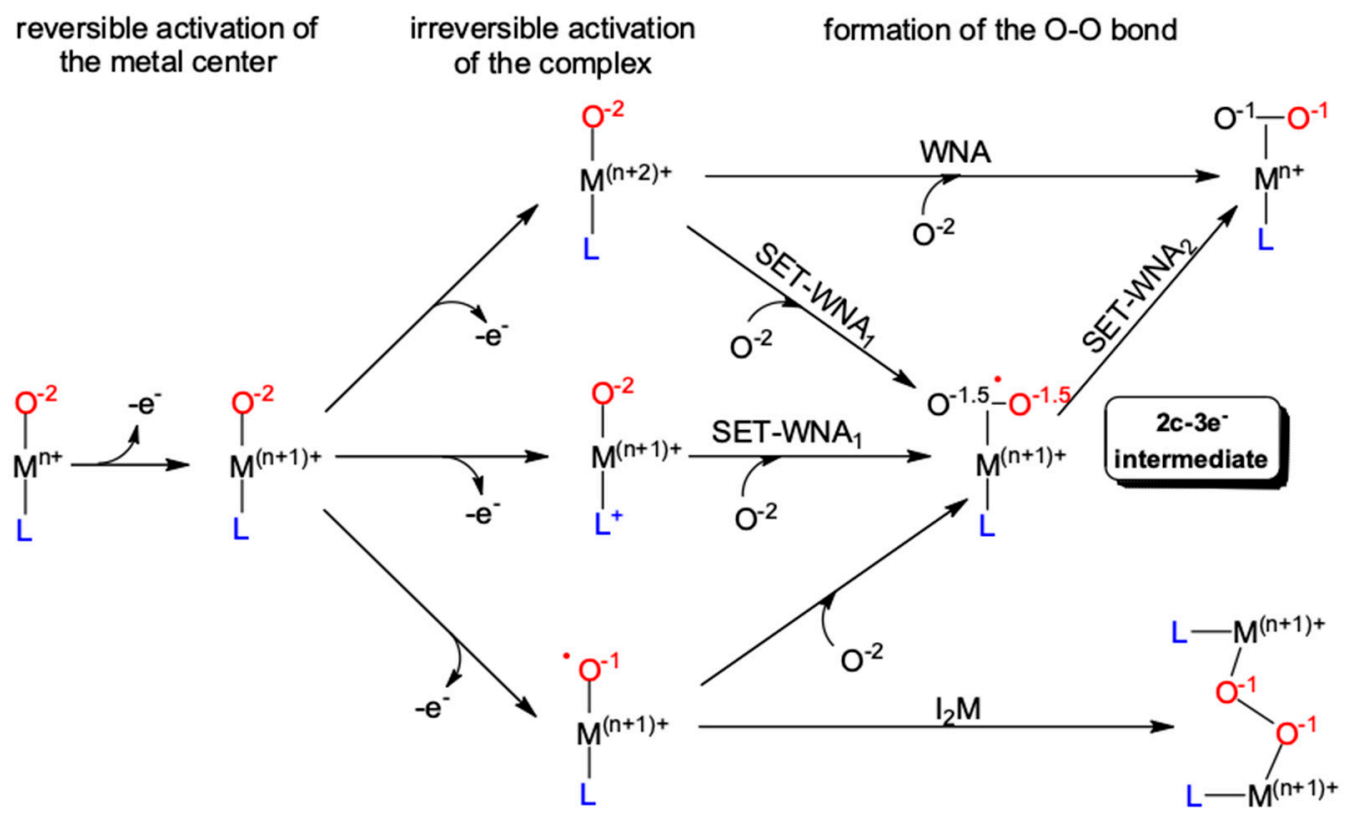

Figure 18. Mechanistic scenarios for single-site Cu-catalysts, protons were omitted [29]. 
Note that in most of the studies concerning single-site electrocatalysis the expectedly very basic ' $\mathrm{Cu}{ }^{\mathrm{III}}-\mathrm{O} \bullet \bullet^{\prime}$ ( or ' $\mathrm{Cu}^{\mathrm{IV}}=\mathrm{O}^{\prime}$ ) intermediate has been proposed as the thermodynamically competent species to conduct the WNA. Although diatomic $[\mathrm{CuO}]^{+}$or ligated $[\mathrm{LCuO}]^{+}$(with trigonal geometry) have been evidenced in the gas phase [78,79], with other ancillary ligands such formations have never been detected. The ground state of $\left[\mathrm{CuO}^{+}\right.$has been found as a high-spin (triplet) state, with the bonding situation described in analogy to $\mathrm{O}_{2}$ having biradicaloid $\pi$-bonding. The antibonding $\pi^{*}$ orbitals exhibit a strong $2 \mathrm{p}_{\pi}$ orbital character, thus the spin density is accumulated at the oxygen. At the same time oxo-metal complexes with late transition metals like copper and ancillary ligands arranged in tetragonal symmetry are disfavored due to filled antibonding orbitals known as the 'oxo-wall' principle [80]. However, $(\mathrm{L}) \mathrm{Cu}^{\mathrm{III}}-\mathrm{O} \bullet$ might be viable through geometry changes and lowered number of ancillary ligands that lead to the reordering the metal d-orbitals with two nonbonding levels that lie below the degenerate $\mathrm{Cu}^{\mathrm{III}}-\mathrm{O} \bullet \pi^{*}$ orbitals. Considering all these facts, revealing the true nature of the species responsible for the O-O bond formation step in the various proposed single-site molecular catalysts seems to require further efforts.

\subsection{Dicopper Catalysis}

In single-site catalysis the ' $\mathrm{Cu}-\mathrm{O}$ ' intermediates become thermodynamically competent in the $\mathrm{O}-\mathrm{O}$ bond formation step, if a second electron is removed from the $(\mathrm{L}) \mathrm{Cu}^{\mathrm{II}}-\mathrm{OH}_{2}$ ternary system that requires a relatively large energy barrier. As the natural $\mathrm{CaMn}_{4} \mathrm{O}_{4}$ cluster of the OEC exemplifies, transition metals may form (hydr)oxo-bridged architectures that gain reactivity against $\mathrm{H}_{2} \mathrm{O}$ via cooperation between the redox active metal ions. In molecular water oxidation electrocatalysis bimetallic $\mathrm{M}-\mathrm{O}(\mathrm{H})-\mathrm{M}$ or small, multi-metallic $\mathrm{M}_{\mathrm{x}} \mathrm{O}_{\mathrm{y}}$ moieties with $\mu^{2}-$, or $\mu^{3}$-bridging oxides can be built by applying ancillary ligands that pre-arrange and hold together the overall architecture so that it can act as an efficient catalytic unit that prevails several cycles.

The first dinuclear complex, $\left[\mathrm{Cu}_{2}(\mathrm{BPMAN})(\mu-\mathrm{OH})\right]\left(\mathrm{CF}_{3} \mathrm{SO}_{3}\right)_{3}\left(30\left(\mathrm{CF}_{3} \mathrm{SO}_{3}\right)_{3}, 30\right.$ is shown in Figure 19, BPMAN = 2,7-[bis(2-pyridylmethyl)aminomethyl]-1,8-naphthyridine) exhibited electrocatalytic water oxidation with a modest $k_{o b s}$ and considerable $\eta$ in phosphate buffer at $\mathrm{pH}$ 7.0 (Table 3) [51]. Single crystal structure of 30 revealed copper centers that were separated by $3.4 \AA$ and linked by a hydroxide ligand. The two $\mathrm{Cu}-(\mu-\mathrm{OH})$ bond lengths were $1.87 \AA$ in average and the $\mathrm{Cu}-\mathrm{O}-\mathrm{Cu}$ angle was $\sim 132^{\circ}$. The copper centers were coordinated to four $\mathrm{N}$ donor atoms of the BPMAN ancillary ligand.

The evolution of $\mathrm{O}_{2}$ was monitored by an optical probe in the course of CPE at $1.87 \mathrm{~V}$ versus NHE with ITO electrode and degradation of the catalyst could not be detected even after 4 hours. The proposed mechanism was largely based on detailed DFT calculations involving several possible intermediates and it was in line with the experimental observations: $(a)$ the onset potential for the catalytic current was dependent on $\mathrm{pH}$, with a slope of approximately $-59 \mathrm{mV} / \mathrm{pH}$ unit consistent with a PCET process, $(b)$ plotting $i_{\text {cat }}$ (the initial plateau current after $400 \mathrm{~s}$ of CPE at $1.87 \mathrm{~V}$ ) against [30] gave linear dependence, and (c) rinse tests were negative confirming a homogeneous process. According to DFT the most important novelty compared to single-site mechanisms was that the O-O bond formation took place by the intramolecular attack of $\mathrm{Cu}^{\mathrm{III}}-\mathrm{OH}$ at the $\mu-\mathrm{O}$ moiety (Figure 20). More recently, the same authors compared $\mathbf{2 8}$ and $\mathbf{3 0}$ to further confirm their proposal on the dinuclear catalysis, as the mononuclear counterpart was less active than 30 [65]. 


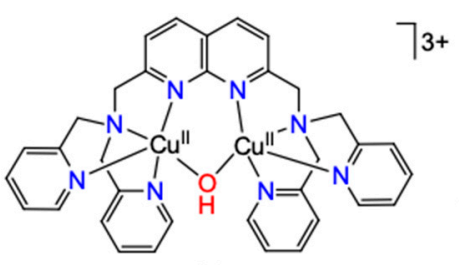

30

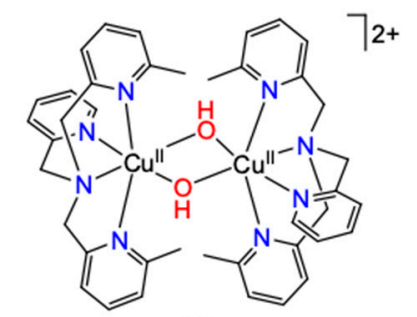

32

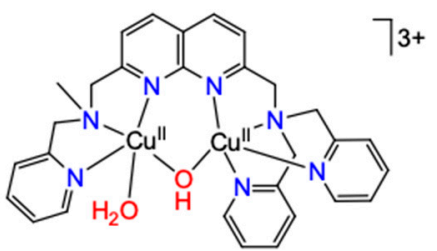

31

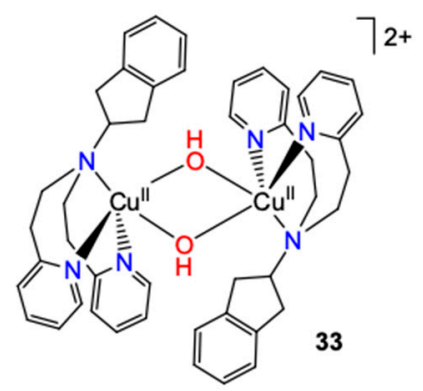<smiles>CC1(C)CNC2NCC(C)(C)C3OC(O)(O)OC3N2C1</smiles>

Figure 19. Molecular WOCs containing two copper centers.
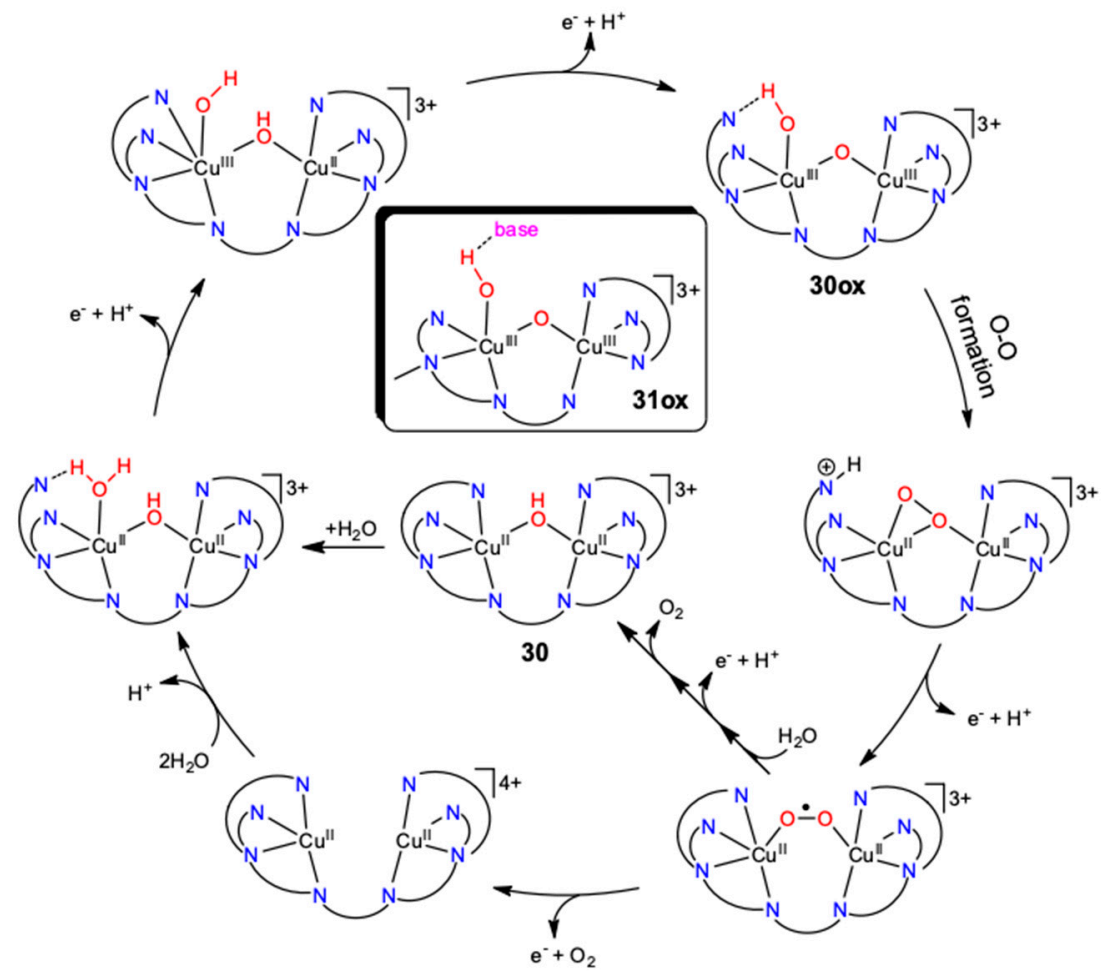

Figure 20. Proposed mechanism for 30 [65] highlighting the main difference to 31.

A non-symmetrical dicopper complex [81], closely related to 30, provided further evidence that the attack of the coordinated hydroxide at the $\mu-\mathrm{O}$ unit would create the $\mathrm{O}-\mathrm{O}$ bond in the key step of catalysis. In the $\left[(\mathrm{TPMAN}) \mathrm{Cu}_{2}(\mu-\mathrm{OH})\left(\mathrm{OH}_{2}\right)\right]^{3+}$ complex (Figure 19, 31), TPMAN = 2-[bis(2-pyridylmethyl)aminomethyl]-7-[N-methyl-N-(2-pyridyl-methyl)aminomethyl]-1,8-naphthyridine, one methylpyridine group has been replaced by a methyl group thus one site was left open for water coordination. As a result, homogeneous catalysis took place at neutral $\mathrm{pH}$ by somewhat 
better activity than that of $\mathbf{3 0}$ (see Table 3). More importantly, the altered structure of $\mathbf{3 1}$ manifested in traceable differences between the electrochemical behaviors. The two consecutive, catalytically enhanced oxidation steps showed different $\mathrm{pH}$-dependence, the first peak at $1.75 \mathrm{~V}$ versus NHE was $\mathrm{pH}$-independent, whereas the second peak depended on it, with a slope of $-64 \mathrm{mV} / \mathrm{pH}$ unit, consistent with a PCET oxidation. The KIE of $\sim 2$ (versus $~ 1$ for 30) indicated an APT rate limiting step and the catalytic rate was dependent on the buffer concentration at $<20 \mathrm{mM}$. All these changes were ascribed to the open site at the $\mathrm{Cu}$ center in the absence of the labile pyridine group like that of $\mathbf{3 0}$, which in turn acted as an intramolecular proton acceptor assisting the $\mathrm{O}-\mathrm{O}$ bond formation step as illustrated in Figure 20 (compare 30ox and 31ox).

Note that the single crystal structure of $\mathbf{3 0}$ revealed a symmetric tethering by the naphthyridine moiety between the two cupric centers with equal $\mathrm{Cu}-\mathrm{N}$ bond lengths of ca. $2.2 \AA$ [51]. Although the structure of $\mathbf{3 1}$ could not be determined, in that of the close analog $\left[\mathrm{Cu}_{2}\right.$ (TPMAN) $\left.(\mu-\mathrm{Cl})\left(\mathrm{OH}_{2}\right)\right]\left(\mathrm{CF}_{3} \mathrm{SO}_{3}\right)_{3}$ the naphthyridine tethering moiety was located closer to the aqua-ligated copper center, whereas the corresponding $\mathrm{Cu}-\mathrm{N}$ distance at the other site is $2.8 \AA$, which may also have influence on the activation barriers of catalytic intermediates. Overall, the key feature of this unsymmetrical complex was the lack of an intramolecular proton acceptor.

In contrast to other $\mathrm{Cu}$ complexes that contained TPA-derived ligands (Figure 15, 28 and 28f), based on very detailed solution equilibrium and kinetic studies, moreover, DFT calculations Kieber-Emmons et al. suggested a dicopper mechanism involving 32, the dimeric, bis- $\mu$-hydroxide bridged equilibrium species for $\mathbf{2 8 m}$ (Figure 15) [75]. According to their starting hypothesis the occurrence of a ligated oxo-metal species, i.e., $(\mathrm{L}) \mathrm{Cu}^{\mathrm{IV}}=\mathrm{O} /(\mathrm{L}) \mathrm{Cu}^{\mathrm{III}}-\mathrm{O} \bullet$ in the catalytic cycle would be an unlikely event beyond the 'oxo-wall'. Thus the authors were seeking alternate pathways that led them to associate water oxidation catalysis at high Faraday efficiency and reasonable catalytic rates with 32, a dinuclear complex (Table 3). The crystallographic structure of the complex has been published earlier with perchlorate counter-ions [82] and the authors found basically the same geometry for the cationic complex core only with trifluoromethylsulfonate anions. In acetonitrile the dimeric form was found to be predominant, with an antiferromagnetically coupled ground state and a thermally accessible, excited triplet state. In aqueous solution on the other hand the dimer partially dissociated at the high $\mathrm{pH}$ of catalysis (12.5) to generate the mononuclear $28 \mathrm{~m}-\mathrm{H}^{+}$. Despite this fact, calculations and experimental findings revealed that oxidation of either $28 \mathrm{~m}-\mathrm{H}^{+}$or 32 (aided by coupled proton transfers) results in a common dinuclear intermediate, $\left\{\left[\left(\mathrm{Me}_{2} \mathrm{TPA}\right) \mathrm{Cu}^{\mathrm{III}}\right]_{2}-(\mu-\mathrm{O})_{2}\right\}^{2+}$, $\mathrm{Me}_{2} \mathrm{TMPA}=\operatorname{bis}((6-$-methyl-2-pyridyl)methyl)(2-pyridylmethyl)amine), thus avoiding formation of the disfavored mononuclear oxo-species. Both intermolecular WNA and redox isomerization of $\left\{\left[\left(\mathrm{Me}_{2} \mathrm{TPA}\right) \mathrm{Cu}^{\mathrm{III}}\right]_{2}-(\mu-\mathrm{O})_{2}\right\}^{2+}$ were concluded energetically accessible pathways for $\mathrm{O}-\mathrm{O}$ bond formation and the large KIE of 20 suggested PCET as the rate-determining step (Figure 21). In their concluding remarks the authors dismissed the intermediacy of a terminal oxyl/oxo species due to its too high basicity and the existence of a low-energy route to the dinuclear intermediate. 


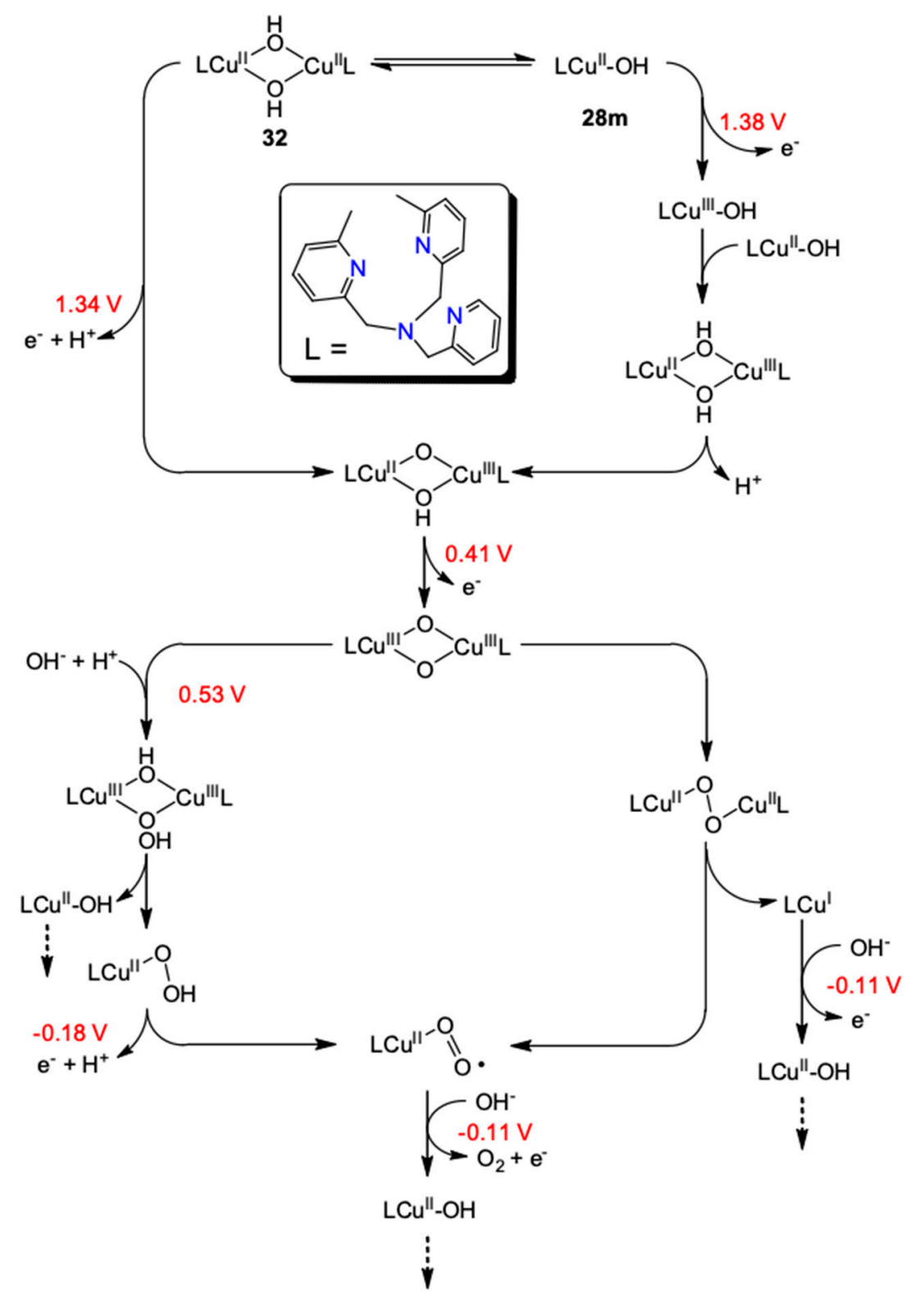

Figure 21. The most probable mechanistic scenario for 32 according to Kieber-Emmons [75].

Note that electrocatalytic production of $\mathrm{O}_{2}$ by $\mathbf{1 4}$ has been suggested to follow single-site mechanism near neutral $\mathrm{pH}$, but the catalysis ceased at higher $\mathrm{pH}$, where the bis $(\mu-\mathrm{OH})$ dicopper form, 33 (Figure 19) became the predominant solution equilibrium species [54]. The intramolecular $\mathrm{O}$-atom insertion into a well-oriented indane $\mathrm{C}-\mathrm{H}$ bond taking place instead generated a non-catalytic complex. Dinuclear complexes were also prepared with oxamide derived ligands $\left(\mathrm{Me}_{2} \mathrm{Oxpn}=\right.$ $N, N^{\prime}$-bis(2,2'-dimethyl-3-aminopropyl)oxamide), which were active molecular catalysts for water oxidation (Figure 19, 34, see Table 3 for data), however, no cooperation of any kind could be confirmed, instead, both of the metals were reported to act as single sites $[83,84]$. Similar observations were made by us for the peptide-based catalyst 27 that also exists in a dimeric form at $\mathrm{pH}<9$, but showed no catalysis under those conditions [32]. It seems reasonable to conclude that the pre-organization of $(\mu-\mathrm{OH})_{1 / 2}$-dicopper cores in order to promote cooperative catalysis requires ligands that stabilize the dimeric structure under conditions ( $\mathrm{pH}$, buffer, temperature, solvent, etc.), under which WOC efficiently takes place. This also puts in perspective future systems that detectably shift between reaction pathways depending on the conditions to better understand the boundary conditions of the different reaction mechanisms. 
Table 3. Kinetic, electrochemical data and reaction conditions of dicopper water oxidation catalysts.

\begin{tabular}{ccccccc}
\hline Catalyst & $\mathbf{p H}$ & Electrolyte & $\boldsymbol{k}_{\text {obs }}\left(\mathbf{s}^{-\mathbf{1}}\right)$ & $\boldsymbol{\eta} \mathbf{( m V )}$ & Faraday Eff. (\%) & Ref. \\
\hline$\left[(\mathrm{BPMAN}) \mathrm{Cu}_{2}(\mu-\mathrm{OH})\right]^{3+}(\mathbf{3 0})$ & 7.0 & phosphate, $0.1 \mathrm{M}$ & 0.6 & 1050 & 98 & {$[51]$} \\
{$\left[(\mathrm{TPMAN}) \mathrm{Cu}_{2}(\mu-\mathrm{OH})\right]^{3+}(\mathbf{3 1})$} & 7.0 & phosphate, $0.1 \mathrm{M}$ & 0.78 & 780 & n.a. & {$[81]$} \\
$\left\{\left[\left(\mathrm{Me} \mathrm{TMP}_{2}\right) \mathrm{Cu}\right]_{2}-(\mu-\mathrm{OH})_{2}\right]^{2+}(\mathbf{3 2})$ & 12.5 & NaOH/NaOTf & 33 & 1007 & $>90$ & {$[75]$} \\
{$\left[\mathrm{Cu}\left(\mathrm{Me}_{2} \mathrm{oxpn}\right) \mathrm{Cu}(\mathrm{OH})_{2}\right](\mathbf{3 4})^{1}$} & 10.4 & phosphate, $0.25 \mathrm{M}$ & $\sim 2.14$ & 636 & 90 & {$[84]$} \\
\hline
\end{tabular}

${ }^{1}$ the two copper centers act independently, as single catalytic sites.

\subsection{Multi-Copper Catalysis}

It has been discussed earlier that Lin et al. reported the formation of a catalytically active 1-D coordination polymer from 5 and its deposition on electrode surfaces during electrolysis [31]. Their observation highlighted that discrete $\mathrm{Cu}$ clusters might be appealing candidates as WOCs on the analogy of the natural OEC $[85,86]$. Indeed, a tethering ligand applied earlier in a Fe cluster [87] inspired the synthesis of 1,3-bis(6-hydroxy-2-pyridyl)-1H-pyrazole $\left(\mathrm{H}_{2} \mathrm{~L}_{\mathrm{pa}}\right)$ to be used in a tetranuclear $\mathrm{Cu}$ species (Figure 22, 35) [88]. This ligand, beyond stabilizing the tetracopper assembly, was supposed to facilitate proton channeling from the substrate water molecules in the water oxidation reaction by its two pendant hydroxyl groups. The crystallographic structure of $\mathbf{3 5}$ revealed that four ligands were assembled with four $\mathrm{Cu}^{\mathrm{II}}$ centers, of which one was five coordinate in distorted square pyramidal geometry while the rest was four coordinate in distorted square planar geometry. The $\mathrm{Cu} \cdots \mathrm{Cu}$ distances were in the range 4.146-4.282 A. Importantly, UV-Vis absorption spectra in solution were identical with those in the solid state of 35 confirming that the species maintained its tetranuclear structure in solution as (ESI-MS showing only the tetrameric $\mathrm{Cu}$ species both in neutral and in basic ( $\mathrm{pH}$ 12.5) solutions also confirmed this conclusion). Catalytically enhanced, irreversible currents centered at $0.9 \mathrm{~V}$ versus $\mathrm{Ag} / \mathrm{AgCl}$ were observed in the $\mathrm{pH}$ range of 10-13 in $\mathrm{NaOH} / \mathrm{NaOAc}$ and similar CVs were also obtained in $0.1 \mathrm{M}$ phosphate buffer at various $\mathrm{pH}$ values ( $\mathrm{pH}$ 9.5-12.5). The catalysis occurred at a relatively low overpotential, moderate $k_{o b s}$ and acceptable Faraday efficiency (Table 4). The $\mathrm{CV}$ profiles of 35 in the $\mathrm{pH}$ range of 11-13 showed typical single waveforms linearly dependent on the total catalyst concentration implying that polymeric species were not generated the catalytic current and the process was homogeneous. To our knowledge, no hypothesis or mechanistic analysis has been communicated about the possible role of cooperation between the cupric centers.

Another hydrolytically stable, but hydroxide-bridged tetranuclear complex has been reported to drive water oxidation electrocatalysis at neutral $\mathrm{pH}[28]$. The $\left[\mathrm{Cu}_{4}(\mathrm{bpy})_{4}\left(\mu_{2}-\mathrm{OH}\right)_{2}\left(\mu_{3}-\mathrm{OH}\right)_{2}\left(\mathrm{H}_{2} \mathrm{O}\right)_{2}\right]^{2+}$ cation (36) could be isolated and crystallized earlier with two terephthalate anions and six guest water molecules [89]. The metal centers in the chair-like $\mathrm{Cu}_{4} \mathrm{O}_{4}$ core displayed tetragonal pyramidal geometry and each $\mathrm{Cu}$ atom was found to be coordinated by two $\mathrm{N}$ atoms of the bpy ligand, two bridging $\mathrm{O}$ atoms of $\mu-\mathrm{OH}$ ligands and either one coordinated water molecule, or a $\mu_{3}-\mathrm{OH}$ in the apical position. Magnetic properties of 36 indicated ferromagnetic exchange interactions between the $\mathrm{Cu}(\mathrm{II})$ ions with positive $J$ values [89]. 


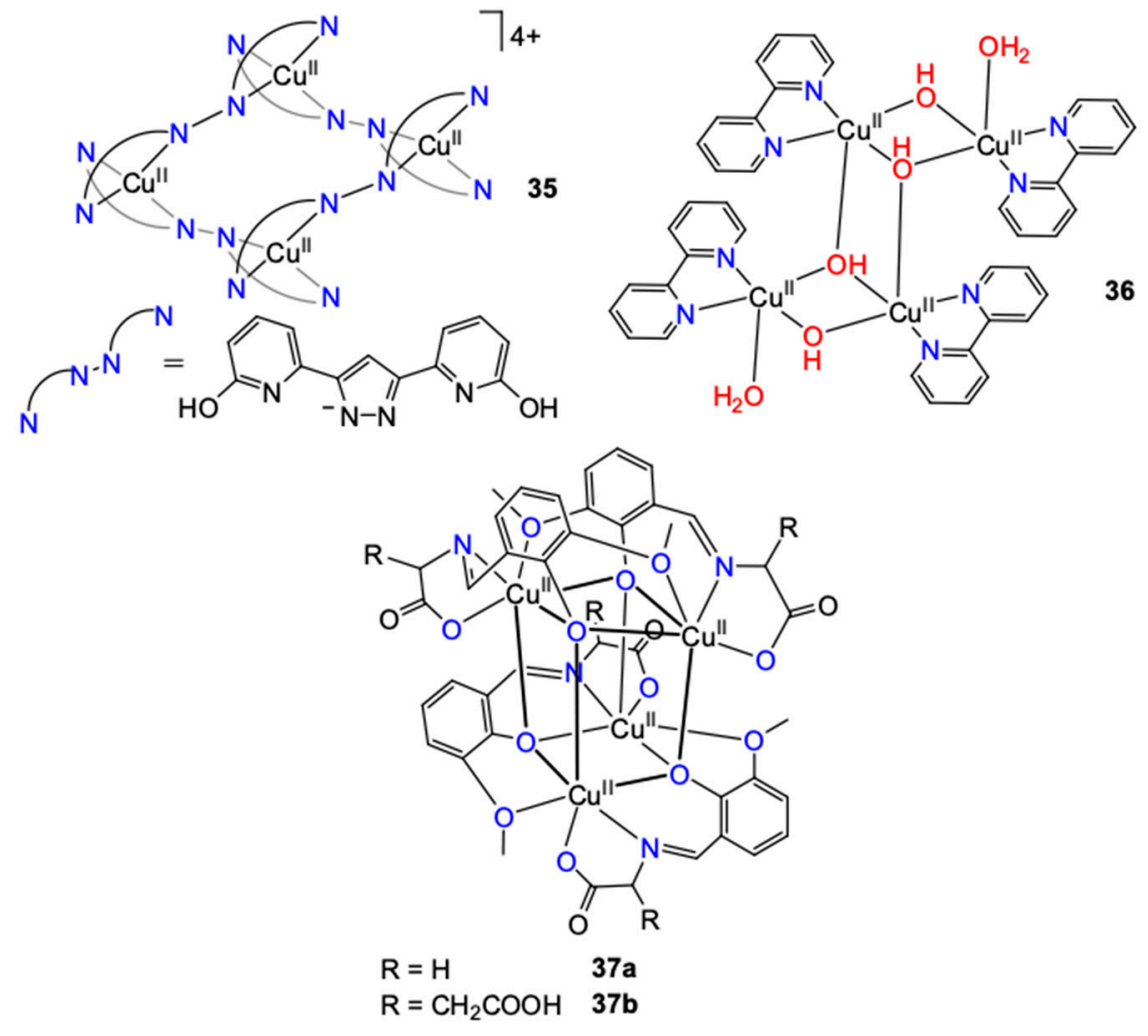

Figure 22. Multi-copper catalysts.

Table 4. Kinetic, electrochemical data and reaction conditions of multi-copper water oxidation catalysts.

\begin{tabular}{ccccccc}
\hline Catalyst & $\mathbf{p H}$ & Electrolyte & $\left.\boldsymbol{k}_{\text {obs }} \mathbf{s}^{-\mathbf{1}}\right)$ & $\boldsymbol{\eta}(\mathbf{V})$ & Faraday Eff. (\%) & Ref. \\
\hline$\left[\mathrm{Cu}_{4}\left(\mathrm{H}_{2} \mathrm{~L}_{\mathrm{pa}}\right)_{4}\right]^{4+}(\mathbf{3 5})$ & 12.5 & NaOH/NaOAc, $0.1 \mathrm{M}$ & 0.8 & 500 & 75 & {$[88]$} \\
{$\left[\mathrm{Cu}_{4}(\mathrm{bpy})_{4}\left(\mu_{2}-\mathrm{OH}\right)_{2}\right.$} & 7.0 & phosphate, $0.1 \mathrm{M}$ & n.a. & 730 & 98 & {$[28]$} \\
$\left.\left(\mu_{3}-\mathrm{OH}\right)\left(\mathrm{H}_{2} \mathrm{O}\right)_{2}\right]^{2+}(\mathbf{3 6})$ & 12.0 & phosphate, $0.2 \mathrm{M}$ & 257 & $620^{1}$ & 97 & {$[90]$} \\
{$\left[\left(\mathrm{L}_{\mathrm{Gly}}-\mathrm{Cu}\right)_{4}\right](37 \mathrm{a})$} & 12.0 & phosphate, $0.2 \mathrm{M}$ & 105 & $760^{1}$ & n.a. & {$[90]$} \\
{$\left[\left(\mathrm{L}_{\mathrm{Glu}}-\mathrm{Cu}\right)_{4}\right](\mathbf{3 7 b})$} & \multicolumn{1}{c}{ at $1 \mathrm{~mA} / \mathrm{cm}^{2}$ current density. }
\end{tabular}

The $\mathrm{CV}$ of 36 in deoxygenated phosphate buffer $(0.1 \mathrm{M}, \mathrm{pH} 7.0)$ exhibited an irreversible reduction wave at $-0.06 \mathrm{~V}$ versus NHE, which has been ascribed to the reduction process of $\mathrm{Cu}_{4}^{\mathrm{II}}$ to $\mathrm{Cu}_{3}{ }_{3} \mathrm{Cu}^{\mathrm{I}}$. One irreversible oxidation wave at $0.15 \mathrm{~V}$ was observed during the reverse $\mathrm{CV}$ scan ascribed to a structurally rearranged complex. The onset potential for WOC was $\mathrm{pH}$-dependent, with a slope of $-55 \mathrm{mV} / \mathrm{pH}$ in consistence with a PCET process. The lower overpotential compared with other molecular $\mathrm{Cu}$ (II)-WOCs under neutral conditions has been attributed to the multinuclear structure and the simultaneous presence of aqua and bridging $\mu-\mathrm{OH}$ ligands in the $\mathrm{Cu}_{4} \mathrm{O}_{4}$ core. As the authors concluded: "the multinuclear structure typically possesses high redox flexibility, and the bridging ligands would harmonize the electronic communication between the adjacent metal centers, which are expected to be favorable for reactions involving PCET processes." They also hypothesized that the presence of aqua and bridging $\mu-\mathrm{OH}$ ligands in 36 might play an important role in the water oxidation catalysis as these structural features could provide access to intramolecular $\mathrm{O}-\mathrm{O}$ bond formation with a relatively low activation barrier. However, no experimental certification of an intramolecular PCET process could be presented due to the complicated kinetic steps.

The most detailed kinetic and mechanistic analysis has been published very recently on two variants of bio-inspired $\mathrm{Cu}_{4} \mathrm{O}_{4}$ cubanes that worked as molecular catalysts at $\mathrm{pH}=12$ [90]. Beside $\left[\left(\mathrm{L}_{\mathrm{Gly}}-\mathrm{Cu}\right)_{4}\right]$ (Figure 22, 37a) the $\left[\left(\mathrm{L}_{\mathrm{Glu}}-\mathrm{Cu}\right)_{4}\right](37 \mathbf{b})\left(\mathrm{L}_{\mathrm{Gly}}=\right.$ (3-methoxy-salicylidene)-glycine and $\mathrm{L}_{\mathrm{Glu}}$ $=(3$-methoxy-salicylidene)-glutamic acid) with better solubility in a broad $\mathrm{pH}$ range has been also 
studied in detail. The reaction of $\mathrm{Cu}(\mathrm{OAc})_{2}$ with the ligands readily provided the cubane-like clusters. $\mathrm{X}$-ray crystallography on the dark green crystals of 37a revealed a tetrameric structure, in which each $\mathrm{Cu}$ atom was six-coordinate to a $\{1 \mathrm{~N}, 5 \mathrm{O}\}$ donor set. In the published structure the amino acid moiety of each ligand formed a 5-member chelate with one of the $\mathrm{Cu}$ centers, while the phenolate $\mathrm{O}$ donor occupied a $\mu_{3}$-bridging position and the methoxy group was bound to an adjacent $\mathrm{Cu}$ atom. An important feature of the cube-shaped $\mathrm{Cu}_{4} \mathrm{O}_{4}$ core was that one of the three $\mu_{3}-\mathrm{O}$ bonds was elongated on the opposite faces of the cube, which offered access for water attack. The intensity of the characteristic $\mathrm{d}-\mathrm{d}$ absorption of $\mathrm{Cu}$ around $650 \mathrm{~nm}$ increased linearly with the concentration of both complexes that demonstrated the integrity of the cubane cores in aqueous solution. Temperature dependent molar magnetic susceptibility for 37a revealed strong antiferromagnetic coupling between the cupric ions. The redox properties of $37 \mathbf{a}$ and $37 \mathbf{b}$ were investigated by $\mathrm{CV}$ in $0.2 \mathrm{M}$ phosphate buffer at $\mathrm{pH}$ 12. The careful evaluation of the scan rate dependence of current peaks allowed their assignment as the $2 \mathrm{e}^{-}$reactions, such as $\mathrm{Cu}_{4}{ }^{\mathrm{II}} / \mathrm{Cu}_{2}{ }^{\mathrm{II}} \mathrm{Cu}_{2}{ }^{\mathrm{I}}, \mathrm{Cu}_{4}{ }^{\mathrm{II}} / \mathrm{Cu}_{2}{ }^{\mathrm{II}} \mathrm{Cu}_{2}{ }^{\mathrm{III}}$ and $\mathrm{Cu}_{2}{ }^{\mathrm{II}} \mathrm{Cu}_{2}{ }^{\mathrm{III}} / \mathrm{Cu}_{4}{ }^{\mathrm{III}}$ thus the copper centers of $\mathrm{Cu}_{4} \mathrm{O}_{4}$ have been considered as two equivalent groups, each of which being susceptible for $2 \mathrm{e}^{-}$processes.

The high catalytic activity was manifested in outstanding turnover frequencies of $267 \mathrm{~s}^{-1}$ for $37 \mathrm{a}$ at $1.70 \mathrm{~V}$ and $105 \mathrm{~s}^{-1}$ for $37 \mathrm{~b}$ at $1.56 \mathrm{~V}$ (Table 4 ) and no detectable sign of decomposition. The proposed mechanism is shown in Figure 23. Importantly, EPR active and silent species could be tracked for 37a by means of in-situ recording the spectra at different potentials. To confirm that the formation of $\mu_{4}$-coordinated peroxide in situ was viable, $\mathrm{H}_{2} \mathrm{O}_{2}$ has been added to the complex. In the Raman spectra the same peak was present of the in situ generated and the chemically generated species at 875 $\mathrm{cm}^{-1}$ that has been assigned as the $\tilde{v}(\mathrm{O}-\mathrm{O})$ vibration of the $\mu_{4}$-peroxide. Based on the results, it has been proposed that under catalytic conditions, the $\mathrm{Cu}_{4}{ }_{4}{ }^{\mathrm{II}}$ species was oxidized via two successive $2 \mathrm{e}^{-}$ oxidations to $\mathrm{Cu}_{4}{ }^{\mathrm{III}}$ intermediates and further to $\mathrm{Cu}_{2}{ }^{\mathrm{III}} \mathrm{O} \bullet$ species. The redox properties of the $\mathrm{Cu}_{4} \mathrm{O}_{4}$ core seem promising in light of the achieved rates in water oxidation. This example may encourage the further investigation of multinuclear complexes.

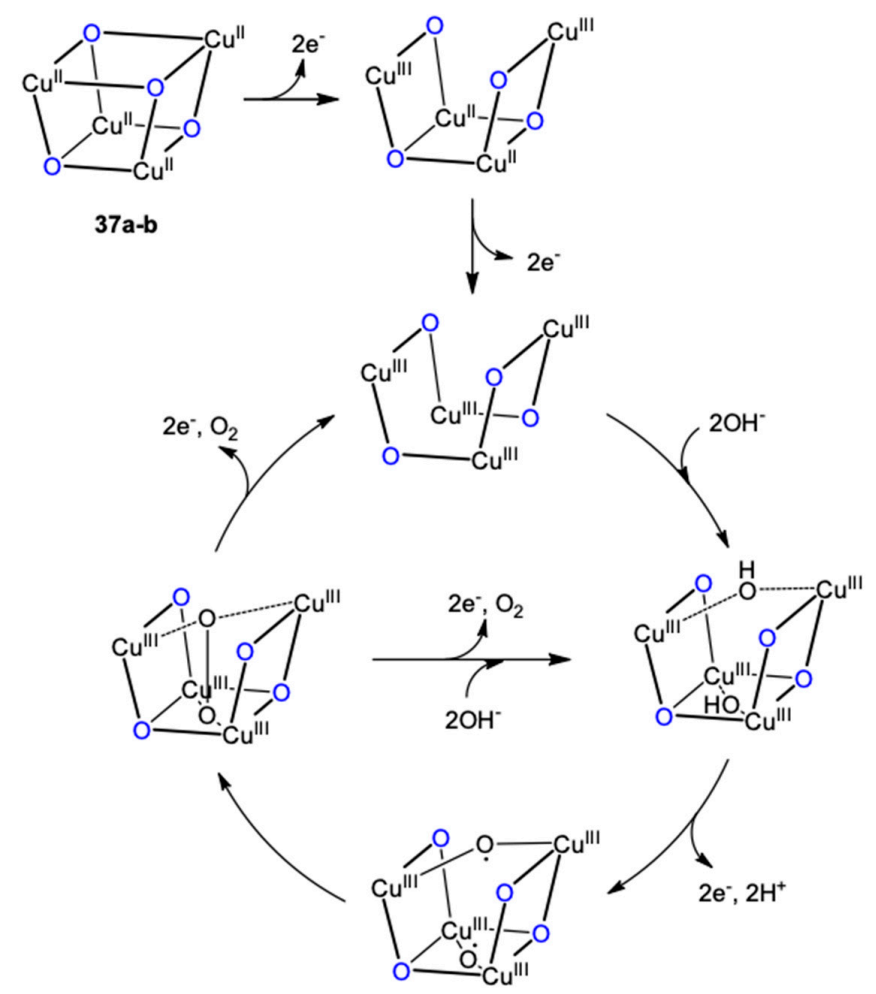

Figure 23. Proposed WOC mechanism for the cubane-like copper clusters [90]. 


\subsection{Cu Complexes as Precursors}

Detailed studies on $\mathrm{Cu}$ complexes revealed that the true catalyst responsible for water oxidation in a number of cases has been a copper oxide/hydroxide deposit instead of (or beside) the complex molecule itself. Deposits can be formed in situ on the electrode surface due to the demanding conditions of electrocatalytic water oxidation that will either break apart labile metal-ligand interactions or make ligand moieties prone to oxidative degradation. In the case of copper complexes the ligand exchange kinetics can be fast enough to release the metal ion making the control over the Cu-based catalyst structures difficult. The in situ oxidation of the ligand may also lead to the degradation of the complex due to a lower binding ability of the oxidation product. Discrimination between homogeneous and heterogeneous catalysis is very complex as it could be seen from the earlier examples, moreover, the high variety of the catalysts shows that the question of stability/true catalyst is case sensitive. During initial experiments one has to find the right $\mathrm{pH}$ range in the right buffer(s) and the polarization to trigger WOC. However, the question arises: has one just found the right conditions to initiate complex degradation and $\mathrm{CuO} / \mathrm{OH}$ deposition? The type of catalytic species in situ can be largely dependent on the reaction conditions applied, especially in the case of such dynamic systems.

While decomposition of the molecular catalyst is generally an unwanted scenario, on the other hand less expensive and controllable precursor complexes represent an exciting option to build nanostructured $\mathrm{Cu}_{2} \mathrm{O}$ or $\mathrm{CuO}$ coatings that are not only interesting as electrocatalysts for WOC, but also as efficient (photo)cathodes for hydrogen evolution (however, $\mathrm{Cu}_{2} \mathrm{O}$ is prone to undergo oxidative or reductive photocorrosion to form $\mathrm{CuO}$ or $\mathrm{Cu}$ ).

Substituted tris(2-pyridylmethyl)amine (TPA) ligands set an example for the highly condition-dependent behavior of molecular systems. While the TPA complex (28) at $\mathrm{pH} 7$ in phosphate buffer, the $\mathrm{F}_{3}$ TPA complex (28f) at $\mathrm{pH} 8.5$ in borate buffer and the $\mathrm{Me}_{2} \mathrm{TPA}$-containing dimeric complex (32) at $\mathrm{pH} 12.5 \mathrm{in} \mathrm{NaOH} / \mathrm{NaOAc}$ have all been described as molecular catalysts. Complex 28, the MeTPA complex 38, moreover, 38d containing di(2-pyridylmethyl)benzylamine (DPA) and $38 \mathrm{dm}$ containing di(2-pyridylmethyl)(3-methylbenzylamine) (MeDPA) (Figure 24) have been applied as precursors in the electrodeposition of a nanostructured oxide/hydroxide catalysts at above $\mathrm{pH}$ 9 in borate buffer by two different methods [77,91]. As for 28 and $\mathbf{3 8}$ an electrocatalytic current peak associated with oxygen production at $\sim 1.6 \mathrm{~V}$ showed linear $\mathrm{pH}$-dependence increasing up to pH 11 [77]. Upon reverse scans current crossover was reported and associated with the re-oxidation of an intermediate. Controlled potential electrolysis at $1.41 \mathrm{~V}$ yielded within 1 hour a catalyst film on the surface of the FTO working electrode that grew thicker upon longer periods. The used FTO produced then a similar catalytic current in pure buffer, indicating that a catalyst film was irreversibly deposited on the electrode and it was responsible for the $\mathrm{O}_{2}$ evolution. Experiments on the other hand with the same concentration of $\mathrm{CuCl}_{2}$ and $\mathrm{CuO}$-ethanol suspension dispersed on the FTO electrode could not cope with the performance of the in situ electrodeposited film from 38 or 28. SEM-EDX and XPS results helped to identify the film as $\mathrm{CuO}$ covering the FTO in $~ 300 \mathrm{~nm}$ thickness. 


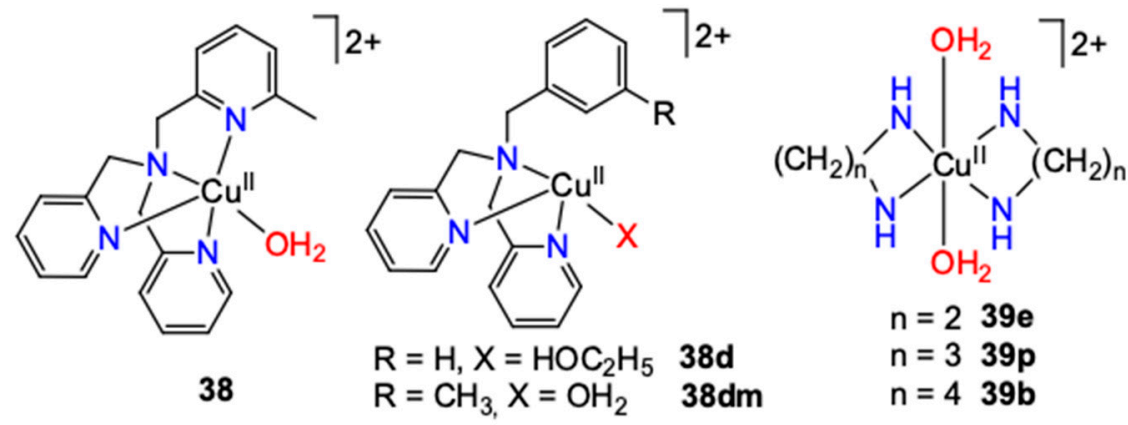<smiles>[R]C1NC2(CO)NC([R])C2OC1=O</smiles>

40

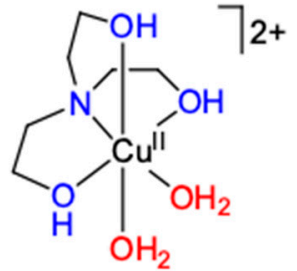

41<smiles>OCC1(CO)COC2(N1)NC(CO)(CO)CO2</smiles>

42

Figure 24. Precursor complexes.

In a later publication the same authors discussed a cathodic electrodeposition method that provided a bifunctional catalyst film equally capable of catalyzing the HER as well as the OER in the same borate buffer, but under opposite polarization [91]. Four complexes $(\mathbf{2 8}, \mathbf{3 8}, \mathbf{3 8 d}$, and $\mathbf{3 8 d m})$ have been investigated and all of those were found to be good precursors in the electrodeposition carried out at $-1.2 \mathrm{~V}$. Note that this method also worked at $\mathrm{pH} 7$ in phosphate buffer. However, the complexes with the TPA type ligands (28 and $\mathbf{3 8}$ ) were the better precursors indicating that the organic ligands should play an important role in the deposition process and thus might control the morphology of the films. Due to difficulties in tracing the intermediates, the actual role of these ligands remained unclear. The authors speculated that the TPA ligand in $\mathbf{2 8}$ might promote the electrochemical generation of $\mathrm{Cu}^{+}$instead of $\mathrm{Cu}^{0}$ that was indicated by a small reduction peak at $-0.50 \mathrm{~V}$. Under basic conditions, cuprous ions might react with hydroxide to form $\mathrm{CuOH}$, which is not stable and should produce $\mathrm{Cu}_{2} \mathrm{O}$ or $\mathrm{Cu}(\mathrm{OH})_{2}$ on the electrode. Indeed, physical characterization of the film revealed $\mathrm{Cu}_{2} \mathrm{O}$ and $\mathrm{Cu}(\mathrm{OH})_{2}$ nanoparticles as the two major components with rather uniform morphology, instead of metallic copper. As this film has been exposed to anodic polarization to trigger WOC, the composition at the surface has changed to $\mathrm{Cu}_{2} \mathrm{O}: \mathrm{Cu}(\mathrm{OH})_{2}: \mathrm{CuO}$ in roughly 1:1:3 ratio. The parameters describing the WOC performance of the film are remarkable (Table 5), more so, since switching between the HER and OER in the same buffer by simply changing the polarization set to the film on FTO has been demonstrated as fully reversible.

It has to be noted at this point that in borate a stable copper oxide thin film could be generated without any ancillary ligands [92]. The copper oxide film in this case contained B in a considerable ratio (roughly 1:2 to $\mathrm{Cu}$ ), thus named as $\mathrm{Cu}-\mathrm{B}_{\mathrm{i}}$ and it was a highly active electrocatalyst for WOC in near-neutral conditions (Table 5), moreover, inert to corrosion. Electrodeposition was possible in-situ from a $\mathrm{Cu}\left(\mathrm{NO}_{3}\right)_{2}$ containing solution by $\mathrm{CPE}$ at $1.3 \mathrm{~V}$ at $\mathrm{pH} 9$ to give $\mathrm{Cu}-\mathrm{B}_{\mathrm{i}}$ in $\sim 200 \mathrm{~nm}$ thickness. These results underline the crucial effect of the electrolyte on the equilibrium between dissolution and precipitation of copper ions under anodic potentials.

Another interesting example on a 'chameleon-like' system has been presented with alkylenediamine ligands (Figure 24, 39e, 39p, and 39b) in closely related papers [93,94]. At $\mathrm{pH}$ 12 in phosphate buffer 39e decomposed to give a phosphate-incorporated $\mathrm{Cu}(\mathrm{OH})_{2} / \mathrm{CuO}$ film on ITO and FTO electrodes that produced $\mathrm{O}_{2}$ at lower overpotential compared to other $\mathrm{Cu}$-based surface catalysts (Table 5). Beyond the catalytic current peak, the reverse scans of CVs showed current crossover along with a small re-reduction wave at $\sim 0.78 \mathrm{~V}$. The increased catalytic currents were stabilized only after several scans. This has been attributed to interfacial catalysis and a surface-bound intermediate. 
Morphological analysis of the electrodeposited catalyst film revealed nanoparticles with diameters of tens of nanometers covering fully the electrode surface. Under steady state electrolysis conditions, the $\mathrm{CuO} / \mathrm{Cu}(\mathrm{OH})_{2}$ film grew $400 \mathrm{~nm}$ thick incorporating a substantial amount of phosphate at a stoichiometric ratio of $\sim 3: 1 \mathrm{Cu}: \mathrm{P}$.

The authors gave a very detailed picture of the possible mechanism of ligand oxidation as shown in Figure 25. The product has been identified as glyoxal by means of NMR analysis and the two electrocatalytic waves observed in $\mathrm{CVs}$ at $1 \mathrm{Cu}^{\mathrm{II}}$ :2ligands ratio were associated with a sequential oxidation to $\mathrm{Cu}^{\mathrm{III}}$ and $\mathrm{Cu}^{\mathrm{IV}}$ (or $\mathrm{Cu}^{\mathrm{III}}-\mathrm{O} \bullet$ ) of the diaqua complex, 39e, the dominant form in solution. The electrochemical oxidation to $\mathrm{Cu}^{\mathrm{III}}$ was presumed to induce intramolecular electron transfer to give the $1 \mathrm{e}^{-}$oxidized nitrogen radical $-(\mathrm{H}) \mathrm{N} \bullet$ coordinated to $\mathrm{Cu}{ }^{\mathrm{II}}$. At the potential used, further oxidation steps were supposed to lead to the monoamine and eventually, to the coordinated di-imine, $\mathrm{HN}=\mathrm{CH}-\mathrm{CH}=\mathrm{NH}$, which is known to undergo hydrolysis to generate glyoxal and ammonia. Strong proton acceptor bases $\left(\mathrm{OH}^{-}\right.$or $\left.\mathrm{PO}_{4}^{3-}\right)$ were concluded to aid PCET in the oxidative decomposition of the ligands. Adjusting the ligand-to-copper ratio helped decreasing the fraction of the diaqua species 39e and increasing that of $\left[\mathrm{Cu}^{\mathrm{II}}\left(\mathrm{NH}_{2} \mathrm{CH}_{2} \mathrm{CH}_{2} \mathrm{NH}_{2}\right)_{3}\right]^{2+}$ which substantially inhibited WOC. Surprisingly, maximized film formation was detected at a $\mathrm{Cu}^{\mathrm{II}}$ :ethylenediamine ratio of $1: 5$, where the molecular contribution to the catalytic current was negligible.

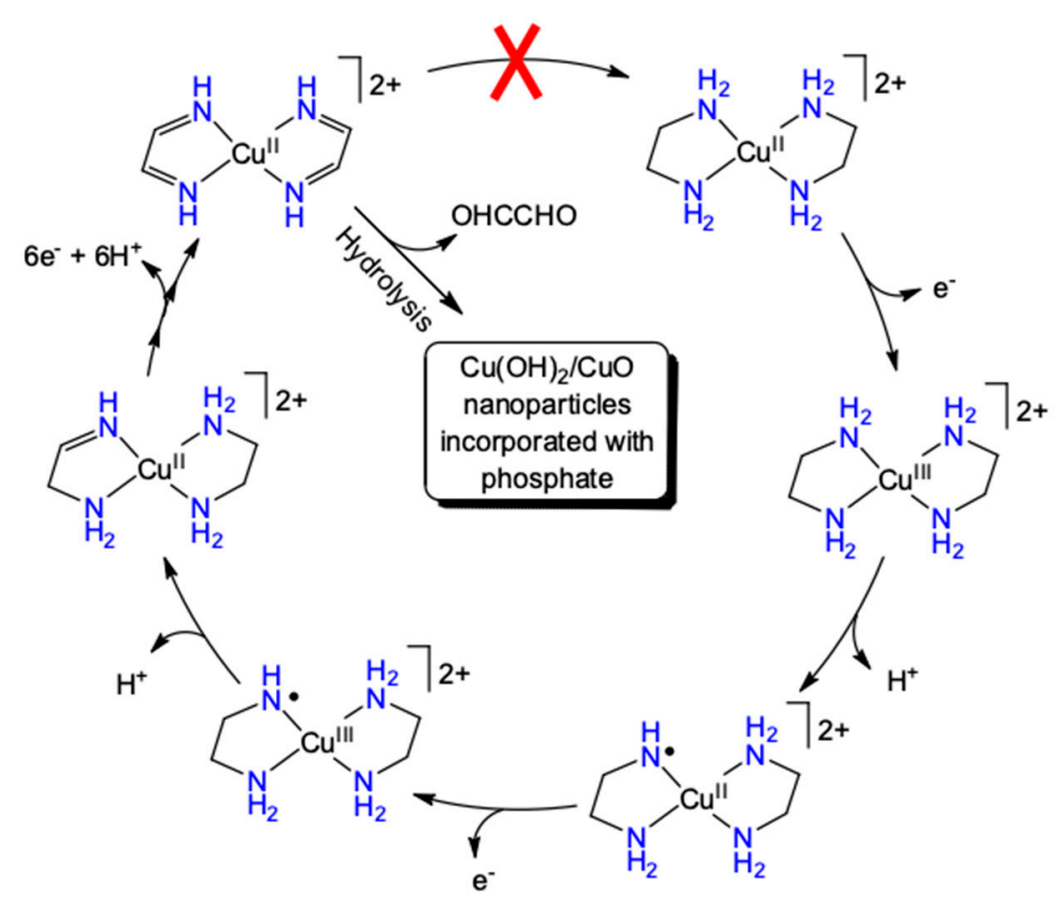

Figure 25. Mechanism proposed for the degradation of diamine complexes [94].

At $7<\mathrm{pH}<10$ water oxidation by 39e was found to be homogeneous with no evidence for a heterogeneous contribution. The catalytic onset potential was $\mathrm{pH}$-dependent while the catalytic current was linearly dependent on the catalyst concentration from 0.1-2.5 mM, typical signatures of the single-site scenario involving a PCET process to reach the catalytically active intermediate. The Faraday efficiency was $75 \%$ indicating the possibility of a moderate ligand oxidation as side reaction, although not dominant. A rate constant for catalytic water oxidation of $k_{\mathrm{obs}} \sim 0.4 \mathrm{~s}^{-1}$ has been estimated from the steady state catalytic current density during electrolysis. Below $\mathrm{pH} 7$ on the other hand a blue passivating film of $\mathrm{Cu}_{3}\left(\mathrm{PO}_{4}\right)_{2}$ ceased water oxidation.

The authors also investigated the 1,3-propylenediamine containing system (39p) that, similarly to 39e, was efficient as precursor under the same conditions, thus their results indicated a general water oxidation reactivity for diamine complexes. In another study, however, three systems (39e, 39p, and 
39b) were tested as precursor in $0.1 \mathrm{M} \mathrm{KOH}$ and fundamental differences were found depending on the size of the chelate ring [93]. The overall conclusion was that the butylenediamine system, $\mathbf{3 9 b}$, has insufficient stability to initiate deposition. As for $39 \mathrm{e}$ and $39 \mathrm{p}$, the former was the better precursor generating a $\sim 780 \mathrm{~nm}$ thick $\mathrm{CuO}$ catalyst film consisting of interlaced nanoblocks and exhibiting the higher roughness factor and double layer capacitance resulting in better performance in WOC.

Amino acids (AAs) added to copper solutions at various stoichiometric ratios exhibited very similar behavior to that of aliphatic diamine utilizing precursors [95]. The most detailed results were published about the $\mathrm{Cu}^{\mathrm{II}}$-Gly system (Figure 24, 40, $\mathrm{R}=\mathrm{H}$ ), although it turned out that the side chain did not play a critical role in the film formation. However, the reactivity of the catalytic films was dependent on the nature of the applied AA. In general, the reactivity of the films precipitated from $\mathrm{Cu}^{\mathrm{II}}$-Gly and $\mathrm{Cu}^{\mathrm{II}}$-methionine were superior to those from $\mathrm{Cu}^{\mathrm{II}}$-isoleucine or $\mathrm{Cu}^{\mathrm{II}}$-glutamine, confirming the fact that the reactivity of the $\mathrm{CuO} / \mathrm{Cu}(\mathrm{OH})_{2}$ film was related to the precursors used.

In more detail the $\mathrm{pH}$-dependent activity indicated that the presence of deprotonated primary amines was necessary for the formation of the copper oxide/hydroxide species. The current density increased with the concentration of added Gly, reaching a maximum value at $4 \mathrm{Gly}: 1 \mathrm{Cu}^{\mathrm{II}}$. Further addition of Gly resulted in an increased catalytic onset potential. Stepwise oxidation from the mixed Gly-aqua complexes to proposed $\mathrm{Cu}^{\mathrm{III}}$ or $\mathrm{Cu}^{\mathrm{IV}}$ intermediates by PCET, prior to decomposition, has been presumed to play important role in film precipitation. The choice of buffer/electrolyte in the appropriate $\mathrm{pH}$ domain was critical for the precipitation, activity and stability of the film that is likely related to the $\mathrm{pH}$-dependent speciation of $\mathrm{Cu}-\mathrm{AA}$ systems. The authors followed changes in speciation by UV-Vis spectroscopy and found a bathochromic shift of the $\lambda_{\max }$ of the $\mathrm{Cu}^{\mathrm{II}} \mathrm{d}-\mathrm{d}$ transitions by increasing the $\mathrm{pH}$ from 10 to 12 that was associated with the coordination competition from $\mathrm{OH}^{-}$. On the other hand, the decrease in $\mathrm{pH}$ to 8 also resulted in the red-shift of $\lambda_{\max }$, consistent with de-coordination of the amine group by protonation and reactivity attenuation in this $\mathrm{pH}$ domain.

Surface analysis results indicated that the anodic electrodeposition in $0.2 \mathrm{M}$ phosphate at $\mathrm{pH} 12$ containing $4 \mathrm{Gly}: 1 \mathrm{Cu}^{\mathrm{II}}$ was optimal. The morphology of the precipitated catalyst film (SEM) showed a nano-sized amorphous solid assembled into a ca. $300 \mathrm{~nm}$ thick film completely covering the ITO substrate. This highly active amorphous precipitate of $\mathrm{CuO} / \mathrm{Cu}(\mathrm{OH})_{2}$ mixture incorporated phosphate anions at a stoichiometric ratio of $\sim 5: 1$ for $\mathrm{Cu} / \mathrm{P}$.

Beside diamines and amino acids, alcanolamines have been also utilized as precursor ligands in order to prepare catalyst films. $\left[\mathrm{Cu}(\mathrm{TEOA})\left(\mathrm{OH}_{2}\right)_{2}\right]^{2+}$ (Figure 24, 41), TEOA = tris(2-ethanol)amine, was one of the first reported precursors that had a thoroughly characterized structure [96]. The $\mathrm{Cu}^{\mathrm{II}}$ center was hexacoordinate including two aqua ligands in cis-positions. CPE at $1.30 \mathrm{~V}$ versus NHE in the presence of $2.0 \mathrm{mM}$ of $\mathbf{4 1}$ produced a stable current density of $1.6 \mathrm{~mA} / \mathrm{cm}^{2}$ for about 5 hours resulting in $\mathrm{O}_{2}$ with $80 \%$ Faraday efficiency. However, during CPE a brown precipitate was observed on the ITO working electrode even when the complex concentration was decreased to $0.5 \mathrm{mM}$. The precipitate retained its electrocatalytic activity in a pure buffer for about 3 hours and turned out to be a catalytically active, amorphous $\mathrm{CuO}$ film consisting of micrometer sized particles. In this case, the early electrochemical oxidation and concomitant dissociation of the tris(2-ethanol)amine ligand from the metal center was held responsible for the $\mathrm{CuO}$ deposition.

A very robust catalyst layer was fabricated from the $\left[\mathrm{Cu}(\mathrm{Tris})_{2}\left(\mathrm{OH}_{2}\right)\right]^{2+}$ complex (Figure 24, 42, Tris = tris(hydroxymethyl)aminomethane) at $\mathrm{pH} 12.0$ in phosphate buffer [97]. The film was a highly active electrocatalyst for water oxidation in a phosphate $(\mathrm{pH} 12)$, borate $(\mathrm{pH} 9.2)$ or carbonate $(\mathrm{pH} 9.2)$ buffer. The data for Tafel plotting were collected for a catalyst film operated in different concentrations of PBS (0.002-0.6 M) at $\mathrm{pH} 12.0$ and a zeroth order dependence on phosphate concentration was observed at each potential. The very low overpotential and Tafel slope (Table 5), moreover, the long-term stability of the catalyst film $(>10$ hours, SEM images of the film on an ITO substrate after electrolysis for $10 \mathrm{~h}$ showed a basically unchanged morphology) rank this system among the best to date. A mechanistic hypothesis about the formation of the film claimed that stepwise PCET oxidation of the aqua ligated 42 to form $\mathrm{Cu}^{\mathrm{III}}$ or $\mathrm{Cu}^{\mathrm{IV}}$ intermediates prone to surface precipitation of $\mathrm{CuO} / \mathrm{Cu}(\mathrm{OH})_{2}$ 
presumably played the key role. In this context, the excellent performance has been attributed to "the regulating effect of the pentacoordinate planar structure of the $\mathrm{Cu}$-Tris complex precursor and the four hydroxymethyl groups during the electrodeposition period" and further work is in progress to shed light on the details of this assumption.

Macrocycles may be also interesting precursor candidates according to some recent reports. The use of a Cu II -macrocycle (Figure 26, 43), synthesized by a known reaction [98] between ethylenediamine and 1,4-bis(2-carboxyaldehydephenoxy)butane in the presence of cupric ions has been reported to act as precursor for electrodeposited catalyst film that was grown on GC and ITO electrodes upon CPE at $1.34 \mathrm{~V}$ for $5 \mathrm{~h}$ in borate buffer at $\mathrm{pH} 12$ [99]. X-ray diffraction (XRD) along with X-ray photoelectron spectroscopy (XPS) indicated the preferential formation of $\mathrm{Cu}_{2} \mathrm{O}$ next to some $\mathrm{CuO}$ that performed remarkably well as heterogeneous WOC (Table 5). The dense catalyst layer on ITO exhibited a granular surface morphology with nanocrystals of about $450 \mathrm{~nm}$ in size and their micrometric agglomerates building a layer of $\sim 1.3 \mu \mathrm{m}$ thickness. A possible mechanism for the formation of $\mathrm{Cu}_{2} \mathrm{O}$ from 43 has been provided by the authors. According to this mechanism the stepwise oxidation of $\mathbf{4 3}$ to the high valence $\mathrm{LCu}^{\mathrm{III}}$-O• intermediate by PCET leads to oxygen evolution and in parallel, induces film precipitation. The coordination environment and coordination structure of the copper ion were claimed to determine the ultimate construction and performance of the $\mathrm{Cu}$-based catalyst film.

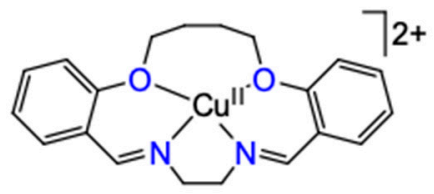

43

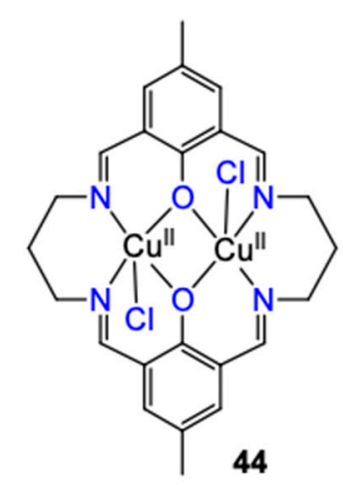

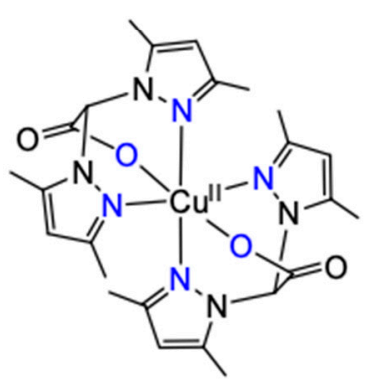

45<smiles>O=[N+]([O-])C12Oc3cc4ccccc4cc3N(O1)c1ccccc12</smiles>

46

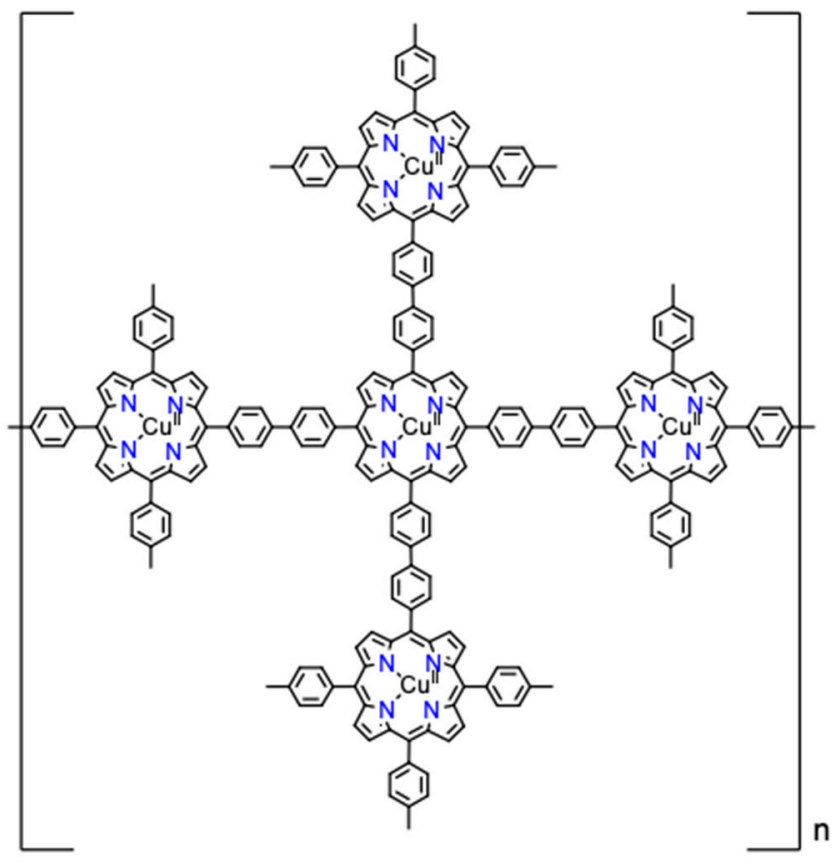

47

Figure 26. Precursor complexes with versatile structures.

A Robson-type [100] dinuclear complex, 44 (Figure 26) also yielded a thin catalytic film [101]. The synthesis of the precursor complex was a one-pot template reaction that required the mixing of 4-methyl-2,6-diformylphenol and 1,3-propanediamine in the presence of cupric chloride. In this case a catalytically active thin film of $\sim 40 \mathrm{~nm}$ has been deposited at $-1.2 \mathrm{~V}$ versus $\mathrm{Ag} / \mathrm{AgCl}$ at $\mathrm{pH}$ 
9.2 in borate buffer within a short period of time ( 1 hour and $20 \mathrm{~min})$ and showed bifunctionality, similarly to the earlier results with TPA-based system. The film was characterized as a mixture of crystalline $\mathrm{Cu}(\mathrm{OH})_{2}$ and amorphous $\mathrm{Cu}_{2} \mathrm{O}$ that was efficient in electrocatalytic HER under cathodic polarization. On the other hand, when anodic polarization was set to the $\mathrm{Cu}(\mathrm{OH})_{2} / \mathrm{Cu}_{2} \mathrm{O}$ on $\mathrm{FTO}$, oxygen evolution could be observed for over $4 \mathrm{~h}$, with parameters comparable to electrodeposited films prepared from different precursors (Table 5). Under these conditions the morphology of the deposit has been changed along with its transformation to crystalline $\mathrm{Cu}(\mathrm{OH})_{2}$. Remarkably, alternating between HER at $-1.2 \mathrm{~V}$ and OER at $+1.2 \mathrm{~V}$ in the same buffer gave currents that did not decrease with the number of changing polarity.

The coordinatively saturated $\left[\mathrm{Cu}(\text { bdmpza })_{2}\right]$ complex (Figure 26, 45, bdmpza $^{-}=$bis $(3,5-$ dimethyl1H-pyrazol-1-yl)acetate) was utilized as precursor by generating $\mathrm{CuO}$ films in two different ways [102]. Water oxidation studies on 45 revealed that the catalytic activity was entirely due to deposited $\mathrm{CuO}$, but the electrochemical pretreatment of the molecular catalyst largely affected the rate of deposition and the activity of the deposited material under the same conditions. This work sets a fascinating example of how one can control the formation of the catalytic species. The redox chemistry of $\mathbf{4 5}$ was explored by drop-casting the complex onto $\mathrm{Au} W \mathrm{WE}$ by recording $\mathrm{CV}$ s in a $0.1 \mathrm{M}$ aqueous $\mathrm{NaOH}$ solution at $\mathrm{pH}$ 13. Under oxidative conditions $\mathbf{4 5}$ was slowly converted to $\mathrm{CuO}$ with moderate activity only. When the polarization was started at high positive polarization and scanned towards more positive potentials initially, the first scan showed little, whereas the second and third scans following cathodic polarization showed increased catalytic currents. On the reverse (cathodic) direction a series of sharp reduction peaks lying on top of a broad negative baseline current were associated with the reduction of the complex to metallic copper at the electrode surface that in turn could be oxidized to $\mathrm{CuO}$ in-situ. Quartz crystal microbalance experiments confirmed mass gain of the electrode in the course of low scan rate $\mathrm{CVs}$ that indicated not only the deposition of $\mathrm{Cu}^{0}$, but also some residual organic materials attached to the surface. Similar experiments with cupric triflate and $\mathrm{CuO}$ nanoparticles confirmed that this ligand-derived deposit had crucial role in stabilizing the in-situ formed catalytic $\mathrm{CuO}$ film. In accordance with the catalytic currents, online electrochemical mass spectrometry (OLEMS) data showed formation of some dioxygen over the course of time. According to the authors' speculation the bdmpza ligand stabilizing effect on copper oxide preventing its solvation upon the potential release of $\mathrm{Cu}^{\mathrm{II}}$ similarly to coordinating anions like carbonate and borate. This assumption offers an interesting application of organic ligands and/or additives in heterogeneous water oxidation chemistry.

An azo-copper(II) complex, 46 (Figure 26, originally described as a homogeneous catalyst [103]) also underwent decomposition in phosphate buffer at $\mathrm{pH} 11$ and generated a catalytically active layer on FTO working electrode that was tentatively related to weaker attachment between the electrode and the deposit [104]. This example underlines again that the scope of potential precursor ligands may be very broad and further studies in this field are highly justified. 
Table 5. Electrochemical data and reaction conditions of $\mathrm{Cu}$ precursor complexes and the in situ formed catalytic films.

\begin{tabular}{|c|c|c|c|c|c|c|c|c|}
\hline Precursor & $\mathrm{pH}$ & Electrolyte & $\begin{array}{l}\text { [Precursor] } \\
(\mathrm{mM})\end{array}$ & $\stackrel{\eta}{(\mathrm{mV})}$ & $\begin{array}{c}j \\
\left(\mathrm{~mA} / \mathrm{cm}^{2}\right)\end{array}$ & $\begin{array}{c}\text { Tafel } \\
\text { Slope } \\
\text { (mV/pH) }\end{array}$ & $\begin{array}{l}\text { Far. Eff. } \\
(\%)\end{array}$ & Ref. \\
\hline$\left[\mathrm{Cu}(\mathrm{MeTPA})\left(\mathrm{OH}_{2}\right)\right]^{2+}(38)$ & $9-11$ & borate, $0.1 \mathrm{M}$ & 0.68 & 600 & 1.0 & 56 & $>90$ & [77] \\
\hline$\left[\mathrm{Cu}(\mathrm{TPA})\left(\mathrm{OH}_{2}\right)\right]^{2+}(\mathbf{2 8})^{1}$ & 9.2 & borate, $0.1 \mathrm{M}$ & 0.68 & 749 & 1.0 & 85 & 97 & [91] \\
\hline$C u-B_{i}$ & 9 & borate, $0.2 \mathrm{M}$ & 1.0 & $\sim 550$ & 1.0 & 89 & 95 & [92] \\
\hline$\left[\mathrm{Cu}(\mathrm{en})_{2}\left(\mathrm{OH}_{2}\right)_{2}\right]^{2+}(39 \mathrm{e})$ & 12.0 & phosphate, $0.2 \mathrm{M}$ & 1.0 & 540 & 1.0 & 62 & 92 & [94] \\
\hline$\left[\mathrm{Cu}(\mathrm{en})_{2}\left(\mathrm{OH}_{2}\right)_{2}\right]^{2+}(39 \mathrm{e})$ & 13.6 & $\mathrm{KOH}, 1.0 \mathrm{M}$ & 3.0 & 370 & 1.0 & 90 & $>95$ & [93] \\
\hline$\left[\mathrm{Cu}(\mathrm{AA})_{2}\left(\mathrm{OH}_{2}\right)\right](40)$ & 12.0 & phosphate, $0.2 \mathrm{M}$ & 1.0 & 450 & 1.0 & 64 & 96 & [95] \\
\hline$\left[\mathrm{Cu}(\mathrm{TEOA})\left(\mathrm{H}_{2} \mathrm{O}\right)_{2}\right]^{2+}(\mathbf{4 1})$ & 12.4 & $\mathrm{NaOH} / \mathrm{NaOAc}$ & 2.0 & 550 & $0.5-2.5^{2}$ & 130 & $\sim 100$ & [96] \\
\hline$\left[\mathrm{Cu}(\text { Tris })\left(\mathrm{H}_{2} \mathrm{O}\right)_{2}\right]^{2+}(42)$ & 12.0 & phosphate, $0.2 \mathrm{M}$ & 1.0 & 390 & 1.0 & 41 & 97 & [97] \\
\hline$\left[\mathrm{Cu}\left(\mathrm{L}^{\mathrm{M}}\right)\right]^{2+}(43)$ & 12.0 & borate, $0.1 \mathrm{M}$ & 0.5 & 400 & 1.0 & 72 & 99 & [99] \\
\hline$\left[\mathrm{Cu}_{2}\left(\mathrm{~L}^{\mathrm{R}}\right)(\mathrm{Cl})_{2}\right](44)$ & 9.2 & borate, $0.1 \mathrm{M}$ & 0.3 & 630 & 1.0 & 71 & 96 & [101] \\
\hline$\left[\mathrm{Cu}(\mathrm{bdmpza})_{2}\right](45)$ & $\sim 13$ & $\mathrm{NaOH}, 0.1 \mathrm{M}$ & $\begin{array}{l}150 \mathrm{nmol} / \\
0.72 \mathrm{~cm}^{2}\end{array}$ & 370 & n.d. & n.d. & n.d. & [102] \\
\hline$\left[\mathrm{Cu}\left(\mathrm{L}^{\mathrm{aza}}\right)\left(\mathrm{ONO}_{2}\right)\right]^{3+}(\mathbf{4 6})$ & 7.0 & phosphate, $0.1 \mathrm{M}$ & 0.78 & n.d. & n.d. & n.d. & n.d. & [104] \\
\hline [Cu-CMP] (47) & $\sim 14$ & $\mathrm{KOH}, 1.0 \mathrm{M}$ & $0.28 \mathrm{mg} / \mathrm{cm}^{2}$ & 350 & 1.0 & 62 & 97 & [33] \\
\hline
\end{tabular}

${ }^{1}$ cathodic deposition at $-1.2 \mathrm{~V}$ versus $\mathrm{Ag} / \mathrm{AgCl}^{2}{ }^{2}$ dependent on the applied buffer: in $\mathrm{NaOH} / \mathrm{NaOAc} \sim 0.5$ $\mathrm{mA} / \mathrm{cm}^{2}$, in borate and carbonate: $\sim 2.5 \mathrm{~mA} / \mathrm{cm}^{2}$.

Lastly, let us mention another way of fabricating a bifunctional electrocatalysts for HER and OER. Du et al. published the use of a porphyrin-based conjugated mesoporous polymer (Figure 26, 47) that has been annealed at different temperatures from 600 to $900{ }^{\circ} \mathrm{C}$ under $\mathrm{N}_{2}$ atmosphere prior to use as catalyst [33]. The precursor polymer was synthesized of a copper(II) $5,10,15,20$-tetrakis(4'-bromophenyl) porphyrin complex catalyzed by $\mathrm{Ni}(\mathrm{COD})_{2}$ in the presence of bpy by following a published, Yamamoto coupling procedure [105]. Thermal treatment of the Cu-CMP polymer displaying rod-like morphology yielded a nitrogen-enriched porous carbon material with hollow architecture that contained copper nanoparticles in the pores and some $\mathrm{CuO}$ on its surface. Catalytic water oxidation of this composite has been investigated in $1.0 \mathrm{KOH}$ and required a record low overpotential of $350 \mathrm{mV}$ (Table 5). This was attributed to the very good accessibility of the active sites thanks to the unique porous architecture and a presumed synergistic effect between $\mathrm{CuO}, \mathrm{Cu}$ and the porous carbon promoting the charge transfer processes. Chronopotentiometry for over $12 \mathrm{~h}$ and switching between $\pm 1 \mathrm{~mA} / \mathrm{cm}^{2}$ for HER and OER showed remarkable stability of the catalyst manifested in basically unchanged overpotentials.

Although the main topic of this review is the application of complexes majorly based on organic ligands either as molecular catalyst of OER or precursor remaining on the grounds of preferably in situ electrochemical methods, it has to be mentioned that several papers have been published on systems that have been fabricated from the corresponding pre-made inorganic components such $\mathrm{Cu} / \mathrm{CuO}$ nanowires [106,107], $\mathrm{CuO}$ [107], annealed $\mathrm{CuO}$ [108], $\mathrm{H}_{2} \mathrm{O}_{2}$-treated $\mathrm{CuO}$ [109], or others. These examples were summarized by Naruta et al. recently (see the ESI of their publication) [101], therefore we do not intend to duplicate their work.

\section{Conclusions}

The story of $\mathrm{Cu}$-based molecular WOCs started with single-site catalysts involving very simple ligands like bpy or the tetrapeptide H-GGGG-OH. The initial reports encouraged the scientific community to survey several, rationally modified ligand derivatives that have led to remarkable improvements such as reduced overpotentials, moderated $\mathrm{pH}$, or considerably increased catalytic rates. Beside some newly designed ligands, the majority of the applied substances have been known to the (bio)inorganic community for long and it is likely that other known, but untested systems will bring similarly significant achievements. Especially the redox non-innocent ligands can step forward as prospective candidates with their robust aromatic bonds and adjustable redox transitions. However, beside the always attractive aim of improved catalysis insight into the mechanistic scenarios 
by in-depth analysis of these systems provide perhaps even more important knowledge for the design of new systems.

Another promising group of compounds are the di- or multicopper constructs that circumvent the high energy LCuIII-O• species often proposed in the case of single-site catalysts by allowing cooperation between the pre-organized sites. The cooperation between copper sites is a fascinating option and the upcoming years will surely witness some major leaps in the performance of these catalysts.

Some of the putative molecular catalysts proved to be precursors to in situ deposited $\mathrm{CuO} / \mathrm{Cu}_{2} \mathrm{O} / \mathrm{Cu}(\mathrm{OH})_{2}$ films, which sometimes exhibited activities depending on the initial molecular structures. This is an appealing way of fabricating surface attached $\mathrm{CuO}$ nanoparticles with controllable size distribution, which are provably highly efficient, robust and outperform the pre-synthesized and then surface deposited counterparts.

Significant efforts were made to explore the morphology of the films and the presence of carbonaceous residues on some of the particle surfaces, yet the studies so far focused almost exclusively on the particular way of molecular decomposition and its relation to the WOC mechanism keeping in focus the catalysis versus decomposition rate by the $\mathrm{LCu}^{\mathrm{III}}-\mathrm{O} \bullet$ (or equivalent) species, which is undoubtedly a very important junction point between the different scenarios. Nevertheless, organic ligands (or degradation products) tend to cover particle surfaces hence it is possible that size-regulation, strong electrode surface attachment and conductivity are influenced by ligand properties less related to molecular catalysis. Processes or their combination like condensation-hydrolysis cascade reactions or agglomeration have not been investigated in this field yet. These aspects connect the study of precursors to nano-sized copper oxide compounds with the modification of semiconducting oxides other than ITO or FTO by electrodeposition under WOC conditions. There are readily available and essentially nontoxic precursors, making this fabrication method ideal for industrial scale over.

Funding: This work was funded by the National Research, Innovation and Development Office of Hungary, grant number NKFI-128841, and the VEKOP-2.3.2-16-2016-00011 grant supported by the European Structural and Investment Funds. J. S. Pap is grateful for the János Bolyai Research Scholarship from the Hungarian Academy of Sciences.

Conflicts of Interest: The authors declare no conflict of interest. The funders had no role in the design of the study; in the collection, analyses, or interpretation of data; in the writing of the manuscript, or in the decision to publish the results.

$\begin{array}{ll}\text { Abbreviations } \\ \text { AP } & \text { Artificial photosynthesis } \\ \text { BDD } & \text { Boron doped diamond } \\ \text { CA } & \text { Chronoamperometry } \\ \text { CD } & \text { Circular dichrosim } \\ \text { CP } & \text { Chronopotentiometry } \\ \text { CPE } & \text { Controlled potential electrolysis } \\ \text { CV } & \text { Cyclic voltammetry } \\ \text { DFT } & \text { Density functional theory } \\ \text { DLS } & \text { Dynamic light scattering } \\ \text { DPV } & \text { Differential pulse voltammetry } \\ \eta & \text { Overpotential of OER, defined as } \eta=\left(E_{c a t}-1.23 \mathrm{~V}+0.059 \mathrm{pH}\right) \\ E_{c a t} & \text { Potential of the catalytic reaction } \\ \text { EC-OWLS } & \text { Electrochemical optical waveguide lightmode spectroscopy } \\ \text { EIS } & \text { Electrochemical impedance spectroscopy } \\ \text { EPR } & \text { Electron paramagnetic resonance } \\ \text { ESI-MS } & \text { Electrospray ionization mass spectrometry } \\ \text { EXAFS } & \text { Extended X-ray absorption fine structure spectroscopy }\end{array}$




\begin{tabular}{|c|c|}
\hline FTO & Fluorine doped tin oxide \\
\hline GC & Glassy carbon \\
\hline HER & Hydrogen Evolving Reaction \\
\hline HYSCORE & Hyperfine sublevel correlation \\
\hline$i_{c a t}, i_{d}$ & catalytic and diffusion controlled current, respectively \\
\hline$j_{c a t}, j_{d}$ & catalytic and diffusion controlled current density, respectively \\
\hline $\mathrm{I} 2 \mathrm{M}$ & Interaction of two $\mathrm{M}=\mathrm{O}$ units \\
\hline ITO & Indium tin oxide \\
\hline KIE & Kinetic isotope effect \\
\hline$k_{o b s}$ & pseudo-first order catalytic rate constant, $\mathrm{s}^{-1}\left(\equiv \mathrm{TOF}, k_{\text {cat }}\right)$ \\
\hline LSV & Linear sweep voltammetry \\
\hline $\mathrm{NADP}(\mathrm{H})$ & Nicotinamide adenine dinucleotide phosphate \\
\hline NHE/SHE & Normal/Standard hydrogen electrode \\
\hline $\mathrm{OAc}^{-}$ & Acetate anion \\
\hline OEC & Oxygen evolving center \\
\hline OER & Oxygen evolving reaction \\
\hline $\mathrm{OTf}^{-}$ & Trifluoromethyl sulfonate anion \\
\hline PCET & Proton coupled electron transfer \\
\hline PS II & Photosystem II \\
\hline RHE & Reversible hydrogen electrode \\
\hline SEM-EDS & Scanning electron microscopy, energy dispersive spectroscopy \\
\hline SET-WNA & Single electron transfer water nucleophilic attack \\
\hline SP-4 & Square planar coordination geometry \\
\hline SPBY-5 & Square based bipyramidal coordination geometry \\
\hline SWV & Square wave voltammetry \\
\hline TPBY-5 & Trigonal bipyramidal coordination geometry \\
\hline TOF & Turnover frequency, $\mathrm{s}^{-1}$ \\
\hline TON & Tornover number, dimensionless \\
\hline XANES & X-ray absorption near edge structure \\
\hline XPS & X-Ray photoelectron spectroscopy \\
\hline WNA & Water nucleophilic attack \\
\hline WOC & Water oxidation (electro)catalyst \\
\hline
\end{tabular}

\section{References}

1. Bard, A.J.; Fox, M.A. Artificial Photosynthesis: Solar Splitting of Water to Hydrogen and Oxygen. Acc. Chem. Res. 1995, 28, 141-145. [CrossRef]

2. Meyer, T.J. Chemical approaches to artificial photosynthesis. Acc. Chem. Res. 1989, 22, 163-170. [CrossRef]

3. McConnell, I.; Li, G.; Brudvig, G.W. Energy Conversion in Natural and Artificial Photosynthesis. Chem. Biol. 2010, 17, 434-447. [CrossRef] [PubMed]

4. Cho, A. Energy's Tricky Tradeoffs. Science 2010, 329, 786-787. [CrossRef] [PubMed]

5. Dau, H.; Limberg, C.; Reier, T.; Risch, M.; Roggan, S.; Strasser, P. The Mechanism of Water Oxidation: From Electrolysis via Homogeneous to Biological Catalysis. Chem CatChem 2010, 2, 724-761. [CrossRef]

6. Karkas, M.D.; Akermark, B. Water oxidation using earth-abundant transition metal catalysts: Opportunities and challenges. Dalton Trans. 2016, 45, 14421-14461. [CrossRef]

7. Blakemore, J.D.; Crabtree, R.H.; Brudvig, G.W. Molecular Catalysts for Water Oxidation. Chem. Rev. 2015, 115, 12974-13005. [CrossRef]

8. Hunter, B.M.; Gray, H.B.; Müller, A.M. Earth-Abundant Heterogeneous Water Oxidation Catalysts. Chem. Rev. 2016, 116, 14120-14136. [CrossRef]

9. Li, J.; Güttinger, R.; Moré, R.; Song, F.; Wan, W.; Patzke, G.R. Frontiers of water oxidation: The quest for true catalysts. Chem. Soc. Rev. 2017, 46, 6124-6147. [CrossRef]

10. Suen, N.-T.; Hung, S.-F.; Quan, Q.; Zhang, N.; Xu, Y.-J.; Chen, H.M. Electrocatalysis for the oxygen evolution reaction: Recent development and future perspectives. Chem. Soc. Rev. 2017, 46, 337-365. [CrossRef] 
11. Wang, N.; Zheng, H.; Zhang, W.; Cao, R. Mononuclear first-row transition-metal complexes as molecular catalysts for water oxidation. Chin. J. Catal. 2018, 39, 228-244. [CrossRef]

12. Kondo, M.; Masaoka, S. Water Oxidation Catalysts Constructed by Biorelevant First-row Metal Complexes. Chem. Lett. 2016, 45, 1220-1231. [CrossRef]

13. Liu, S.; Lei, Y.-J.; Xin, Z.-J.; Lu, Y.-B.; Wang, H.-Y. Water splitting based on homogeneous copper molecular catalysts. J. Photochem. Photobiol. Chem. 2018, 355, 141-151. [CrossRef]

14. Wang, J.-W.; Zhong, D.-C.; Lu, T.-B. Artificial photosynthesis: Catalytic water oxidation and $\mathrm{CO}_{2}$ reduction by dinuclear non-noble-metal molecular catalysts. Coord. Chem. Rev. 2018, 377, 225-236. [CrossRef]

15. Weinberg, D.R.; Gagliardi, C.J.; Hull, J.F.; Murphy, C.F.; Kent, C.A.; Westlake, B.C.; Paul, A.; Ess, D.H.; McCafferty, D.G.; Meyer, T.J. Proton-Coupled Electron Transfer. Chem. Rev. 2012, 112, 4016-4093. [CrossRef] [PubMed]

16. Scholz, F.; Bond, A.M.; Compton, R.G.; Fiedler, D.A.; Inzelt, G.; Kahlert, H.; Komorsky-Lovrić, Š.; Lohse, H.; Lovrić, M.; Marken, F.; et al. (Eds.) Electroanalytical Methods; Springer: Berlin/Heidelberg, Germany, 2010; ISBN 978-3-642-02914-1.

17. Bard, A.J.; Faulkner, L.R. Electrochemical Methods: Fundamentals and Applications, 2nd ed.; Wiley: New York, NY, USA, 2001; ISBN 978-0-471-04372-0.

18. Artero, V.; Fontecave, M. Solar fuels generation and molecular systems: Is it homogeneous or heterogeneous catalysis? Chem. Soc. Rev. 2013, 42, 2338-2356. [CrossRef]

19. Barnett, S.M.; Goldberg, K.I.; Mayer, J.M. A soluble copper-bipyridine water-oxidation electrocatalyst. Nat. Chem. 2012, 4, 498-502. [CrossRef]

20. Zhu, L.; Du, J.; Zuo, S.; Chen, Z. Cs(I) Cation Enhanced Cu(II) Catalysis of Water Oxidation. Inorg. Chem. 2016, 55, 7135-7140. [CrossRef]

21. Chen, Z.; Meyer, T.J. Copper(II) Catalysis of Water Oxidation. Angew. Chem. Int. Ed. 2013, 52, 700-703. [CrossRef]

22. Winikoff, S.G.; Cramer, C.J. Mechanistic analysis of water oxidation catalyzed by mononuclear copper in aqueous bicarbonate solutions. Catal. Sci. Technol. 2014, 4, 2484-2489. [CrossRef]

23. Mizrahi, A.; Maimon, E.; Cohen, H.; Kornweitz, H.; Zilbermann, I.; Meyerstein, D. Mechanistic Studies on the Role of $\left[\mathrm{Cu}^{\mathrm{II}}\left(\mathrm{CO}_{3}\right)_{n}\right]^{2-2 n}$ as a Water Oxidation Catalyst: Carbonate as a Non-Innocent Ligand. Chem. Eur. J. 2018, 24, 1088-1096. [CrossRef] [PubMed]

24. Elwell, C.E.; Gagnon, N.L.; Neisen, B.D.; Dhar, D.; Spaeth, A.D.; Yee, G.M.; Tolman, W.B. Copper-Oxygen Complexes Revisited: Structures, Spectroscopy, and Reactivity. Chem. Rev. 2017, 117, 2059-2107. [CrossRef] [PubMed]

25. Lewis, E.A.; Tolman, W.B. Reactivity of Dioxygen-Copper Systems. Chem. Rev. 2004, 104, 1047-1076. [CrossRef] [PubMed]

26. Huang, H.-H.; Wang, J.-W.; Sahoo, P.; Zhong, D.-C.; Lu, T.-B. Electrocatalytic water oxidation by Cu(II) ions in a neutral borate buffer solution. Chem. Commun. 2017, 53, 9324-9327. [CrossRef] [PubMed]

27. Powell, K.J.; Brown, P.L.; Byrne, R.H.; Gajda, T.; Hefter, G.; Sjöberg, S.; Wanner, H. Chemical speciation of environmentally significant metals with inorganic ligands Part 2: The $\mathrm{Cu}^{2+}-\mathrm{OH}^{-}, \mathrm{Cl}^{-}, \mathrm{CO}_{3}{ }^{2-}, \mathrm{SO}_{4}{ }^{2-}$, and $\mathrm{PO}_{4}{ }^{3-}$ systems (IUPAC Technical Report). Pure Appl. Chem. 2007, 79, 895-950. [CrossRef]

28. Li, T.-T.; Zheng, Y.-Q. Electrocatalytic water oxidation using a chair-like tetranuclear copper(II) complex in a neutral aqueous solution. Dalton Trans. 2016, 45, 12685-12690. [CrossRef] [PubMed]

29. Funes-Ardoiz, I.; Garrido-Barros, P.; Llobet, A.; Maseras, F. Single Electron Transfer Steps in Water Oxidation Catalysis. Redefining the Mechanistic Scenario. ACS Catal. 2017, 7, 1712-1719. [CrossRef]

30. Garrido-Barros, P.; Funes-Ardoiz, I.; Drouet, S.; Benet-Buchholz, J.; Maseras, F.; Llobet, A. Redox Non-innocent Ligand Controls Water Oxidation Overpotential in a New Family of Mononuclear Cu-Based Efficient Catalysts. J. Am. Chem. Soc. 2015, 137, 6758-6761. [CrossRef]

31. Zhang, T.; Wang, C.; Liu, S.; Wang, J.-L.; Lin, W. A Biomimetic Copper Water Oxidation Catalyst with Low Overpotential. J. Am. Chem. Soc. 2014, 136, 273-281. [CrossRef]

32. Szyrwiel, Ł.; Lukács, D.; Srankó, D.F.; Kerner, Z.; Kotynia, A.; Brasuń, J.; Setner, B.; Szewczuk, Z.; Malec, K.; Pap, J.S. Armed by Asp? C-terminal carboxylate in a Dap-branched peptide and consequences in the binding of $\mathrm{Cu}^{\mathrm{II}}$ and electrocatalytic water oxidation. RSC Adv. 2017, 7, 24657-24666. [CrossRef] 
33. Cui, S.; Qian, M.; Liu, X.; Sun, Z.; Du, P. A Copper Porphyrin-Based Conjugated Mesoporous Polymer-Derived Bifunctional Electrocatalyst for Hydrogen and Oxygen Evolution. ChemSusChem 2016, 9, 2365-2373. [CrossRef] [PubMed]

34. Kuwamura, N.; Kurioka, Y.; Yoshinari, N.; Konno, T. Heterogeneous catalytic water oxidation controlled by coordination geometries of copper(II) centers with thiolato donors. Chem. Commun. 2018, 54, 10766-10769. [CrossRef] [PubMed]

35. Mishra, R.; Ülker, E.; Karadas, F. One-Dimensional Copper(II) Coordination Polymer as an Electrocatalyst for Water Oxidation. ChemElectroChem 2017, 4, 75-80. [CrossRef]

36. Gerlach, D.L.; Bhagan, S.; Cruce, A.A.; Burks, D.B.; Nieto, I.; Truong, H.T.; Kelley, S.P.; Herbst-Gervasoni, C.J.; Jernigan, K.L.; Bowman, M.K.; et al. Studies of the Pathways Open to Copper Water Oxidation Catalysts Containing Proximal Hydroxy Groups During Basic Electrocatalysis. Inorg. Chem. 2014, 53, 12689-12698. [CrossRef] [PubMed]

37. Burks, D.B.; Vasiliu, M.; Dixon, D.A.; Papish, E.T. Thermodynamic Acidity Studies of 6,6'-Dihydroxy2,2'-bipyridine: A Combined Experimental and Computational Approach. J. Phys. Chem. A 2018, 122, 2221-2231. [CrossRef]

38. DePasquale, J.; Nieto, I.; Reuther, L.E.; Herbst-Gervasoni, C.J.; Paul, J.J.; Mochalin, V.; Zeller, M.; Thomas, C.M.; Addison, A.W.; Papish, E.T. Iridium Dihydroxybipyridine Complexes Show That Ligand Deprotonation Dramatically Speeds Rates of Catalytic Water Oxidation. Inorg. Chem. 2013, 52, 9175-9183. [CrossRef]

39. Ghosh, T.; Fridman, N.; Kosa, M.; Maayan, G. Self-Assembled Cyclic Structures from Copper(II) Peptoids. Angew. Chem. Int. Ed. 2018, 57, 7703-7708. [CrossRef]

40. Ghosh, T.; Ghosh, P.; Maayan, G. A Copper-Peptoid as a Highly Stable, Efficient and Reusable Homogeneous Water Oxidation Electrocatalyst. ACS Catal. 2018, 8, 10631-10640. [CrossRef]

41. Zhang, M.-T.; Chen, Z.; Kang, P.; Meyer, T.J. Electrocatalytic Water Oxidation with a Copper(II) Polypeptide Complex. J. Am. Chem. Soc. 2013, 135, 2048-2051. [CrossRef]

42. Pap, J.S.; Szyrwiel, Ł.; Srankó, D.; Kerner, Z.; Setner, B.; Szewczuk, Z.; Malinka, W. Electrocatalytic water oxidation by $\mathrm{Cu}^{\mathrm{II}}$ complexes with branched peptides. Chem. Commun. 2015, 51, 6322-6324. [CrossRef]

43. Farkas, E.; Srankó, D.; Kerner, Z.; Setner, B.; Szewczuk, Z.; Malinka, W.; Horvath, R.; Szyrwiel, Ł.; Pap, J.S. Self-assembled, nanostructured coatings for water oxidation by alternating deposition of Cu-branched peptide electrocatalysts and polyelectrolytes. Chem. Sci. 2016, 7, 5249-5259. [CrossRef] [PubMed]

44. Costentin, C.; Drouet, S.; Robert, M.; Savéant, J.-M. Turnover Numbers, Turnover Frequencies, and Overpotential in Molecular Catalysis of Electrochemical Reactions. Cyclic Voltammetry and Preparative-Scale Electrolysis. J. Am. Chem. Soc. 2012, 134, 11235-11242. [CrossRef] [PubMed]

45. Stott, L.A.; Prosser, K.E.; Berdichevsky, E.K.; Walsby, C.J.; Warren, J.J. Lowering water oxidation overpotentials using the ionisable imidazole of copper(2-(2'-pyridyl)imidazole). Chem. Commun. 2017, 53, 651-654. [CrossRef]

46. Fisher, K.J.; Materna, K.L.; Mercado, B.Q.; Crabtree, R.H.; Brudvig, G.W. Electrocatalytic Water Oxidation by a Copper(II) Complex of an Oxidation-Resistant Ligand. ACS Catal. 2017, 7, 3384-3387. [CrossRef]

47. Rudshteyn, B.; Fisher, K.J.; Lant, H.M.C.; Yang, K.R.; Mercado, B.Q.; Brudvig, G.W.; Crabtree, R.H.; Batista, V.S. Water-Nucleophilic Attack Mechanism for the $\mathrm{Cu}^{\mathrm{II}}$ (pyalk) 2 Water-Oxidation Catalyst. ACS Catal. 2018, 8, 7952-7960. [CrossRef]

48. Shopov, D.Y.; Rudshteyn, B.; Campos, J.; Batista, V.S.; Crabtree, R.H.; Brudvig, G.W. Stable Iridium(IV) Complexes of an Oxidation-Resistant Pyridine-Alkoxide Ligand: Highly Divergent Redox Properties Depending on the Isomeric Form Adopted. J. Am. Chem. Soc. 2015, 137, 7243-7250. [CrossRef] [PubMed]

49. Michaelos, T.K.; Lant, H.M.C.; Sharninghausen, L.S.; Craig, S.M.; Menges, F.S.; Mercado, B.Q.; Brudvig, G.W.; Crabtree, R.H. Catalytic Oxygen Evolution from Manganese Complexes with an Oxidation-Resistant N,N,O-Donor Ligand. ChemPlusChem 2016, 81, 1129-1132. [CrossRef]

50. Yu, F.; Li, F.; Hu, J.; Bai, L.; Zhu, Y.; Sun, L. Electrocatalytic water oxidation by a macrocyclic Cu(II) complex in neutral phosphate buffer. Chem. Commun. 2016, 52, 10377-10380. [CrossRef]

51. Su, X.-J.; Gao, M.; Jiao, L.; Liao, R.-Z.; Siegbahn, P.E.M.; Cheng, J.-P.; Zhang, M.-T. Electrocatalytic Water Oxidation by a Dinuclear Copper Complex in a Neutral Aqueous Solution. Angew. Chem. Int. Ed. 2015, 54, 4909-4914. [CrossRef] 
52. Wang, J.; Huang, H.; Lu, T. Homogeneous Electrocatalytic Water Oxidation by a Rigid Macrocyclic Copper(II) Complex. Chin. J. Chem. 2017, 35, 586-590. [CrossRef]

53. Ullman, A.M.; Liu, Y.; Huynh, M.; Bediako, D.K.; Wang, H.; Anderson, B.L.; Powers, D.C.; Breen, J.J.; Abruña, H.D.; Nocera, D.G. Water Oxidation Catalysis by Co(II) Impurities in Co(III) ${ }_{4} \mathrm{O}_{4}$ Cubanes. J. Am. Chem. Soc. 2014, 136, 17681-17688. [CrossRef] [PubMed]

54. Kafentzi, M.-C.; Papadakis, R.; Gennarini, F.; Kochem, A.; Iranzo, O.; Le Mest, Y.; Le Poul, N.; Tron, T.; Faure, B.; Simaan, A.J.; et al. Electrochemical Water Oxidation and Stereoselective Oxygen Atom Transfer Mediated by a Copper Complex. Chem. Eur. J. 2018, 24, 5213-5224. [CrossRef] [PubMed]

55. Blain, I.; Bruno, P.; Giorgi, M.; Lojou, E.; Lexa, D.; Réglier, M. Copper Complexes as Functional Models for Dopamine $\beta$-Hydroxylase-Stereospecific Oxygen Atom Transfer. Eur. J. Inorg. Chem. 1998, 1998, 1297-1304. [CrossRef]

56. Nestke, S.; Ronge, E.; Siewert, I. Electrochemical water oxidation using a copper complex. Dalton Trans. 2018, 47, 10737-10741. [CrossRef] [PubMed]

57. Terao, R.; Nakazono, T.; Parent, A.R.; Sakai, K. Photochemical Water Oxidation Catalyzed by a Water-Soluble Copper Phthalocyanine Complex. ChemPlusChem 2016, 81, 1064-1067. [CrossRef]

58. Coggins, M.K.; Zhang, M.-T.; Chen, Z.; Song, N.; Meyer, T.J. Single-Site Copper(II) Water Oxidation Electrocatalysis: Rate Enhancements with $\mathrm{HPO}_{4}{ }^{2-}$ as a Proton Acceptor at $\mathrm{pH}$ 8. Angew. Chem. Int. Ed. 2014, 53, 12226-12230. [CrossRef]

59. Shen, J.; Wang, M.; Zhang, P.; Jiang, J.; Sun, L. Electrocatalytic water oxidation by copper(II) complexes containing a tetra- or pentadentate amine-pyridine ligand. Chem. Commun. 2017, 53, 4374-4377. [CrossRef]

60. Zhang, P.; Wang, M.; Yang, Y.; Yao, T.; Sun, L. A Molecular Copper Catalyst for Electrochemical Water Reduction with a Large Hydrogen-Generation Rate Constant in Aqueous Solution. Angew. Chem. Int. Ed. 2014, 53, 13803-13807. [CrossRef]

61. Garrido-Barros, P.; Gimbert-Suriñach, C.; Moonshiram, D.; Picón, A.; Monge, P.; Batista, V.S.; Llobet, A. Electronic $\pi$-Delocalization Boosts Catalytic Water Oxidation by $\mathrm{Cu}(\mathrm{II})$ Molecular Catalysts Heterogenized on Graphene Sheets. J. Am. Chem. Soc. 2017, 139, 12907-12910. [CrossRef]

62. Solomon, E.I.; Heppner, D.E.; Johnston, E.M.; Ginsbach, J.W.; Cirera, J.; Qayyum, M.; Kieber-Emmons, M.T.; Kjaergaard, C.H.; Hadt, R.G.; Tian, L. Copper Active Sites in Biology. Chem. Rev. 2014, 114, 3659-3853. [CrossRef]

63. Naqvi, K.R.; Melø, T.B. Reduction of tetranitromethane by electronically excited aromatics in acetonitrile: Spectra and molar absorption coefficients of radical cations of anthracene, phenanthrene and pyrene. Chem. Phys. Lett. 2006, 428, 83-87. [CrossRef]

64. Fu, L.-Z.; Fang, T.; Zhou, L.-L.; Zhan, S.-Z. A mononuclear copper electrocatalyst for both water reduction and oxidation. RSC Adv. 2014, 4, 53674-53680. [CrossRef]

65. Su, X.-J.; Zheng, C.; Hu, Q.-Q.; Du, H.-Y.; Liao, R.-Z.; Zhang, M.-T. Bimetallic cooperative effect on O-O bond formation: Copper polypyridyl complexes as water oxidation catalyst. Dalton Trans. 2018, 47, 8670-8675. [CrossRef] [PubMed]

66. Xiang, R.-J.; Wang, H.-Y.; Xin, Z.-J.; Li, C.-B.; Lu, Y.-X.; Gao, X.-W.; Sun, H.-M.; Cao, R. A Water-Soluble Copper-Polypyridine Complex as a Homogeneous Catalyst for both Photo-Induced and Electrocatalytic $\mathrm{O}_{2}$ Evolution. Chem. Eur. J. 2016, 22, 1602-1607. [CrossRef] [PubMed]

67. Chen, F.; Wang, N.; Lei, H.; Guo, D.; Liu, H.; Zhang, Z.; Zhang, W.; Lai, W.; Cao, R. Electrocatalytic Water Oxidation by a Water-Soluble Copper(II) Complex with a Copper-Bound Carbonate Group Acting as a Potential Proton Shuttle. Inorg. Chem. 2017, 56, 13368-13375. [CrossRef] [PubMed]

68. Farkas, E.; Sóvágó, I. Metal complexes of amino acids and peptides. In Amino Acids, Peptides and Proteins; Ryadnov, M., Hudecz, F., Eds.; Royal Society of Chemistry: Cambridge, UK, 2016; Volume 41, pp. 100-151. ISBN 978-1-78262-537-7.

69. Kim, M.K.; Martell, A.E. Copper(II) Complexes of Triglycine and Tetraglycine. J. Am. Chem. Soc. 1966, 88, 914-918. [CrossRef]

70. Nagy, N.V.; Szabó-Plánka, T.; Rockenbauer, A.; Peintler, G.; Nagypál, I.; Korecz, L. Great Structural Variety of Complexes in Copper(II)-Oligoglycine Systems: Microspeciation and Coordination Modes as Studied by the Two-Dimensional Simulation of Electron Paramagnetic Resonance Spectra. J. Am. Chem. Soc. 2003, 125, 5227-5235. [CrossRef] [PubMed] 
71. Pap, J.S.; Szyrwiel, Ł. On the Cu(III)/Cu(II) Redox Chemistry of Cu-Peptide Complexes to Assist Catalyst Design. Comments Inorg. Chem. 2017, 37, 59-77. [CrossRef]

72. Szyrwiel, Ł.; Szczukowski, Ł.; Pap, J.S.; Setner, B.; Szewczuk, Z.; Malinka, W. The $\mathrm{Cu}^{2+}$ Binding Properties of Branched Peptides Based on L-2,3-Diaminopropionic Acid. Inorg. Chem. 2014, 53, 7951-7959. [CrossRef] [PubMed]

73. Szyrwiel, Ł.; Pap, J.S.; Szczukowski, Ł.; Kerner, Z.; Brasuń, J.; Setner, B.; Szewczuk, Z.; Malinka, W. Branched peptide with three histidines for the promotion of $\mathrm{Cu}^{\mathrm{II}}$ binding in a wide $\mathrm{pH}$ range-Complementary potentiometric, spectroscopic and electrochemical studies. RSC Adv. 2015, 5, 56922-56931. [CrossRef]

74. Jakab, N.I.; Gyurcsik, B.; Körtvélyesi, T.; Vosekalna, I.; Jensen, J.; Larsen, E. Design of histidine containing peptides for better understanding of their coordination mode toward copper(II) by CD spectroscopy. J. Inorg. Biochem. 2007, 101, 1376-1385. [CrossRef] [PubMed]

75. Koepke, S.J.; Light, K.M.; VanNatta, P.E.; Wiley, K.M.; Kieber-Emmons, M.T. Electrocatalytic Water Oxidation by a Homogeneous Copper Catalyst Disfavors Single-Site Mechanisms. J. Am. Chem. Soc. 2017, 139, 8586-8600. [CrossRef]

76. Nagao, H.; Komeda, N.; Mukaida, M.; Suzuki, M.; Tanaka, K. Structural and Electrochemical Comparison of Copper(II) Complexes with Tripodal Ligands. Inorg. Chem. 1996, 35, 6809-6815. [CrossRef] [PubMed]

77. Liu, X.; Jia, H.; Sun, Z.; Chen, H.; Xu, P.; Du, P. Nanostructured copper oxide electrodeposited from copper(II) complexes as an active catalyst for electrocatalytic oxygen evolution reaction. Electrochem. Commun. 2014, 46, 1-4. [CrossRef]

78. Schröder, D.; Holthausen, M.C.; Schwarz, H. Radical-Like Activation of Alkanes by the Ligated Copper Oxide Cation (Phenanthroline) $\mathrm{CuO}^{+}$. J. Phys. Chem. B 2004, 108, 14407-14416. [CrossRef]

79. Dietl, N.; van der Linde, C.; Schlangen, M.; Beyer, M.K.; Schwarz, H. Diatomic [CuO]+ and Its Role in the Spin-Selective Hydrogen- and Oxygen-Atom Transfers in the Thermal Activation of Methane. Angew. Chem. Int. Ed. 2011, 50, 4966-4969. [CrossRef] [PubMed]

80. Molecular Electronic Structures of Transition Metal Complexes I; Mingos, D.M.P.; Day, P.; Dahl, J.P. (Eds.) Structure and Bonding; Springer Berlin Heidelberg: Berlin/Heidelberg, Germany, 2012; Volume 142, ISBN 978-3-642-27369-8.

81. Hu, Q.-Q.; Su, X.-J.; Zhang, M.-T. Electrocatalytic Water Oxidation by an Unsymmetrical Di-Copper Complex. Inorg. Chem. 2018, 57, 10481-10484. [CrossRef]

82. Hayashi, H.; Fujinami, S.; Nagatomo, S.; Ogo, S.; Suzuki, M.; Uehara, A.; Watanabe, Y.; Kitagawa, T. A Bis( $\mu$-oxo)dicopper(III) Complex with Aromatic Nitrogen Donors: Structural Characterization and Reversible Conversion between Copper(I) and Bis( $\mu$-oxo)dicopper(III) Species. J. Am. Chem. Soc. 2000, 122, 2124-2125. [CrossRef]

83. Fang, T.; Fu, L.-Z.; Zhou, L.-L.; Zhan, S.-Z. A water-soluble dinuclear copper electrocatalyst, $[\mathrm{Cu}(\mathrm{oxpn}) \mathrm{Cu}(\mathrm{OH}) 2]$ for both water reduction and oxidation. Electrochim. Acta 2015, 161, 388-394. [CrossRef]

84. Zhou, L.-L.; Fang, T.; Cao, J.-P.; Zhu, Z.-H.; Su, X.-T.; Zhan, S.-Z. A dinuclear copper(II) electrocatalyst both water reduction and oxidation. J. Power Sources 2015, 273, 298-304. [CrossRef]

85. Suga, M.; Akita, F.; Hirata, K.; Ueno, G.; Murakami, H.; Nakajima, Y.; Shimizu, T.; Yamashita, K.; Yamamoto, M.; Ago, H.; et al. Native structure of photosystem II at $1.95 \AA ̊$ resolution viewed by femtosecond X-ray pulses. Nature 2015, 517, 99-103. [CrossRef] [PubMed]

86. Umena, Y.; Kawakami, K.; Shen, J.-R.; Kamiya, N. Crystal structure of oxygen-evolving photosystem II at a resolution of $1.9 \AA$ A. Nature 2011, 473, 55. [CrossRef] [PubMed]

87. Okamura, M.; Kondo, M.; Kuga, R.; Kurashige, Y.; Yanai, T.; Hayami, S.; Praneeth, V.K.K.; Yoshida, M.; Yoneda, K.; Kawata, S.; et al. A pentanuclear iron catalyst designed for water oxidation. Nature 2016, 530, 465-468. [CrossRef] [PubMed]

88. Praneeth, V.K.K.; Kondo, M.; Woi, P.M.; Okamura, M.; Masaoka, S. Electrocatalytic Water Oxidation by a Tetranuclear Copper Complex. ChemPlusChem 2016, 81, 1123-1128. [CrossRef]

89. Li, X.; Cheng, D.; Lin, J.; Li, Z.; Zheng, Y. Di-, Tetra-, and Hexanuclear Hydroxy-Bridged Copper(II) Cluster Compounds: Syntheses, Structures, and Properties. Cryst. Growth Des. 2008, 8, 2853-2861. [CrossRef]

90. Jiang, X.; Li, J.; Yang, B.; Wei, X.-Z.; Dong, B.-W.; Kao, Y.; Huang, M.-Y.; Tung, C.-H.; Wu, L.-Z. A Bio-inspired $\mathrm{Cu}_{4} \mathrm{O}_{4}$ Cubane: Effective Molecular Catalysts for Electrocatalytic Water Oxidation in Aqueous Solution. Angew. Chem. Int. Ed. 2018, 57, 7850-7854. [CrossRef] [PubMed] 
91. Liu, X.; Zheng, H.; Sun, Z.; Han, A.; Du, P. Earth-Abundant Copper-Based Bifunctional Electrocatalyst for Both Catalytic Hydrogen Production and Water Oxidation. ACS Catal. 2015, 5, 1530-1538. [CrossRef]

92. Yu, F.; Li, F.; Zhang, B.; Li, H.; Sun, L. Efficient Electrocatalytic Water Oxidation by a Copper Oxide Thin Film in Borate Buffer. ACS Catal. 2015, 5, 627-630. [CrossRef]

93. Liu, X.; Cui, S.; Qian, M.; Sun, Z.; Du, P. In situ generated highly active copper oxide catalysts for the oxygen evolution reaction at low overpotential in alkaline solutions. Chem. Commun. 2016, 52, 5546-5549. [CrossRef] [PubMed]

94. Lu, C.; Du, J.; Su, X.-J.; Zhang, M.-T.; Xu, X.; Meyer, T.J.; Chen, Z. Cu(II) Aliphatic Diamine Complexes for Both Heterogeneous and Homogeneous Water Oxidation Catalysis in Basic and Neutral Solutions. ACS Catal. 2016, 6, 77-83. [CrossRef]

95. Lu, C.; Wang, J.; Chen, Z. Water Oxidation by Copper-Amino Acid Catalysts at Low Overpotentials. ChemCatChem 2016, 8, 2165-2170. [CrossRef]

96. Li, T.-T.; Cao, S.; Yang, C.; Chen, Y.; Lv, X.-J.; Fu, W.-F. Electrochemical Water Oxidation by In Situ -Generated Copper Oxide Film from $\left[\mathrm{Cu}(\mathrm{TEOA})\left(\mathrm{H}_{2} \mathrm{O}\right)_{2}\right]\left[\mathrm{SO}_{4}\right]$ Complex. Inorg. Chem. 2015, 54, 3061-3067. [CrossRef] [PubMed]

97. Chen, H.; Gao, Y.; Lu, Z.; Ye, L.; Sun, L. Copper Oxide Film In-situ Electrodeposited from Cu(II) Complex as Highly Efficient Catalyst for Water Oxidation. Electrochim. Acta 2017, 230, 501-507. [CrossRef]

98. Ilhan, S.; Temel, H.; KIllc, A. Synthesis and spectral studies of macrocyclic $\mathrm{Cu}(\mathrm{II})$ complexes by reaction of various diamines, copper(II) perchlorate and 1,4- bis (2-carboxyaldehyde phenoxy)butane. J. Coord. Chem. 2008, 61, 277-284. [CrossRef]

99. Amiri, M.; Fallahi, M.; Bezaatpour, A.; Jijie, R.; Nozari-asbmarz, M.; Rouhi, M.; Boukherroub, R.; Szunerits, S. Solution Processable $\mathrm{Cu}(\mathrm{II})$ macrocycle for the Formation of $\mathrm{Cu}_{2} \mathrm{O}$ Thin Film on Indium Tin Oxide and Its Application for Water Oxidation. J. Phys. Chem. C 2018, 122, 16510-16518. [CrossRef]

100. Pilkington, N.; Robson, R. Complexes of binucleating ligands. III. Novel complexes of a macrocyclic binucleating ligand. Aust. J. Chem. 1970, 23, 2225.

101. Majumder, S.; Abdel Haleem, A.; Nagaraju, P.; Naruta, Y. A new preparation of a bifunctional crystalline heterogeneous copper electrocatalyst by electrodeposition using a Robson-type macrocyclic dinuclear copper complex for efficient hydrogen and oxygen evolution from water. Dalton Trans. 2017, 46, 9131-9139. [CrossRef]

102. van der Ham, C.J.M.; Işık, F.; Verhoeven, T.W.G.M.; Niemantsverdriet, J.W. (Hans); Hetterscheid, D.G.H. Activation pathways taking place at molecular copper precatalysts for the oxygen evolution reaction. Catal. Today 2017, 290, 33-38. [CrossRef]

103. Yu, W.-B.; He, Q.-Y.; Ma, X.-F.; Shi, H.-T.; Wei, X. A new copper species based on an azo-compound utilized as a homogeneous catalyst for water oxidation. Dalton Trans. 2015, 44, 351-358. [CrossRef]

104. Najafpour, M.M.; Ebrahimi, F.; Safdari, R.; Ghobadi, M.Z.; Tavahodi, M.; Rafighi, P. New findings and the current controversies for water oxidation by a copper(II)-azo complex: Homogeneous or heterogeneous? Dalton Trans. 2015, 44, 15435-15440. [CrossRef]

105. Wu, Z.-S.; Chen, L.; Liu, J.; Parvez, K.; Liang, H.; Shu, J.; Sachdev, H.; Graf, R.; Feng, X.; Müllen, K. High-Performance Electrocatalysts for Oxygen Reduction Derived from Cobalt Porphyrin-Based Conjugated Mesoporous Polymers. Adv. Mater. 2014, 26, 1450-1455. [CrossRef] [PubMed]

106. Du, J.; Chen, Z.; Ye, S.; Wiley, B.J.; Meyer, T.J. Copper as a Robust and Transparent Electrocatalyst for Water Oxidation. Angew. Chem. Int. Ed. 2015, 54, 2073-2078. [CrossRef] [PubMed]

107. Hou, C.-C.; Fu, W.-F.; Chen, Y. Self-Supported Cu-Based Nanowire Arrays as Noble-Metal-Free Electrocatalysts for Oxygen Evolution. ChemSusChem 2016, 9, 2069-2073. [CrossRef]

108. Liu, X.; Cui, S.; Sun, Z.; Ren, Y.; Zhang, X.; Du, P. Self-Supported Copper Oxide Electrocatalyst for Water Oxidation at Low Overpotential and Confirmation of Its Robustness by Cu K-Edge X-ray Absorption Spectroscopy. J. Phys. Chem. C 2016, 120, 831-840. [CrossRef]

109. Handoko, A.D.; Deng, S.; Deng, Y.; Cheng, A.W.F.; Chan, K.W.; Tan, H.R.; Pan, Y.; Tok, E.S.; Sow, C.H.; Yeo, B.S. Enhanced activity of $\mathrm{H}_{2} \mathrm{O}_{2}$-treated copper(II) oxide nanostructures for the electrochemical evolution of oxygen. Catal. Sci. Technol. 2016, 6, 269-274. [CrossRef]

(C) 2019 by the authors. Licensee MDPI, Basel, Switzerland. This article is an open access article distributed under the terms and conditions of the Creative Commons Attribution (CC BY) license (http:/ / creativecommons.org/licenses/by/4.0/). 